\title{
A Dual-Process Account of Moral Judgment: What Psychopaths Can Teach Us About Morality
}

Deirdre Kelly

A thesis submitted to the Faculty of Graduate and Postdoctoral Affairs in partial fulfillment of the requirements for the degree of

\author{
Doctor of Philosophy \\ in Cognitive Science
}

Carleton University

Ottawa, Ontario

(C) 2016

Deirdre Kelly 


\begin{abstract}
Researchers who argue that mora] ${ }^{1}$ judgment is based on emotions ('emotion-backers') and those who believe that it is based on reasoning and deliberation ('reasoningbackers') have both struggled to account for the notorious moral deviance of incarcerated psychopaths.

Emotion-backers, such as Jonathan Haidt, focus on psychopaths' lack of affect, or deficiencies in particular emotions, such as sympathy. Reasoning-backers, such as Lawrence Kohlberg, focus instead on psychopaths' deficient reasoning. Both accounts offer separate descriptions of what goes wrong in the disorder, but neither can fully explain psychopathic moral deviance.

The moral account that I built, bridges these accounts in an attempt to better and more fully describe the empirical data available on psychopathic moral judgment. I argue that their judgment is best explained with a dual-process account of moral judgment that incorporates a large system of moral emotions as well as integrates multiple bases of morality, such as concerns of fairness, harm, and purity.

It is only by focusing on both the reasoning and emotional deficits in psychopaths that we can begin to understand psychopaths' use of utilitarian reasoning, general population psychopaths, and psychopaths' differential presence in the prison population. All of these issues are best described using a dual-process account of moral

\footnotetext{
${ }^{1}$ I will predominantly use "moral" judgment as morality pertains to a broader range of decisions than does ethical which tends to pertain to external codes of conduct. personal decisions we make are moral decisions; whereas, ethical decision-making typically refers to a realm of professional standards such as those practiced in law, medicine, and business.
} 
judgment that incorporates a larger system of moral emotions than other accounts of morality as well as a pluralistic conception of moral foundations.

I used psychopaths because their moral deviance can teach us about morality more broadly. By understanding the cognitive processes implicated in the moral judgment of psychopaths, I better explain how moral judgment works in the general population more broadly.

My account of moral judgment has both theoretical and practical applications. Theoretically, it offers a new dual-process paradigm for describing moral behaviour which bridges reasoning-based and emotion-based accounts. This description can explain both the moral deviance of psychopaths as well as, more broadly, moral judgment in non-psychopaths. Additionally, my theory challenges accounts of moral emotion that narrowly focus on specific emotions, such as guilt or empathy. It instead integrates all emotions, including disgust, fear, and sympathy, and links specific emotions to moral judgments. Practically, my paradigm of moral judgment encourages the development of new moral judgment measurements such as new self-report questionnaires of moral reasoning. According to my research, in order for these tools to accurately measure morality, they need to account for both emotion-based and reasoning-based judgments. 


\section{Acknowledgements}

I can only begin to express the gratitude for all of the amazing people who were there for me through my scholastic journey. My thesis is a culmination of years of research and study that wouldn't have been possible without a supportive community. I cannot thank you all enough!

To my husband, Andre, I want to begin by thanking you for your constant and unwavering patience, kindness, and love. You have been there for me at every turn: from attending conferences to listening to countless presentations and papers, to being there when I needed a shoulder to cry or sleep on, and to looking at me like I'm the most important person in the world. I don't think you'll ever truly understand how much of a difference you've made, but it was everything.

My supervisor, Dr. Andrew Brook, has ensured that this project has made it to where it needs to be. For as long as I've known him, it was clear Dr. Brook cares about his students. In having had him as my supervisor, I can more than attest to this fact. He made me feel like my work is a valuable contribution and this has kept me going even when things were difficult. I appreciate everything he has done for me and his wisdom and compassion have inspired me in many aspects of my life in both in and out of academia.

I have been fortunate to have had such engaged committee members in Dr. Jim Davies and Dr. Adelle Forth. Dr. Davies' insight into psychological models helped me to put the last piece in place on my project. His constant questions and challenges about my work have made me into a better researcher and cognitive scientist. Early in my doctoral work, I did a directed study with Dr. Forth and was blown away by her knowledge of psychopathy. Her passion for her work was infectious and by 
inviting me into her lab, she made me truly feel welcomed and encouraged.

My family and friends have been there through the scrapes and the wins. You mean so much to me! Things in life aren't always easy, but they are a lot easier when you know that you have your own cheering section. You have given me the strength and courage to be myself and I love you for it.

Matthew and Liz, we started off this journey together. Over all of the games, ridiculous hypothetical discussions, innumerable puns, and the longest role playing game ever, you have become my best friends. I will miss being able to just wander into each other's offices to chat or just because. Always know, I'm only a call or message away.

I want to thank the funding agencies that made this research possible including the Social Sciences and Humanities Research Council and the Ontario Graduate Scholarship Program. Additionally, I wish to thank the generosity of the Carleton sponsors of internal scholarships. 


\section{Contents}

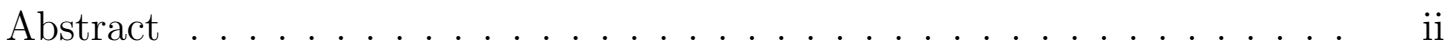

Acknowledgements $\ldots \ldots \ldots \ldots \ldots \ldots \ldots \ldots \ldots \ldots \ldots$ iv

1 Introduction 1

1.0.1 Background . . . . . . . . . . . . . . . . . . . . . . 3

2 Debates about morality 10

2.1 Emotion-based explanations . . . . . . . . . . . . . . . . 10

2.1.1 Extreme emotion-backer- Haidt's social intuitionism . . . . . 13

2.1 .2 Morality and empathy . . . . . . . . . . . . . . . 19

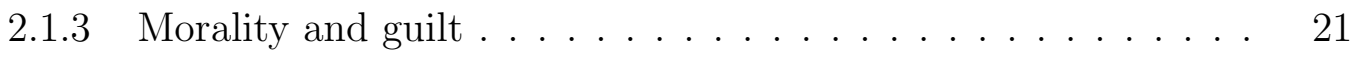

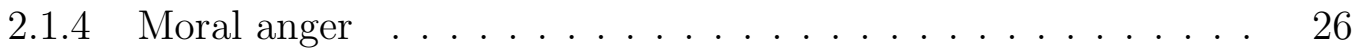

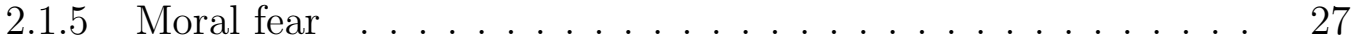

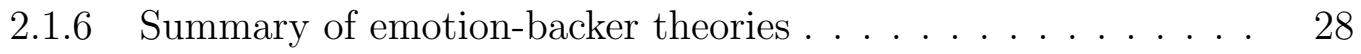

2.2 Reasoning-based accounts . . . . . . . . . . . . . . . . . . . . 29

2.2.1 Normative self-governance: A fairly extreme account . . . . . 30

2.2.2 An extreme moral reasoning-backer: Kohlberg's moral stage

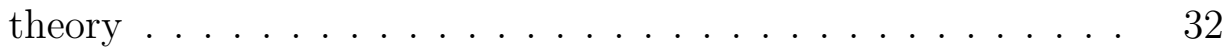

2.2 .3 Care ethics . . . . . . . . . . . . . . . 36 
3 Psychopathy explained $\quad 38$

3.1 Historical sketch of psychopathy . . . . . . . . . . . . 38

3.2 Overview of psychopathy ....................... 43

3.2.1 Diagnosing psychopathy . . . . . . . . . . . . 47

3.2.2 Beyond Hare: Measuring psychopathy . . . . . . . . . . . . . . . 49

3.2.3 Psychopathy and Antisocial Personality Disorder . . . . . . . 51

3.2.4 Sociopathy vs. Psychopathy . . . . . . . . . . . . . 54

3.2.5 Psychopathy in women ................. 56

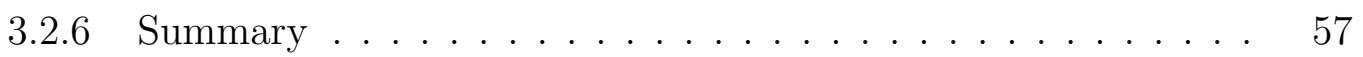

4 Framing the cognitive moral deficits of psychopaths 58

4.1 Emotional deficits . . . . . . . . . . . . . . . 58

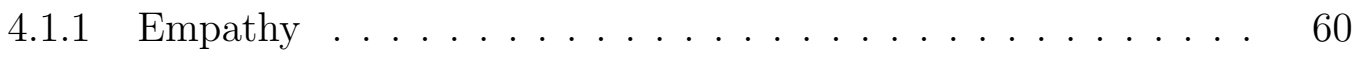

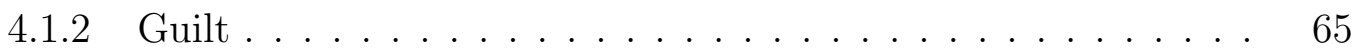

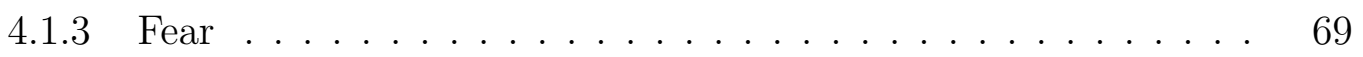

4.1 .4 Sadness ............................. 71

4.1.5 Discussion of affective empathy, guilt, fear, and sadness . . . . 72

4.2 Psychopathic Moral Reasoning . . . . . . . . . . . . . . . 73

4.2.1 Psychopaths' cognitive deficits in reasoning . . . . . . . . . . . . 74

4.2.2 Summarizing deficits and linking the summary to the model . 76

5 Explaining psychopaths' moral judgment $\quad 79$

5.1 Kantianism applied to psychopaths . . . . . . . . . . . . 79

5.2 Utilitarianism as applied to psychopaths . . . . . . . . . . . . 82

5.3 Kohlbergian moral reasoning interview . . . . . . . . . . . 83 
5.4 Turiel's Moral-Conventional (M-C) Distinction . . . . . . . . . . 85

5.5 Further applications of moral reasoning and psychopaths . . . . . . . 90

5.6 Caring in psychopaths . . . . . . . . . . . . . . . . 94

5.7 Personal/impersonal harm . . . . . . . . . . . . . . 96

5.8 Haidt's moral foundations . . . . . . . . . . . . . . . 97

5.9 The failure of current accounts to explain psychopaths' moral judgments 99

6 Models of moral decision-making 101

6.1 Reasoning-based modeling . . . . . . . . . . . . . . 103

6.1.1 Criticism of Rest's model . . . . . . . . . . . . . . . . . . 104

6.2 Haidt's social intuitionist model . . . . . . . . . . . . . . . . . 106

6.2.1 Criticism of moral dumbfounding findings . . . . . . . . . . 107

6.3 Dual-process models . . . . . . . . . . . . . . . . . . . . . 108

6.3.1 Trolley and footbridge cases . . . . . . . . . . . . . 108

6.3 .2 Reynolds (2006) . . . . . . . . . . . . . . 111

6.3.3 Messervey, Nelson, and Peach (manuscript in progress) . . . . 113

6.4 Broader criticisms of dual-process models . . . . . . . . . . . . . . . 114

7 The Dual-process moral judgment (DPMJ) model 117

7.1 Top-down mental states . . . . . . . . . . . . . . . . 118

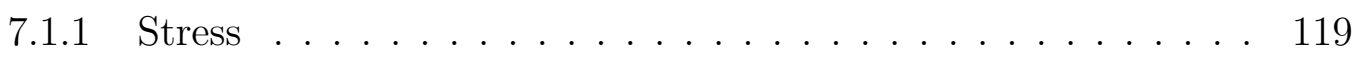

7.1 .2 Emotional . . . . . . . . . . . . . . . 120

7.1 .3 Moral foundations . . . . . . . . . . . . . . . . . . 121

7.2 Imagination . . . . . . . . . . . . . . . . . . . . . 122

7.3 Empathy ............................. 123 
7.3.1 Cognitive empathy . . . . . . . . . . . . . . . . 123

7.3 .2 Affective empathy . . . . . . . . . . . . . . . . . 124

7.3.3 Final thoughts on empathy . . . . . . . . . . . . . . 124

7.4 Emotional Judgment . . . . . . . . . . . . . . . . . . . 125

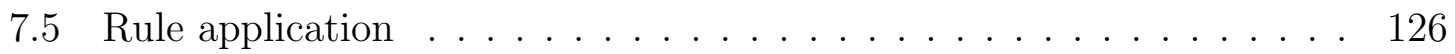

7.6 Self-control/Akrasia . . . . . . . . . . . . . . . . . . . 128

7.7 Self-interest . . . . . . . . . . . . . . . . . . . . . . 129

7.8 Running a trolley case through the DPMJ model . . . . . . . . . 131

7.9 Further applications of the DPMJ model _ . . . . . . . . . . . 132

7.10 Conclusions from the DPMJ model . . . . . . . . . . . . . . . 134

8 Accommodating successful psychopaths under the DPMJ Model of Moral Decision-Making 136

8.1 The successful psychopath . . . . . . . . . . . . . . 136

8.2 The DPMJ model and the successful psychopath . . . . . . . . . 140

9 Conclusion

$\begin{array}{ll}\text { Appendices } & 148\end{array}$

A Additional information on empathy studies and moral judgment studies

$\begin{array}{ll}\text { Bibliography } & 159\end{array}$ 


\section{List of Figures}

6.1 Jones' (1991) synthesis of ethical decision-making models which built on Rest's . . . . . . . . . . . . . . . . . . . . 105

6.2 Haidt's (2001) Social Intuitionist Model of Moral Judgment . . . . . . 106

6.3 Reynolds (2006) dual-process model of ethical judgment . . . . . . . . 112

7.1 The DPMJ dual-process model of moral judgment . . . . . . . . . . . . 119 


\section{Chapter 1}

\section{Introduction}

Before proceeding, there are two things that need to be done. The first is that I need to provide an explanation of what is meant by 'moral' throughout this project. Morality pertains to anything that has intrinsic value. In other words, that which is moral is good in itself. If an individual holds something as a moral good, then it will trump or take precedence over other goods. If a person has to choose between two goods where one is moral and the other is not, then the moral will be that which is most highly valued. Morality is underpinned by psychological mechanisms and cognitive capacities (Greene, 2013). Some of these psychological mechanisms are concerns about harm, fairness, and purity, and other moral considerations (Haidt, 2012). These moral concerns are the basis on which we make moral judgments (Haidt, 2012). These judgments are important in the moral system where they are integral in the formation of moral beliefs. They are the way in which people evaluate good and bad, right and wrong. These moral judgments are central to the moral decision-making process where I define moral decision-making as a process where people take information either from external stimuli or from imagination and either form an emotional or 
reasoning-based judgment. ${ }^{1}$

Second I need to emphasize that this is not a normative account. My account of how moral decisions are made is meant as a description of morality and not as prescriptive. My theory is not meant to make any claims as to what people should do. My goal is to provide a description of psychopathic morality and to describe how this helps us to better understand normal morality. By examining psychopaths and understanding the cognitive processes affected in their moral judgment, I argue that we can draw wider conclusions about how moral judgment works in non-psychopathic populations.

Most psychopaths are known for their criminality and disregard for moral concerns (Hare, 2003). Their moral deviance and criminality have made them an interesting figure for both psychologists focused on morality and moral philosophers. Attempts have been made to explain psychopaths' behaviour and lack of concern for morality by appealing either to their lack of moral reasoning (Nichols, 2002a; Smith, 1994) or to a lack of social or moral emotions, such as empathy (Maibom, 2008). I use a better understanding of how moral judgment works (or fails to work) in the cognitive system of psychopaths to draw conclusions about the nature of the processes underlying moral judgment. The first conclusion is that neither those who argue that moral judgment is rooted in emotion (moral emotion-backers) nor those who believe it is founded in deliberative, reasoning processes (the moral reasoning-backer) has a complete picture of moral judgment.

A large part of the problem is that the way in which both reasoning-backers and

\footnotetext{
${ }^{1}$ While many of our judgments concur with generally accepted standards, it is possible to make moral decisions that are unjustified. This lack of justification, for example, can be seen with how Germans during Naziism often made choices that they deemed to be correct, but by external observers were seen to be unjustified.
} 
emotion-backers use 'morality' results in their speaking past one another. Where Lawrence Kohlberg (1977) sees the realm of moral judgment as pertaining to moral reasoning founded in concerns of justice and fairness, he's talking about something completely different from Jonathan Haidt (2009) who is considering an intuitive, less deliberative form of moral judgment which draws on a plurality of moral concerns. According to these two accounts, morality is either a slow, deliberative cognitive process or an intuitive one. However, I argue that there is merit to both of these approaches and advocate for an account of morality which is dual-process involving both emotions and deliberative, reasoning-based processes. Only an account which focuses on both reasoning and emotion can accurately describe the moral judgment impairments of psychopaths.

\subsubsection{Background}

There is a longstanding debate in moral philosophy regarding the role of emotions in moral judgment. Within this debate, there are two central positions. Reasoningbackers, who argue that emotions are not a part of moral judgment, and the emotionbackers, who believe emotions are central to it. Emotion-backers tend to trace their roots back to David Hume (1775/1975). Hume claimed that it is only in the sentiments of people that moral judgment is formed. He claimed that sympathy, or what is now commonly thought of as empathy and sympathy, is what motivates people to

do good. He saw rationality as being slave to the passions. In the case of a lack of appropriate emotional backing, moral judgment would also lack motivational force. Hume's opinions would open the door for many moral philosophers who would follow, such as Jesse Prinz, Michael Slote, Shaun Nichols, Allan Gibbard, and Patricia 


\section{Greenspan.}

In response to Hume, Immanuel Kant (1785/2005) viewed emotions as detrimental to moral judgment. Kant argued that moral judgment can and should be reasoningbased. Knowing the right thing to do, is motivation enough to do it. According to Kant, it is only when a person is free of her passions that she is assured that she is acting out of respect for moral law and for no other reason. Moral reasoning-backers, such as Kant, viewed moral standards as being absolute and that emotions are too variable to provide anything other than relative standards of morality (Gill, 2007). This is not to say that Kant did not believe that emotions never play a role in morality. Indeed, he saw that morality was often influenced by emotions, but he thought that at least some people have the capacity to do moral judgment based on reasoning alone; and from a normative perspective, he saw this as the better way of doing moral judgment. This kind of reasoning-backing in moral judgment was fundamental to many later accounts, such as those of Korsgaard, Russ Shafer-Landau and Michael Smith.

This bias against emotion in moral judgment found its way into psychological research thanks to Lawrence Kohlberg, whose research put moral judgment on the agenda for psychologists. Kohlberg (1970) developed a view of moral judgment heavily influenced by reasoning-backers such as Kant. Similar to Kant, Kohlberg also believed that emotion had no place in moral judgment (Pizarro, 2000). Kohlberg's view of the role of reasoning in moral judgment was more radical than Kant's. According to Kohlberg, as people grow and develop, they move from more to less egocentric ways of reasoning about morality. Because of Kohlberg's influence, the early days of moral judgment research in psychology took a reasoning-driven focus. Indeed, the 
first twenty years of empirical moral judgment research was of a Kohlbergian variety with an emphasis on the role of reasoning, rather than emotion, in moral judgment. Reasoning's dominance in psychology is only further exemplified by the state of psychological models of moral judgment following Kohlberg. John Rest (1986) and Linda Trevino (1986) used Kohlberg's theory to develop psychological models of moral judgment which focused exclusively on reasoning and omitted the role of emotion in moral judgment. It was only when psychologists such as Haidt entered the scene in the mid-to-late 1990's that the role of emotion in moral judgment was reconsidered by psychologists (Haidt, 1993; 2001).

The role of emotion in moral judgment has been investigated by both moral philosophers and psychologists using the morally deviant psychopath. ${ }^{2}$

I show that neither reasoning-backers nor emotion-backers can fully explain psychopathic moral deviance. ${ }^{3}$ This is clearly the case in the more extreme examples of these accounts, such as Kohlberg's and Haidt's. Through a reinterpretation of the past thirty years of moral judgment research with psychopaths, I show that the best description of psychopathic moral judgment is one which requires a moral system that utilizes both reasoning and affect for producing appropriate moral judgment. I argue that an appropriate interpretation of psychopathic morality provides moral psychology with evidence that moral judgment can happen in isolation from emotion;

\footnotetext{
${ }^{2}$ It is important to note that most of these accounts have focused on the criminal behaviour of psychopaths. While many psychopaths are morally deviant and use criminal means, there is a subsection of people who could potentially meet most of the diagnostic criteria for psychopathy but who do not use criminal means. The 'successful' psychopath, as they have been called due to their professional success and avoidance of criminal behaviour, does seem to show similar trends in moral judgment, but seems to show better ability to control his actions, so as to perpetrate crime. However, these same people do appear to be morally deviant in that they instrumentally use others for their own ends (Babiak \& Hare, 2006) This idea will be further elaborated in chapter 8.

${ }^{3}$ Psychopaths are described as morally deviant, because most of the moral choices they make, deviate from generally accepted standards.
} 
however, psychopaths' decision-making and morally deviant choices are evidence to the importance of emotion in moral judgment.

There is empirical evidence that suggests that psychopaths are privileged with being particularly good at utilitarian reasoning and being consequence-focused, which explains their performance on trolley/footbridge cases (Koenigs, Kruepke, Zeier, \& Newman, 2012). Trolley/footbridge cases involve a person having to make a choice between saving one or five people as a train comes towards them on the tracks. The train is headed towards the five people, but if the person chooses to pull a lever then the train will change course and will hit one person and the five will be saved. The footbridge case involves two people standing on a footbridge over the tracks. In order to save the five people, the person has to choose to push the person onto the tracks in order to stop the train from hitting the five (Foot, 1978). In normal populations, the majority of people $(80 \%)$ are willing to pull the switch, but are not willing to push a person onto the tracks (20\%) (Greene, 2013; Greene, Sommerville, Nystrom, Darley, \& Cohen, 2001). On the other hands, psychopaths choose to pull the switch in trolley cases and also push the person onto the tracks in the footbridge case (Koenigs et al., 2012). They are able to show a preference for the utilitarian calculations in both cases, because they lack the emotional capacities to do otherwise. Most people would feel guilt, fear, or sadness at the thought of pushing the person onto the tracks and this would cause a deviance in their judgment. Psychopaths' tendency to focus on the consequences, without emotions to balance their decision, results in their having a preference for utilitarian choice. The difference in results between the trolley and footbridge cases lends support to a dual-process system. Further, the empirical evidence from psychopathy further highlights the importance of emotions' role in 
not causing harm to others, especially when that harm involves personal contact. Additionally, that psychopaths have intact utilitarian reasoning provides insight into their comparable performance to non-psychopaths on Kohlberg's reasoning tasks. Kohlberg's reasoning tasks privileged utilitarian reasoning as being one of the highest

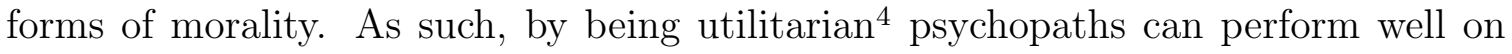
this kind of task.

Psychopaths have no trouble pulling the switch when it saves five at the cost of one. I propose that most of the non-incarcerated psychopaths are able to use non-emotional moral reasoning to navigate their lives effectively. However, as a large proportion of psychopaths will be incarcerated during their lifetime, it is important to understand why this is. I argue that the reason such a high proportion of psychopaths are incarcerated (Hare, 2003) is best understood through a theoretical construct which considers both their emotional deficits and their inability to reason effectively. The Dual-Process Moral Judgment (DPMJ) box-and-arrow psychological model of moral judgment shows how moral judgment can be described cognitively. In so doing, one can show the ways in which psychopathic morality deviate from the norm.

My thesis first examines the emotion-backer and reasoning-backer positions on moral judgment. It mainly focuses on two extreme accounts of reasoning-backing and an emotion-backing — drawing on Haidt's social intuitionism for the former and Kohlberg's theory of moral development for the latter. It then offers an account of what is known of psychopaths with regard to their moral judgment, emotional capacities, and reasoning impairments, considering for example, the ways in which self-control impairs reasoning. It sketches the ways in which the evidence from psy-

\footnotetext{
${ }^{4}$ Utilitarianism is a kind of moral reasoning which argues that that which should be done is that which promotes the most overall utility, where utility is most often expressed at happiness.
} 
chopathy supports a dual-process account of morality Additionally, I use the psychopath to help build a broader account of the role of emotions in moral judgment, which are in turn incorporated into the DPMJ model. In philosophy, most moral emotion-backers focus on there being one or two key emotions for morality, such as Allan Gibbard's account which focuses on anger and guilt (Gibbard, 1990), Patricia Greenspan with guilt (Greenspan, 1995), or Michael Slote (2007) on empathy. A broad consideration of psychopaths helps to understand that guilt, empathy, sympathy, and fear provide a more accurate picture of how morality is motivated. ${ }^{5}$ I focus on these emotions as they are deficient in psychopaths. I argue that these emotions as a whole, as well as individually, contribute to various moral judgments. Only using a model of cognitive can we explain the moral deviance in both criminal and successful psychopaths, both of whom present with cognitive deficits ${ }^{6}$ which impair their ability to make moral judgments. For the former, this moral deviance often results in criminal behaviour. In the latter, it results in manipulation of and callous disregards for others' well-being, and other similar actions. These emotional and reasoning deficits are constitutive of what makes a psychopath. It is what makes both criminal and non-criminal psychopaths who they are. For without these deficits, they would not be as morally deviant. For this reason, I focus on the cognitive aspects of psychopathy and not the behavioural. I developed the DPMJ model of moral judgment to be able to describe the differences between these two groups on a cognitive level. Finally, by

\footnotetext{
${ }^{5}$ It's important to distinguish between the different kinds of emotions which psychopaths lack and a generalized lack of emotion. Psychopaths have been shown to have healthy emotional capacities in certain emotions, such as happiness (Blair, Colledge, \& Mitchell, 2001). Understanding which emotions are affected allows for a better understanding of the roles of individual emotions in moral judgment.

${ }^{6}$ Psychopaths are described as having deficits in reasoning and emotions because compared to the general population, they tend to show less affect than non-psychopaths and to use less adequate reasoning.
} 
studying the deficits of psychopaths, we can better understand the cognition of the non-psychopathic population. 


\section{Chapter 2}

\section{Debates about morality}

\subsection{Emotion-based explanations: Why does moral- ity and moral reasoning require moral emo- tions?}

Before I proceed further, it's important to explain what I mean by emotion. I accept a cognitivist view of emotion. Cognitivist approaches focus on emotion's intentionality. To say that an emotion has intentionality is to indicate that it is about something. For example: If Mary is angry, then Mary is angry about something. George Pitcher explains that emotion is almost always directed towards an object. "Emotions are very often, and perhaps always, directed towards something: a person is afraid of Smith, is afraid that it will fall, is angry at Jones, is indignant because his name was withdrawn, is overjoyed at the turn of events in Ceylon, and so on" (Pitcher, 1965, pp. 326). This aboutness feature which is visible in other important features of the mind, including consciousness, is important and central to my account of emotion. 
Additionally, I argue that emotions are often the result of appraisals. For example, I get angry when I judge that I feel I been wronged. "Suppose Paul is angry at Johnny because he thinks that something Johnny did was wicked: in order to have that evaluational opinion, he must believe, or know, or assume, and so on - i.e. must apprehend-that Johnny did that thing which he considers to be bad" (Pitcher, 1965, 335). This is to say that our emotions often involve an evaluation of some kind, as shown in the case of Johnny and Paul. Paul is angry because of his evaluation or judgment that Johnny did something that Paul believes he should be angry about.

It is true that Paul may find out that he was mistaken about Johnny, but that does not change the fact that his anger was rooted in his initial judgment. Also, it is likely that once he realized that he was mistaken about being wronged he will become less angry. The bodily symptoms may not disappear altogether; however, at the least he will recognize that anger is no longer an appropriate response.

This cognitive appraisal about something causes a physiological reaction. Namely, when a person is said to have an emotion, they feel a particular way. Individual emotions cause unique physiological or felt experiences.

There is a long tradition in philosophy linking emotions to morality. Aristotle is often distinguished as the first to make the connection between emotions and moral action. In the Nicomachean Ethics, he explains the importance of striving for a mean between the two extremes of an emotion as part of a virtuous life (Aristotle, 350BCE/2000). Emotion discourse in morality was significantly influenced by the 18th century Scottish philosopher Adam Smith (1759/2010) who claimed that the concept of sympathy, or what is currently thought of as empathy and sympathy, is the motivation behind moral action. David Hume (1775/1975) similarly claimed 
that sympathy and the ability to feel with your fellow person grounded morality. Emotions as the foundation of moral reasoning and action have been central to moral theory discussion since Smith and Hume. However, the question of which emotion or emotions underlie morality has been debated. There are those, such as Shaun Nichols (2004), who believe that concern grounded in empathy and sympathy can play this role. Patricia Greenspan (1995), on the other hand, favours guilt.

Prinz (2007) claims that many of our moral decisions are influenced by our emotions. People can know the morally right thing to do according to a moral theory, but if their emotions motivate them to do something else, they will likely do that instead. For example: A utilitarian calculus may require the killing of five people to save twenty, but if you asked someone whether she would be willing to do it, she may not as she is distressed, disgusted or appalled at the action. She may recognize that it is required by morality but because of her emotional reaction not be willing to do it. This is further indicated by Greene's trolley/footbridge cases where people show resistance to push the man in the footbridge case. This is because of an emotional reaction. People have more issues with causing personal harm, which is harm caused directly to another by one's own actions, than causing impersonal harm even if the morally right thing to do' would find both actions recommended. This resistance towards personal harm is attributed to an emotional reaction (Greene et al., 2001).

While it is true that we can do moral reasoning without emotion, I have shown some of the ways in which moral reasoning is influenced by emotion. For this reason, emotional deficits, particularly deficient moral emotions, have an impact on the types of moral reasoning that we do. I believe that moral emotions are often connected to and motivate altruistic and moral action too, which will be further explored in the 
coming sections.

\subsubsection{Extreme emotion-backer- Haidt's social intuitionism}

Haidt's social intuitionist model is an example of an extreme emotion-backer. Haidt started doing research in moral reasoning at a time when Lawrence Kohlberg's moral reasoning methodology of moral judgment was the dominant theory and there were no other alternatives in psychology. A person studying morality at this time used a developmental approach using forced-choice moral dilemmas, where harm, justice, and rights were the main foci of morality. As will be discussed, Kohlberg disparaged the role of emotion in morality and believed that sophisticated moral systems did not involve emotional responses. It is in this climate that Haidt began his work. Haidt among others would challenge this approach to the study of morality and in so doing would be instrumental in the development of the new study of moral psychology.

Haidt took issue with the idea that morality is based on reasoning. He explained that reasoning is a slow, deliberative process; however, moral judgments occur rapidly and often without conscious deliberation. This distinction between slow reasoning and rapid moral judgments led to Haidt's (2001) development of his theory of social intuitionism. Most of our moral judgments are made based on emotional instincts. Humans have evolved intuitions that allow us to make moral judgments.

The role of moral reasoning is mainly post hoc. Once we have already made a snap judgment, we use moral reasoning to justify the decision we have already made. Reasoning also has a secondary function of influencing the intuitive judgments we make. However, Haidt explains that one's reasoning alone very rarely changes the initial judgment, but that people are more open to the reasoning of others. There are 
times when persuasive reasoning from others can change our intuitive judgment.

Haidt's best empirical support for the limited role of reasoning in moral judgment comes from his moral dumbfounding experiments (Haidt, 2001; Haidt, Bjorkland, \& Murphy, 2000). Haidt presented subjects with various moral scenarios, such as the following:

Julie and Mark are brother and sister. They are traveling together in France on summer vacation from college. One night they are staying alone in a cabin near the beach. They decide that it would be interesting and fun if they tried making love. At the very least it would be a new experience for each of them. Julie was already taking birth control pills, but Mark uses a condom too, just to be safe. They both enjoy making love, but they decide not to do it again. They keep that night as a special secret, which makes them feel even closer to each other. What do you think about that? Was it OK for them to make love? (Haidt, 2001, pp. $841)$.

Many subjects when presented with this kind of scenario answer that it was not okay for the siblings to do what they did. They maintain this position even when their explicit reasons for maintaining this judgment fail. In other words, it appears that when people are presented with taboos and other moral problems, they make intuitive judgments. Haidt explains that in these cases people are reacting emotionally. More specifically, in this case, they are having a disgust reaction to incest. The disgust that they are feeling is the moral judgment that it is wrong to do it.

Moral disgust has played an important role in informing Haidt's research as well that of David Pizarro. Similar to Haidt, Pizzaro, Inbar, and Helion (2011) explain 
that the feeling of disgust is an appraisal of wrongdoing and that disgust also works as an amplifier of moral wrongness. To elaborate, the presence of something disgusting such as a dirty desk will unconsciously encourage people to make harsher moral judgments on things which they deem bad. For example, if you thought incest was bad, then you will be more likely to want to punish those who do it or punish them more harshly in the presence of something that elicits your disgust mechanism.

Haidt also took issue with how narrow the sphere of morality had become under Kohlberg's influence. Haidt was introduced by anthropologist Alan Fiske to the idea that outside of the West, harm was not the only concern of morality. Other themes, such as sexuality and kinship, were equally worth consideration within the moral realm (Fiske, 1991). Harm was not the only way to consider morality as there were other equally important moral considerations. He found that even within the West there were many moral considerations that were not harm-specific as Kohlberg and Turiel believed. He saw that many Americans have moral concerns such as Cleanliness is next to godliness' that do not tap into harm considerations. The broadening of moral considerations is an important distinction as it presents evidence for the broadening of the moral sphere.

Haidt's later research with Richard Shweder further informed his opinion that morality is not just harm and fairness, but rather should be understood as multifaceted. Shweder had spent time doing research in Orissa, India and this had convinced him that there are actually three kinds of ethics that people use: the ethics of autonomy, community, and divinity. Haidt argued that together these concerns can explain the variety of moral concerns that Shweder had seen in India, America, and other parts of the world. For example, concerns such as 'cleanliness is next to 
godliness' fall under the ethic of divinity, as do concerns about sexuality and purity. People's dislike of homosexual acts cannot be understood by means of a harm or justice-based morality as no one is being hurt by the act; however, by extending the moral realm to include concerns of sexuality, one can better understand the moral concerns that people have than if you have a smaller sphere of moral considerations. The ethic of autonomy includes, but is not limited to, harm concerns. Appeals to fairness also fall into this category. The ethic of community includes concerns of family, community, and country. The rampant patriotism of American conservatives can best be understood through a community lens (Shweder \& Haidt, 1993).

Following in Shweder's footsteps, Haidt went on to develop his own pluralist moral foundations theory. Haidt explains that there are six foundations of morality that people are born with. The foundations developed as a result of various adaptive social challenges that humans encountered. The first foundation, care/harm, developed as a response to our need to care for children and protect them from being harmed. This foundation was originally triggered in response to suffering or distress in children, but can now be triggered in the presence of harm to things we perceive as less powerful being attacked by something more powerful. For example, seeing someone being bullied would generate a response from this foundation. The second foundation is the fairness/cheating foundation which was developed in the face of reaping the benefits of a two-way partnership. It was initially triggered by cheating and cooperation. The appearance of someone cheating on a test in class could generate moral judgments from this moral foundation. The loyalty/betrayal foundation developed to promote group support and can currently be seen in sport team fanatics when supporting their team. The authority/subversion foundation developed in the face of having to 
form societal relationships within a hierarchical group. Interactions with bosses and other superiors can trigger it. The sanctity/degradation foundation evolved out of a desire to avoid contaminants triggered by interactions with waste products. It is now triggered in the face of taboos, such as the one discussed in the sibling incest example. Finally, the sixth foundation is the liberty/oppression foundation. It is concerned with how much freedom people have and can exercise. Viewing bullying or people trying to be dominant over others can trigger this foundation. It is the moral centre for those with libertarian leanings who want the state to have very little authority over their lives.

According to Haidt (2012), we are born with the capacity to develop all six moral foundations. The ones that are developed depend on the culture in which we live, socioeconomic factors, and individual genetics. For example, there is a clear moral divide between the three most popular self-identified American political members, liberal, conservative, and libertarian. Liberals tend to mainly develop harm and fairness concerns. Conservatives show a preference to use all of the foundations. Libertarians only care about the liberty foundation to the point where they defer care for others if it means infringing on personal liberty (Iyer, Koleva, Graham, Ditto, \& Haidt, 2012). The moral divide for liberals and conservatives has also been identified in other places, such as Korea (Kim, Kang \& Yun, 2012). ${ }^{1}$

The development of the moral foundations is closely tied to our emotions and, according to Haidt (2012), each of the foundations is tied to different emotions. Harm is characteristically rooted in a compassion response, fairness in anger and guilt,

\footnotetext{
${ }^{1} \mathrm{I}$ am not committing myself to the view that any of these political positions are 'better' than any other. I am merely reporting on the empirical data that has found that found that there tends to be this political division in America, and in other countries, where those with these divergent political opinions tend to have different moral commitments.
} 
loyalty in pride, authority in fear, and sanctity in disgust. As a result, the development of these moral foundations is tied to proper emotional development. The psychopaths' deficient emotional capacities suggest that full development of these categories may be difficult if not impossible for them. Their deficient empathy and guilt, more specifically, would suggest faulty harm/care and fairness/cheating foundations. This would go far in explaining the behaviour and apparent moral deviance of psychopaths, such as their violent proclivities and high rates of recidivism (Blair, 2007; Hare, 2003; Thornton \& Blud, 2007).

Haidt's account best exemplifies the radical emotion-backer my dual-process account aims to show is too narrow. I believe that Haidt is correct that a lot of our judgments are fast, intuitive and emotionally motivated; however, I have several concerns with his account. First, Haidt provides us with a description of morality as intuitive because it happens rapidly with no reflection. While judgment being fast does present as a reason to discount on the spot reasoning, it does not rule out the possibility that a lot of our reasoning could have been done at some earlier date. Second, there is the problem that just because something is fast does not mean it lacks rules. Our grammatical descriptions and intuitions are quick, but this does not rule out the existence of grammar rules. Third, sentiment does not always trump reasoning. Often we have emotional reactions to things, but which with some reflection are tempered and changed. For example, if my neighbour were to back into my garbage can, I would likely get angry. However, reflection would likely tell me that my anger is unreasonable as my neighbour is usually careful, this hasn't happened before, and this means I should probably cool down and let it go. 


\subsubsection{Morality and empathy}

Drawing on early emotion-backers such as Hume and Smith, Michael Slote (2007, 2010) explains that morality is founded on empathy. Slote defines empathy as the ability to recognize others' emotional states, to feel a vicarious version of that state, and be moved by it to do something to help. ${ }^{2}$ The basis of morality is founded in approval and disapproval and it is through empathy ${ }^{3}$ that approval and disapproval is found. When a person empathizes with another person and feel her empathy in return, this creates within them a feeling of approval for that person. As someone shares our emotional responses, it cultivates feeling of approval; a lack of perceived emotionsharing creates a feeling of disapprobation. Slote views empathy as a medium for emotions important to morality such as pity, guilt, and sympathy. Through empathy an agent can be stirred to feel these emotions that the other is feeling and this in turn leads to moral altruism on behalf of the person in need. This may not always occur, there are people who are very good at reading others' emotions and will even simulate them, but will not have the sympathy required to act on the empathic response. Slote (2007) views empathy as a cognitive capacity that can have better and worse development. As part of a moral life, people should work to develop their sense of empathy. A fully developed sense of empathy allows you to infer the emotional states of others and further to feel what the other should be feeling. For example, you know

\footnotetext{
${ }^{2}$ While Slote and others describe this as empathy alone, it is more accurate to describe this as an empathic reaction which leads to a sympathetic reaction.

${ }^{3}$ Empathy is often characterized as an emotion. For this reason, I capture it in the emotion section. I argue that cognitive and affective empathy play separate roles in the moral decisionmaking process. Cognitive empathy is the ability to take on another's perspective as it does not have the felt component of an emotion, it does not meet the descriptive requirements of an emotion; however, affective empathy, which involves experiencing vicarious emotion, is an emotional process. The reason for distinguishing these processes will become clear in chapter 4 where I consider the evidence from psychopathy which suggests the two are distinct.
} 
that your friend is going to be fired, but your friend does not yet know. A developed sense of empathy allows you to infer that your friend will likely feel saddened, or perhaps angered, by the news; and as a result, you feel this anger or sadness even when they do not. Slote's description of empathy is reactive in this sense.

According to Slote, right and wrong action is decided by the moral criterion of empathic caring (Agosta, 2011). Empathic caring is when we take on the emotional capacities of the other and this moves us. This will sometimes result in our acting on their behalf; however, the morally right thing to do does not always require action. Sometimes it is enough to feel what that other person is feeling. Slote's definition of empathic caring exemplifies what many empathy researchers do, which is collapse empathy and sympathy into one construct. He may be correct that empathy can lead to caring, but omits the importance of sympathy in his definition.

Slote makes further arguments in favour of the role of empathy and empathic caring in ethics of care. Ethics of care will be further discussed in the section on reasoning-backers; however, for now it is enough to understand that it is a reasoningbased approach to moral judgment, where the reasons focus on our relationships with our close relations (Gilligan, 1982). Slote believes that instead of care ethics being a reasoning-backer approach, it is an emotion-based approach dependent on our empathetic responses. The reason that people act morally towards those they are in close relationships with is because they are moved by empathic caring (Slote, 2007). 


\subsubsection{Morality and guilt}

In the next few pages, I will investigate the philosophical account of guilt as a moral emotion. Guilt is believed to be important to morality from both the philosophical and psychological perspectives.

Philosophers such as Allan Gibbard (1990) and Patricia S. Greenspan have asserted that guilt is necessary for moral reasoning and action. Psychological evidence has corroborated these claims in finding that guilt contributes to amending behaviours in the face of wrongdoing, empathic responding to other people in need, and the promotion of stable relationships (Keltner \& Harker, 1998; Tangney, 1995; Baumeister, Still, \& Heatherton 1994, 1995). Haidt (2002) claims that guilt is closely concerned with moral norms and that we feel most guilty over transgressions connected to moral norms.

Gibbard (1990) claims that anger and guilt are the emotions central to morality. While I may disagree with this narrow construal of moral emotions, and more specifically, the inclusion of only these two emotions as moral emotions, it is interesting to consider the ways in which he believes that guilt is needed for morality. Gibbard claims that moral norms are those that we endorse because they promote social cooperation and coordination. He believes that the two emotions which are best suited for promoting these ends are guilt and anger, as they promote it the most effectively.

Gibbard contends that morality is built around judgments motivated by the moral emotions of guilt and anger. We devise norms that demand that when we have done something wrong, we feel guilty. Necessarily tied to this is the audience angered by the transgression. "Moral convictions, we are saying, consist in norms for anger and for that first-person counterpart, guilt" (Gibbard, 1990, pp.126). Guilt and anger are 
able to motivate moral behaviour. The person does not want others mad at them and will often avoid bad action at the anticipation of guilt and disapproval from others.

There are those who question why Gibbard focuses on negative emotions. He contends that negative emotions provide more robust motivation than positive emotions such as love, gratitude and sympathy. "When love fails, bad feelings about bad things we might do can still restrain us" (Gibbard, 1990, pp.295). He believes that anger, guilt, shame, and disdain have longer-lasting effects and are more likely to support morality than are positive emotions.

Gibbard argues that the negative emotions of guilt and anger are the best focus for moral action as they have a component of voluntariness. Guilt is focused on a lack of motivation. In other words, we tend to feel guilty at things we have not done or not been motivated to do. For example, Paul tells his partner Anne that he will pick up milk on the way home from work. On his way home, Paul is tired and chooses not to stop at the store. According to Gibbard, this failure to act appropriately should result in Paul's feeling guilty. In this way, guilt is linked to action.

Gibbard differentiates between shame and guilt. Although he sees both as negative emotions, shame, unlike guilt, does not focus on action. Shame does not focus on what someone has done but rather on a lack that the person has. For example, failing a test could be seen as a failure to properly study (guilt) or as inherent to the person such as that they are lazy or unintelligent (shame). Gibbard claims that shame often results in people withdrawing from the disdain of others. Gibbard ties shame and disdain in much the same way that he ties anger and guilt. "Guilt, we might say, normally involves a consciousness of having done wrong, and shame a consciousness of some personal inadequacy" (Gibbard, 1990, pp.137). The experience of shame is 
different from guilt. Norms concerning guilt tell us only to feel guilty over things that we could have done or not done otherwise. "First, the norms we already accept tell against it; they say not to feel guilty over things we could not have helped" (Gibbard, 1990, pp.296). Guilt focuses on voluntary activity that we undertake. "Guilt and anger, though, may be different. We might tie them much more closely to action. We might decide that what it makes sense to do depends (among other things) on what sorts of things it makes sense to be angry at people for doing, and on what sorts of things it makes sense to feel guilty about having done" (Gibbard, 1990, pp.291). Guilt can be avoided by our voluntarily doing that which will avoid others' anger.

Although Gibbard's account accurately conveys some of the aspects of the emotions, his account suffers because it is inconsistent with psychological evidence on several key features of what the emotions can do. He fails to incorporate positive emotions, such as love, sympathy, or empathy because he feels that negative emotions, such as guilt and anger, better promote social cooperation. Empathy is very important to altruism and prosocial behaviour (Batson et al., 2009) (which are central to Gibbard's account). He also does not consider the ways in which empathy and guilt are related and connected and that there is ample evidence to suggest that the two emotions are linked. However, his worst oversight is his failure to consider survivor guilt.

Greenspan $(1992,1995)$ considers survivor guilt as not only a rational form of guilt, but one which is necessary for morality. Although there is no blame from others or people directly angry with the person who feels guilty, guilt is necessary but not sufficient for morality. "Requiring less to justify guilt may be said to make sense in practical terms on the assumption that an agent has a right to inflict on 
himself what he could not legitimately inflict on others-as a goad to moral perfection, perhaps, beyond what morality requires" (Greenspan, 1992, pp.302). For example, a woman who through no fault of her own kills a child in a car accident may still feel guilty despite not having done anything wrong. No one else may be blaming her, but she may still feel as though she is at fault. This survivor guilt can be linked to morality through norms of fairness.

Greenspan believes that guilt is tied to norms of fairness. In the case where one feels guilty without having done anything wrong, it can be because she feels as if she has transgressed rules of fairness. "That is to say that guilt in the relevant cases functions as a way for the agent to clear himself via emotional self-punishment of any suggestion of benefit from being favored above the other members of a group with which he identifies" (Greenspan, 1995, pp.176). This is supported in the guilt literature as guilt is most often associated with instances of inequity (Baumeister et al., 1994; Hassebrauck, 1986; Brockner et al., 1985, 1986; Newman, 1988). This is the idea that people feel guilty about an advantage at the perceived cost of others and this kind of guilt is most often experienced when the relationships are closer or the people feel as if they share a sense of community.

Baumeister et al. (1994) uses the examples of AIDS in the gay community and job loss to highlight guilt's ties to feelings of inequity: The experience of survivor guilt has been seen in the gay community where people who did not contract AIDS felt guilty because they knew people who were infected. It has also been witnessed in places where some have lost employment and those who remain feel guilty for having kept their jobs. However, they contend that the most famous example is the survivor guilt experienced by Holocaust victims where survivors often experienced feelings of 
guilt, despite there being nothing that they could have done to avoid the wrongs done to their family and friends.

Greenspan is in agreement with survivor guilt being tied to concerns of inequity and explains that the feeling of guilt at having survived while others perish may leave people feeling as though they have received an undeserved benefit. As a result, she claims that feeling guilty in these cases is a rational guilt response.

One of the foundations of morality is fairness. It is natural to feel that something unfair has happened when one has survived and others have not. This is why feeling survivor guilt is not only rational, but also closely tied to moral norms, such as fairness. If Greenspan is correct that survivor guilt is linked, at least in part, to feelings of undeserved benefit, then the idea that it would be associated with norms about fairness is plausible and is indeed substantiated empirically.

If Greenspan is correct, then survivor guilt represents a moral form of guilt which is tied to moral concerns of fairness and is often present in the absence of anger. This is one of the biggest oversights in Gibbard's account of moral guilt. Gibbard contends that guilt and anger are necessarily linked for morality. However, Greenspan shows that it's possible to have moral guilt without anger.

I have demonstrated ways in which guilt is important to and underlies morality. I am hesitant to claim that it is the only moral emotion, or that it should be linked to anger. Contrary to Gibbard's account there are emotions that are central to cooperation and prosocial behaviour, such as empathy, that are as important as guilt. Furthermore, it is unclear whether moral guilt requires anger at all. Gibbard's account suffers because he fails to take into account psychological and empirical evidence which impact the claims and assertions he made about the nature of emotion. This is further 
reason for why it is so important that work in moral emotions be an interdisciplinary project. Fairness may be tied to anger and guilt, as Gibbard believes, but this is but one one way in which people consider morality. If for example, one was to consider Haidt's other moral foundations cases can be made for other moral emotions motivating these concerns (Haidt, 2012). For example, harm/care considerations can be shown to be tied to emotions such as sympathy and compassion. When you see someone else in pain, that can cause you to have a sympathetic reaction. Disgust is closely tied to purity considerations where that which people find disgusting is often deemed morally deviant, such as incest. Authority can be linked to fear. People often do what they are told for fear of the repercussions and consequences, such as following the law for fear of legal ramifications.

\subsubsection{Moral anger}

In Gibbard's (1990) account, there is a case made for the inclusion of anger as a moral emotion. When people see a moral wrong is committed this causes an anger reaction. This idea is seconded by other moral psychologists and ethicists. However, Haidt (2003) explains that many have also seen anger as an immora $]^{4} l$ emotion or an emotion which causes a lot of immoral action. As previously mentioned, demonizing emotions is a long-standing tradition amongst philosophers. Seneca's (Seneca, 4 B.C. $65 / 1963,107)$ most prominent example of the problematic nature of emotion was the corrosive nature of anger. He believed that anger impeded justice and that an angry person cannot see the right thing to do. Haidt explains that researchers have linked anger reactions in animals to the 'immorality' of anger. It is so animalistic to get

\footnotetext{
${ }^{4}$ Immorality is used here by Haidt to explain that people who are angry will at times act morally deviant.
} 
angry, rhetoric suggests, and people are better off when they rise above these lessthan-human emotions. Despite this, Haidt and others such as feminist ethicist Lisa Tessman (2005) believe that sometimes the only morally appropriate emotion is anger. When people are faced with racism, genocide, and other atrocities it is right to feel angry and in these contexts anger is indeed a moral emotion. These elicitors of anger cause a moral judgment. Haidt and Tessman are in agreement that anger is morally motivated when it is outwardly directed towards a third party, as it is, for example, in the case of genocide. No one need cause you a personal affront, for you to be morally outraged when viewing images of and reading stories about genocide in other areas of the world.

Haidt claims that when people feel angry, there is often an accompanied need to act to right the situation. At times the anger is selfishly motivated and the motivated revenge is even morally deviant; however, when the sight of injustice caused to a third-party motivates a person to do something to bring justice to the situation, this is undoubtedly a time at which anger is a moral emotion. Anger's role in morality lends support for its inclusion in the broad sphere of moral emotions included in my dual-process model.

\subsubsection{Moral fear}

This is an area that has not received much theoretical development. However, as will later be discussed, fear deficits are an important cognitive feature of psychopaths and as such it is important to consider how fear as a moral emotion could be further developed. Haidt (2003) claims that any emotion in a specific context can be a moral judgment. He explains that fear can arise as a result of things happen to oneself. 
The fear of losing a good thing or having something bad happen to you are not likely the grounds for moral concern as they are self-interested or selfishly focused instead of other focused. Despite this, there is a second way in which fearful emotions can be elicited. Fear for others' losses, triumphs, mishaps, and joys, can and do cause moral judgment. These triggers, as Haidt names them, are moral elicitors and will often cause some kind of prosocial tendencies or, I would argue, other moral responses beyond just prosociality. In other words, when you're afraid for someone's well-being you are more likely to do something to alleviate your fear by improving their state.

There is a problem however, with fear in itself being a moral emotion. Fearfulness only really motivates a response when the other person feels connected to the person in need, for example a family member or friend. This is to say that fear is most often a self-directed emotion that is not typically considered to be a moral emotion. It is possible that it might generate moral judgment, but it would be highly unlikely if the person felt no connection to the other person, for example because of empathic deficits. This makes fear an unreliable source of morality, at best, and at worst detrimental to the moral process when fear-for-self outweighs the desire to help another person. Further, in reconsidering the concept of morality that was first introduced in chapter 1 (pp.1), we see that that which is moral is good in-and-of-itself. Morality is not dependent on one's personal connection to those involved. It's harder to make a case for how fear is tied to these kinds of goods.

\subsubsection{Summary of emotion-backer theories}

In summation, emotions are important for moral judgment. Haidt explains that depending on the context any emotion could be a moral emotion; however, some emo- 
tions, such as fear may be more problematic for reliably generating moral judgments than are others. Most emotion-backers have narrowly focused their moral explanations on one or two key emotions, such as disgust, empathy, sympathy, guilt, and anger. While all of these emotions are moral emotions and can be shown to generate moral action (Haidt, 2003), having a narrow account runs the risk of missing a full-blown account of moral judgment. As discussed in 2.1.3, different emotions are involved in Haidt's moral foundations. By narrowing the sphere of consideration, to one or two emotions, it is difficult if not possible to explain the emotional roots of their various foundations and the role that emotions play in their development. In chapter 4, I demonstrate that most of the key emotions discussed here are deficient or lacking in psychopaths. From a cognitive as opposed to a behavioural perspective, individually these emotions all play a role in explaining what is going wrong in psychopathy. Further, in building the DPMJ model, it only became more apparent how important it is to include a broad range of moral emotions when thinking about moral decision-making, as individually they all play different moral roles.

\section{$2.2 \quad$ Reasoning-based accounts}

There has been a long philosophical tradition of linking moral judgment to reasoning, where reasoning should lead to moral judgment. ${ }^{5}$ These kinds of arguments can be seen as far back as Plato. In the Gorgias, Plato (380BCE/1994) argues that no person would intentionally harm oneself and as any wrongdoing damages one's character, no person would intentionally do bad. This kind of argumentation has long inspired

\footnotetext{
${ }^{5}$ I define moral reasoning as the application and use of a broad range of rules (where these rules are reason for moral action) to apply to a stimuli that has been presented which will cause a reasoning-based moral judgment.
} 
philosophers and has become a mainstay in the psychological study of moral judgment as reflected by those such as Kohlberg, who takes reasoning to be central to moral judgment. These views stand in opposition to the emotion-backers' claim that moral decision-making is not only independent of reasoning. It goes further to claim that the best moral decisions are made without emotions clouding our judgment.

Shafer-Landau (2007) argues that "that moral obligations entail reasons for action: necessarily, if one has a moral obligation to do something, then one has a reason to do it" (2007; pp.174). It is through reasoning that obligations are derived. If a moral action is right, then the fact that it is right is reason enough to justify action. What is right hold regardless of the person's perspective. The right thing to do is objective and maintains its rightness regardless of one's disposition towards it. In other words, even when you are not emotionally motivated by something, reasoning dictates its rightness and will lead to a moral judgment. Descriptively, reasoning-based judgments are self-motivating which means we should act on judgments made using reason.

\subsubsection{Normative self-governance: A fairly extreme account}

Most philosophical moral accounts that focus on reasoning or rationality are normative accounts. Kant's (1785) account, for example, is mainly focused on the role that rationality 'should' play in morality. Moral judgment should be free of emotion and the best moral motivations are reasoning-based. It is only when we act free from emotion, from duty based in rationality, can we be said to freely express our will. While it can be inferred from this that Kant believed we had the ability to create moral judgments using reasoning-based processes, he did not believe that this is what composed the majority of our moral judgments. 
While Kant may have not made strong commitment to the descriptive role of reasoning, Korsgaard has used his account in this way (Korsgaard, 2010). Korsgaard offers an evolutionary explanation of morality that hinges on her understanding of Kant's 'practical reason'. She explains that practical reason is how people make and understand their moral choices (Korsgaard, 2009). She disagrees with evolutionary biologists who see morality as something shared with animals. She argues that morality is a uniquely human capacity. Only humans have the capacity for self-reflection, memory, and belief maintenance that is required to generate a sense of obligation.

Normative self-government is our capacity to assess the potential grounds of our beliefs and actions, to ask whether they constitute good reasons, and to regulate our beliefs and actions accordingly. In the theoretical realm, the capacity for normative self-government is expressed in the deliberate construction of systems of belief, employing consciously-held standards of good evidence and valid argument. In the practical realm, it is expressed most obviously in the capacity to act from what we familiarly call 'a sense of obligation', grounded in consciously held principles of good or right action (Korsgaard, 2010).

A sense of obligation, Korsgaard argues, is central to the cognitive process of morality.

According to Korsgaard, the human ability to reason about whether actions are worth doing and this justification mechanism tells us what morality is. "There is a further question to be asked about when danger is worth facing or harm worth incurring and when it is not, not just instrumentally, but for its own sake." (Korsgaard, 2010). Korsgaard explains that morality is a reasoning-based self-justification process. 
Korsgaard (2010) claims that animals evolve to exert dominance over one another. Morality developed in response to the internalization of these dominance mechanisms. These mechanisms when self-applied resulted in people keeping themselves in order even without the exterior influence of others. In this way, morality emerged in humans.

Korsgaard is clearly making descriptive claims when she asserts that morality is rooted in reasoning where you can understand your reasons and how those reasons can in turn motivate people to action. Her description of the moral and its foundations in reasoning lead to a description of morality as unique to human cognition.

\subsubsection{An extreme moral reasoning-backer: Kohlberg's moral stage theory}

The most popular descriptive account of moral reasoning-backing is Kohlberg's. Similar to Korsgaard, Kohlberg takes Kantian rationality into the realm of descriptive morality. He prioritized deontic (rule-based) considerations above all others and sees these considerations as represented throughout all stages of moral development. "Kohlberg defines moral perspective taking as being a deontic or prescriptive judgment of obligations and corresponding rights" (Colby, Kohlberg, Gibbs, Lieberman, Fischer et al., 1983, pp.7). Those with the most developed moral reasoning make deontic judgments. ${ }^{6}$ Namely, they use moral reasoning which utilizes universal and exceptionless rules.

Kohlberg was strongly influenced by Piaget. Drawing on Piaget's theories of chil-

\footnotetext{
${ }^{6}$ Deontological moral reasoning is the use of exceptionless, universal moral rules to arrive at a moral judgment.
} 
dren's development, Kohlberg believed that morality was also subject to development. According to James Rest (1988), as children move through the world they acquire new knowledge which allow them to change and fine-tune their moral understanding. As children grow, their spheres of relationships expand outwards. When they are very young, their moral concerns are entirely self-interested; however, as they grow they see themselves as part of family, a larger community, and eventually part of the human race. Human stages of moral development reflect these different spheres. The way in which we reason about morality is founded in the relational sphere that the child is in. According to Kohlberg (1973), as people become more proficient at reasoning and have a more fully developed concept of themselves as connected to the largest sphere of relations, they will develop an abstract, universalized form of morality. At its highest stages, these moralities take the form of utilitarianism, and better still Kantianism. Kohlberg's focus was on reasoning alone. The way people are moral is by becoming ever more proficient reasoners. As people improve their understanding of the world, they are better able to make moral decisions.

In an attempt to assess moral development, Kohlberg (1970) devised moral reasoning tasks focused on determining the stage of moral development of individuals. It is an interview style method where people are presented with a scenario with two possible choices. The most famous example of this kind of dilemma is that of Heinz whose sick wife is dying and the only possible way to save her life is by breaking the law and stealing a medication. The individual is asked whether or not Heinz should steal the medicine. The stage of moral development of the individual is assessed based upon the reasons that the he gives for the answer he provided in answer to the dilemma. 
There are six stages of moral development. People advance through the stages as they age. The young tend to have a more egoistical approach to the world which lends itself to stages one and two. In the third and fourth stages people begin to place greater importance on the needs of others', specifically those with whom they share their lives. Finally, in the fifth and sixth stages people begin to appreciate universal moral principles. Often the fifth stage is equated with a utilitarian perspective where people accept that everyone's happiness is equally important. The sixth stage is exemplified by those who adopt a Kantian morality where one must adhere to universal principles.

Throughout the stages the focus of moral consideration changes, widening as the person develops. What you reason about and how changes. In the earlier stages, one's moral reasoning is self-centred. Avoid doing x, because you will be punished. As one develops, the source of moral consideration expands. Instead of being selffocused, one considers parents, community, or the world. The level of sophistication of the reasoning principles also develops over time. For example, it is only when one is fully morally developed that one can use universal moral principles to generate judgments. "The developing child becomes better able to understand and integrate diverse points of view on a moral conflict situation and to take more of the relevant situational factors into account - each stage provides a more adequate way of making and justifying moral judgments" (Colby, et al. 1983, pp.2).

In the stages, there are four reasoning-based operations used by participants responding to Kohlberg's moral dilemmas: reciprocity, equity, desert, and the Golden Rule (putting yourself in the place of the other) (Colby et al., 1983). The level of moral sophistication used in these four orientations changes depending on the level 
of moral development. For example, in the earlier more egotistical stages, an application of the 'Golden Rule' results in children making decisions such as "I'll scratch your back, if you scratch mine". As they move into later stages and develop a greater understanding of others perspectives and the same operation will result in different reasoning. For example, applying the Golden Rule in these stages involves taking into consideration how the Golden Rule makes others feel.

It is important to note that while reasoning-based decision-making is the best way to arrive at moral judgments, Kohlberg's theory does not preclude the possibility of reasoning in a morally deviant fashion. This is especially the case in stages 1-4 where people are more relativistic and influenced by context and societal pressures. As stages 3 and 4 are conventional, it's possible that you could acquire the wrong conventions. While you might still see your choices as moral, outside audiences might not. A good example of this is Nazism in Germany during World War II. Many people living in Germany during this time used the principles of Nazism. While many would later would come to regret their decisions, at the time it is quite possible that they would view their choices as moral because they accepted the principles. More generally, people can use reasoning and believe that they are acting morally, but from external sources or when more information is presented find that they have made morally deviant choices.

Kohlberg's view of morality had a large effect on the study of morality. Those who subscribed to reasoning-driven morality dominated psychological discussions of morality. All of the psychological models of moral judgment for more than twenty years were exclusively reasoning-based (Jones, 1991; Rest, 1988; Trevino, 1986). ${ }^{7}$

\footnotetext{
${ }^{7}$ The bias in favour of reasoning resulted in overlooking the role of emotion in generating moral judgments. As a result, models of moral judgment excluded emotion until Haidt (2001). This will
} 
From the perspective of this project, it is important to understand the way in which reasoning contributes to moral judgment. The DPMJ model developed through my thesis research embraces rule application. In addition, similar to Korsgaard, it endorses that moral beliefs have top-down effects, where the beliefs that we have prior to receiving information impact the way in which that information is perceived. The beliefs that people have about what is right or wrong influence the kinds of experiences that they have. They also play an important role in the way in which imaginative simulation is done.

\subsubsection{Care ethics}

The care ethics or care reasoning approach to morality and ethics stands in contrast to Kohlberg's justice model of moral reasoning. Kohlberg's theory stressed the importance of impartiality for moral reasoning. He believed that as people become more morally developed, they come to see that all people are of equal importance and that preference to family and community is to be avoided. The theory leaves little room for the importance of personal relationships. Those within the care tradition, on the other hand, see the importance of our personal relationships to morality. In an ethics of care, moral action is motivated by a desire to improve our relationships with others (Noddings, 1984). Care reasoning focuses on the preservation of those relationships and a desire to care well for others. People decide right action based on that which best promotes the maintenance of those relationships and avoids that which would cause them harm unnecessarily (Gilligan, 1982).

Gilligan saw her account as a reasoning-based account. Accordingly, she saw peobe further discussed in chapter 6 . 
ple invoking reasons concerning family, friendships, etc. when making moral judgments. While there is definitely reasoning happening in these people, Slote (2007) argues that these are emotional judgments instead of reasoned judgments.

Care ethics is an approach which, while reasoning-based, is also emotion-based in emotions, as harm and care are closely tied to concerns of empathy and sympathy. Thus it is really a dual-process account. When people make caring decisions, sometimes those decisions are carefully deliberated. For example, the decision to ask an adult living at home to contribute to rent could involve reasoning about the relationship, the health and well-being of that individual and other factors. On the other side; however, there could be feelings of guilt, anger, sympathy, equally affecting the decisions that are made. As a result, unlike Haidt's or Kohlberg's accounts care ethics could be described as a dual-process moral judgment approach (Kelly, 2011). ${ }^{8}$

\footnotetext{
${ }^{8}$ While I argue that care ethics is a dual-process account, it has been traditionally portrayed as form of moral reasoning which is why it's included in this section.
} 


\section{Chapter 3}

\section{Psychopathy explained}

\subsection{Historical sketch of psychopathy}

According to Hare (2003), psychopaths exhibit poor future planning and general proclivities towards morally deviant behaviour. They are also known for their lack of affect and remorse which makes it easy for them to act out in ways which are harmful to others. There are those who believe that these emotional deficits are the root of the disorder and that most of the problems that arise with psychopaths can be attributed to a lack of empathy or concern (Blair, 2007; Blair, Mitchell, \& Blair, 2005; Nichols, 2002a). It is this emotional deficit and its ability to allow for morally deviant and impulsive action that inspired Hervey Cleckley when he first created his description of psychopaths (1941/1982). He discussed how the psychopathic figure shows up many times throughout history. He denied claims that popularly vilified figures such as Adolf Hitler, Nero, and Gilles de Rais fit the profile of a psychopath as he conceives it, viewing them as too emotionally motivated, but devotes considerable time to considering the Greek Alcibiades, as he was depicted in history as well as 
throughout Plato's work, as a historical example of psychopathy.

He [Alcibiades] belonged to one of the noblest families of Athens, and was a near kinsman of Pericles. Though still young, he was influential because of his high birth and his fascinating personality. His talents were brilliant in all directions; but he was lawless and violent, and followed no motive but self-interest and self-indulgence. Through his influence Athens allied herself with Argos, Elis, and Mantinea against the Lacedaemonians and their allies [p. 224] (Cleckley, 1941/1982, pp. 328). Alcibiades' ability to rally his men is a trait attributed to psychopaths. People often follow psychopaths because of their charming and manipulative personalities which draws others to them.

Cleckley focused on Alcibiades' impulsive and reckless behaviour which is often detrimental to himself and others, as well as his lack of concern when he does something that is hurtful. Alcibiades was intelligent and a good leader in many respects but the traits that he lacked often led to his downfall. Cleckley considered the case where before the Athenians sailed on the Sicilian expedition, someone desecrated the statues of the god Hermes throughout Athens. This act was morally deviant and demoralizing for the troops. It was widely suspected that Alcibiades committed the crime and suspicions were only further validated by his caricaturing of the Eleusinian mysteries, further disrespecting the gods. This activity cast Alcibiades in a negative light but also put all the people involved with the attack at risk as they likely feared the disfavour of the gods that Alcibiades' actions could bring on them.

Throughout his history, Alcibiades was noted for his intelligence and bravery, but also for his reckless disregard for rules, other people, and his general unapologetic attitude. When Alcibiades was called to go to trial for the desecration of the statues, 
he ran to Sparta and joined their army. He went on to fight and gain victories against his former countrymen. Most people if they were caught doing something bad, would feel that they owed apology or bad for having done it, or would care enough about their troops not to do it in the first place. In comparison, Alcibiades appears to have been impervious to these common emotional reactions. Even when he could have made repayment by standing trial, he further compounded his bad actions by turning against Athens. In the several descriptions of Alcibiades' life that Cleckley explored, Alcibiades seems to display this lack of remorse and a general lack of affect to his reckless ways.

This lack of affect is very important for Cleckley as he believed it is the central element to psychopathy as it explains psychopaths' bad behaviour and their general lack of concern for others. The example of Alcibiades is used to show that while many of the questions concerning psychopathy are unanswered, experts, such as Cleckley, acknowledge that as long as there has been society there have been psychopaths. Psychopaths are known for their callous disregard for others, their lack of concern and affect, as well as their ability to do morally deviant things (as exemplified by Alcibiades). Even successful psychopaths characterized, in part, by how they do not break the law, act callously towards others and use them for their own benefit (Babiak \& Hare, 2006). They owe no allegiance and are extremely self-serving. As their actions are morally deviant, it would seem likely that their ability to reason about morals should also be impacted. In chapter 4, I consider the empirical evidence to date and discuss what it shows of their moral judgment.

It is appropriate that Cleckley focused on Alcibiades, and more broadly psychopaths' general lack of emotions; however, it is inappropriate to overlook the role 
of impulsivity in Alcibiades' actions. Impulsiveness may point to a lack of emotional restraint; however, Maibom (2005) interprets this kind of behaviour as being attributable to deficits in practical reasoning. She provides the following excerpt from renowned psychopathy expert Robert Hare to provide insight into the lack of reasoning ability of psychopaths.

One of our subjects, who scored high on the Psychopathy Checklist, said that while walking to party he decided to buy a case of beer, but realized that he had left his wallet at home six or seven blocks away. Not wanting to walk back, he picked up a heavy piece of wood and robbed the nearest gas station, seriously injuring the attendant (Hare, 1993, 589) (Maibom, 2005).

Maibom explains that psychopaths have an egocentric viewpoint which generates an inability to fully appreciate the extent of their actions. This can be seen in the example above. The man finds it inconvenient to walk back a few blocks to retrieve his wallet, so instead he robs an attendant, while failing to appreciate the great inconvenience he places on the other. Further, Maibom draws on empirical evidence from Bechara and colleagues' (1994) research with the Wisconsin Card Sorting Task $^{1}$, which show that in gambling tasks, psychopaths are so reward-focused that they overlook negative consequences to themselves, further pointing to a reasoning deficit. Maibom is not making the argument that the emotional deficits are not also implicated in psychopaths' morally deviant behaviour, but rather that it would

\footnotetext{
${ }^{1}$ Wisconsin Card Sorting Test is a card matching task meant to test for "set-shifting" or the demonstration of cognitive flexibility when presented with varying rewards (Monchi et al., 2001). It presents participants with high and low reward decks. High reward decks have high punishments, low reward decks have low punishments. While choosing from the decks participants learn about the various punishments and rewards and are supposed to shift their behaviour accordingly.
} 
be hasty to rule out all reasoning-driven explanations for the same behaviours that Cleckley attributes entirely to emotional deficits.

Similar to Maibom, Jeanette Kennett (2002) argued that psychopaths exhibit poor future planning abilities. Their inability to make plans for the future, arguably, also explains their reckless and impulsive behaviour. According to Kennett, in order to act rationally you have to be able to order yourself according to a life plan. She explains that psychopaths lack this ability and this contributes to their poor life choices. In light of the empirical evidence implicating practical reasoning deficits in psychopaths, a richer and fuller explanation of Alcibiades' actions and lifestyle can be provided. Alcibiades acts erratically, even to the extent that he hurts himself. It is correct to say that he callously disregards others, but it would be inaccurate to overlook the effect of irrationality plays on his life.

This account of the psychopath and his behaviour opens the possibility for consideration of which account of moral judgment is better suited for explaining his morally deviant behaviour. Cleckley focused on the psychopath's emotional dysfunction to explain his behaviour. This would later affect the diagnostic criteria devised by Hare, which would include a focus on the emotional lack of psychopaths as well as their behavioural issues (Hare, 1993). However, there is evidence of psychopaths' having practical reasoning deficits as well. This leaves open the door for the reasoningbacker's explanation of psychopathic immorality which will be further investigated in chapter 5 .

Drawing on the historical description, one can see the dual nature of the psychopath as described earlier. Alcibiades' callousness and lack of remorse in his actions is indicative of deficient emotional response. Also, his inability to act so as to preserve 
his own position and reputation indicates an inability to reason properly about his own well-being. Psychopaths are noted for both their cognitive and behavioural issues and Alcibiades' reckless lifestyle demonstrates this well. I am not interested in Alcibiades' behavior itself, but only in how it sheds light on underlying cognitive deficits. Alcibiades exemplifies the reasoning and emotional deficits of psychopaths. Examples such as these, highlight how neither a reasoning-based nor an emotion-based account can entirely account for psychopathic moral judgment and instead lends support to a dual-process account. The nature of these deficits will be further discussed in chapter 4 .

\subsection{Overview of psychopathy}

This history of psychopathy lends further credence to the long-standing tie of psychopathy to both irrationality and lack of emotions. It further motivates the importance of considering both routes in explaining the disorder.

Psychopathy is a relatively new concept dating back to the 19th century. It was first described by Pinel in 1801 as a form of manie sans délire or madness without delirium. Pinel described an individual who was reckless and impulsive and who seemed to lack remorse for his bad behaviour. Indeed, his patients who presented with madness without delirium were rationally aware of the fact that much of what they were doing was self-destructive but did not seem affected by this. One can see that from its origin as a clinical syndrome, it has been linked to emotion (Hervé, 2007). Additionally, this lack of self-preservation can be understood as a form of irrationality. It is in a sense an irrationality tied closely to a lack of caring, or self-care, attitude.

Morality became important to the psychopathic construct when shortly after 
Pinel, both Rush and Prichard focused the definition of psychopathy on the capacity for immorality of psychopaths. Rush labelled it as a moral dérangement or anomia (understood as ethical derangement). He was the first to take Pinel's fairly neutral diagnosis and make it value-laden. Under his definition psychopaths were considered bad. This spurred the still open debate about whether psychopaths are mentally ill or just bad people (Hervé, 2007). While today it is fairly well excepted today that psychopathy is not a form of mental illness even recently arguments have been made to use psychopaths' cognitive deficits as reason for considering their mental fitness in legal situations (Maibom, 2008).

Maibom argues that psychopaths' lack of emotions is not enough to motivate a defence for legal insanity and that instead claims that psychopaths could avail themselves of non-emotional means to arrive at an understanding of legal rules. This has important implications both for the criminal incarceration of psychopaths as well as for treatment options. Maibom (2008) discusses how it would be very strange to not hold psychopaths criminally responsible as it would be excusing bad people for what they do. As criminal justice is built around punishing bad people for doing bad things, it seems contrary to not punish psychopaths if they are just plain bad people. Further, if psychopaths are inherently bad, then it raises questions about their options for treatment, as well as the more important issue of whether they can be treated at all. There is evidence that psychopaths are resistant to many of the forms of treatment that are effectively used on other offenders. Not only do these measures not work, but often increase the likelihood of recidivism in psychopaths (Thornton \& Blud, 2007). Part of the problem this raises, I argue, is that most attempts have only ever considered the psychopaths' lack of emotion or reasoning and have targeted 
the treatment to these specific concerns. It is only through a broadening of the understanding of their disorder that treatment will become a better possibility.

Early in the history of the term psychopathy, Koch used the term 'psychopathic inferiority' to refer to personality pathology that was biologically determined. This was a move away from viewing psychopathy as a form of clinical syndrome as seen in the above descriptions, and instead towards the more recent concept which is that of a personality disorder. His concept was later rejected because it was over-inclusive and could be considered to include all personality disorders (Hervé, 2007).

In the early 20th century, Partridge advocated for the term 'sociopathy'. He wanted to focus on the importance of environmental factors in determining whether someone is more likely to develop a bad character and be antisocial (acting against the rules) (Hervé, 2007). Although this term is not considered by many to be synonymous with psychopathy, its introduction has led to a confusion of terms for the past eighty years. $^{2}$

In the Mask of Sanity (1941/1982), Cleckley had a significant impact on the study of psychopathy. In order to narrow the construct, he recommended that one focus on the psychopath's lack of affect. Cleckley suggested that psychopathy was a form of semantic dementia where a psychopath cannot understand emotional content. He believed that this lack could explain most of the other issues associated with psychopaths, behavioural and otherwise. His suggestion was very influential and has inspired much of the work concerning emotional semantic tasks and psychopaths, such as those which will be discussed later in this chapter.

The main problem with Cleckley's construct was that it did not allow for easy

\footnotetext{
${ }^{2}$ In my thesis, I explain that the two terms are not descriptively equivalent. As discussed in 3.2.3, there is reason to maintain separation between the two.
} 
diagnosis. For this reason, Hare constructed the Psychopathy Checklist (PCL; Hare, 1980) and later the Psychopathy Checklist-Revised (PCL-R; Hare, 1991, 2003) which is a bi-factor model broken into factor 1 which is interpersonal/affective and factor 2 which concerns lifestyle. Hare's model is well suited to the forensic population and is often used to measure psychopathy. However, its focus on the antisocial behaviours of psychopaths as well as affective personality is a move away from identifying psychopaths just by their lack of affect as Cleckley and others suggested. In essence, Hare added equal consideration to the behavioural component of psychopathy, which was not as much the focus prior to his diagnostic tool. Additionally, Hare's construct also incorporates issues that acknowledge psychopaths' irrationality. Their issues with irresponsibility and impulsiveness can be explained with reference to underlying cognitive, reasoning problems, which I will discuss in chapter 4. Hare's construct is effective as it does allow for accurate measurement of forensic populations. However, the focus on behaviour does leave open an issue as to whether it is partially considering something, namely behaviour, that is not necessary to the construct but may be instead a by-product of cognitive and emotional deficits. In other words, psychopaths' bad behaviour is merely a symptom of the underlying cause. Focusing on the behaviour may provide little to no insight to the underlying problem. It is possible that Cleckley was correct that psychopaths do bad things as a result of their lack of affect or semantic dementia but that this behaviour is not the root of the problem, as Cleckley claimed. Further, in my opinion their reasoning deficits could also be systematically represented by bad behaviour. Equating psychopathy with bad behaviour can lead to a misidentification of the underlying problem. Misidentifying the problem could lead to problems with treatment and a general misunderstanding 
of what psychopathy is. ${ }^{3}$

\subsubsection{Diagnosing psychopathy}

According to the Diagnostic and Statistics Manual Edition V or DSM-5 (2013), psychopathy is a specifier under antisocial personality disorder (ASPD). It is a specific form of ASPD characterized by the especially callous and emotionless attitudes of the patients. The main tool used to measure psychopathy, as explained above, is the PCL-R. It is an expert rating scale divided into two parts: an interview to establish a person's history and a set of questions which measures for different characteristics. It consists of twenty items and is rated out of a possible forty points where each of the 20 items can score $0-2$ where $0=$ not present, $1=$ possibly present or $2=$ definitely present (Hare, 2003). The scale measures for both behavioural characteristics including promiscuity, lying and substance abuse and also considers personality traits including narcissism, shallow affect and superficial charm. One of the psychopath's defining characteristic is his lack of empathy which is often associated with a lack of affect or emotional response. This is, in part, responsible for why it is that psychopaths are able to do horrible things to others that most non-psychopaths would not do. They also lack guilt and remorse, which means that after they do terrible things and harm people, they are unable to feel bad for what they have done.

To further understand the psychopath, one should examine the factor 1 and factor 2 distinction. Harpur, Hakstian and Hare (1988) were early in making this distinction. They explain that there are both factor 1 and factor 2 psychopaths. Factor

\footnotetext{
${ }^{3}$ This is an important question and it is again partly addressed in section 3.2.3 on the problem of antisocial personality disorder and psychopathy, but due to space constraints it will not be addressed in a lot more detail in this project.
} 
1 psychopaths are categorized as selfish, callous, and known for their use of others. Factor 2 psychopaths are characterized by their social deviance (Hare \& Neumann, 2007). Factor 1 psychopaths have cognitive deficits which include deficient affect, fearlessness, attentional deficits, among others. The claim of fearlessness in factor 1 psychopaths is further supported by research which shows that factor 1 psychopaths have low anxiety and that this correlates to their low emotionality (Frick, Lilienfeld, Edens, Porythress, \& McBurnett, 2000; Skeem et al., 2003). Factor 2 psychopaths, on the other hand, are identified by their behavioural issues (Skeem et al., 2003). They are defined by their criminal irresponsibility and recklessness. Frick and colleagues (2000) explain that the main difference between factor 1 and factor 2 psychopaths is that factor 2 psychopaths are high anxiety and factor 1 are low anxiety. Lykken's (1995) claims that primary psychopaths should be distinguished by their fearlessness should lead one to question the role of fear in morality. There are no philosophical moral accounts that include fear, but if fear plays an important role in the reckless behaviour of psychopaths, then it needs to be incorporated in accounts of moral judgment. My account of moral judgment includes fear as an emotion having distinct effects on morality. This will be further developed throughout my thesis.

I want to make clear that while it may be important from a diagnostic position to have cut-offs for psychopathy, as is the case with the PCL-R and other tools, I argue that the construct of psychopathy is a scalar condition where people present with fewer and more of the diagnostic characteristics. It is helpful to understand that people along the psychopathy spectrum can present with different deficits which affect their moral judgment and levels of moral deviance. This is best exemplified in the difference between successful and incarcerated psychopaths which will be further 
elaborated in chapter 8.

\subsubsection{Beyond Hare: Measuring psychopathy}

Hare (2003) offers a diagnostic tool which incorporates both an interview and a background assessment. It has been the most dominant clinical tool used; however, there are other means for evaluating psychopathy including those used with non-incarcerated populations. The Psychopathic Personality Inventory — Revised was a self-report measure comprised of 154-items encompassing eight subscales: social influence, fearlessness, stress immunity, Machiavellian egocentricity, rebellious nonconformity, blame externalization, carefree nonplanfulness, and coldheartedness. This tool has been used to study psychopathy in both university and prison samples.

A second popular self-report measure is the Levenson Self-Report Psychopath Scale (LSRP) (Levenson, Kiehl, Fitzpatrick, 1995). The LSRP is primarily used with non-prison participants. It measures using two scales, primary psychopathy (psychopathic emotional affect) and secondary psychopathy, which are measured by participants' agreement with 26-items. Agreement is measured from strongly disagree to strongly agree.

An approach which deviates from but is still influenced by Hare's bi-factor model, is the Five Factor Model (FFM) of psychopathy which assesses using the NEOPersonality Inventory Revised (NEO PI - R) (Costa \& McRae, 1992; Derefinko \& Lynam, 2013) The NEO PI - R is a self-report measure with 180 items on a five-point scale (ranging from strongly disagree to strongly agree). The five factors which are measured are neuroticism, extraversion, agreeableness, conscientiousness, and openness to experience. Each of the items on the PCL-R were linked with the 
five factors of the model. For example, psychopaths have low scores on five of the six facets of the Agreeableness factor, including modesty, straightforwardness, and altruism.

Despite the popularity of and endurance of Hare's bi-factor approach, there are those who favour a different model. Cook and Michie (2001) proposed that a tripartite model better captures psychopathy. They break psychopathy down into three parts: interpersonal features, affective features, and lifestyle features. They would further separate themselves from Hare in their argument that antisociality should not be included as a component of psychopathic measurement because it is more a resultant than it is an actual trait of the disorder.

In addition to behavioural methods for assessing psychopathy, neuroscientific techniques have also been used. Participants with high psychopathy scores tend to show less reactivity in the amygdala when shown stimuli depicting violence as compared to those with lower scores (Kiehl, Smith, Hare, Mendrek, Forster, Brink, \& Liddle, 2001).

Blair (2003) claims that this dysfunction is largely responsible for psychopaths' deviant behaviour. When people have an emotional experience, the amygdala is responsible for encoding the emotional memory. In the case of negative emotional experiences, people tend to want to avoid re-experiencing that which caused it. However, if the amygdala is dysfunctional then the memory encoding does not happen and as a result the psychopath does not have this avoidance signal necessary for aversive condition. Additionally, Blair (2003) explains that the amygdala is also responsible for registering emotional distress in others. If this signal is missing, it will not deter psychopaths from causing others distress. 


\subsubsection{Psychopathy and Antisocial Personality Disorder}

Psychopathy's classification in the DSM-5 under ASPD is considered problematic for several reasons. Hare (1996) discusses that while most criminal psychopaths also meet the criteria for ASPD, most who meet the requirements for ASPD will not meet the criteria for psychopathy. This is because ASPD will encompass most criminals. ${ }^{4}$ Most people who commit crimes will also meet the criteria listed in the DSM-5 of the assessment of ASPD as it does focus on those who fail to conform to rules (as is the case for all criminals). It is important to note that one of the seven features of the ASPD rating-scale are not solely focused on behaviour. This is a lack of remorse. Arguably, deceitfulness is a characteristic but as defined in the DSM-5, it is described by the behaviours of the individual, including repeated lying and conning of others. The remaining symptoms, however, are solely behaviour focused; including failure to conform to the law and consistent irresponsibility (Walsh \& Wu, 2008).

Hare (1996) is also critical of the fact that the assessment of ASPD is solely focused on behaviour which, as previously discussed, is not usually the case for psychopathy. If someone believes that ASPD captures psychopathy, then they would be overlooking the importance of personality to its assessment. Hare explains that one of the main differences between the two groups is the psychopaths' lack of affect. Psychopaths have difficulty with do semantic word processing tasks that those who meet only the requirements for ASPD do not. While it is improvement that in the DSM-5, a specifier of ASPD is callousness, lack of anxiety or fear, which arguably better targets psychopathy, it is still behaviour-based, rather than cognitive. ${ }^{5}$

\footnotetext{
${ }^{4}$ However, not all psychopaths are criminals and this is a problem which will be discussed in detail in this section.

${ }^{5}$ The focus on the cognitive instead of the behavioural is a feature of the DPMJ model.
} 
Hervé (2007) further elaborated the differences between the two groups. ASPD is much more prevalent, accounting for $50-80 \%$ of people within a forensic setting, whereas psychopathy is much less prevalent accounting for only 15-25\%. Indeed, Walsh and $\mathrm{Wu}(2008)$ explain that given the criteria listed in the DSM-IV for diagnosing ASPD, one would be hard-pressed to find a criminal who does not meet these criteria. ${ }^{6}$ The same is not true of psychopathy. Psychopaths, while overrepresented in prison populations, can also succeed in society. Behaviourally, some psychopaths, namely the general population psychopath, act similarly to other law abiding citizens. What sets them apart in this case are their cognitive deficits. They may not fit the profile of antisocial, but still have emotional and reasoning deficits.

Psychopaths also have higher rates of recidivism than those who are antisocial. This is an important distinction because it shows how a diagnosis of psychopathy tells us something important about the person that ASPD does not. Further, those with ASPD can receive the same treatments as other offenders with effective results, but psychopaths are treated less successfully. Finally, those with ASPD often present with other disorders including anxiety and depression, psychopaths typically do not (Hervé, 2007).

Both Hare (1996) and Hervé (2007) show that similar behaviours may not be caused by the same thing. Criminal psychopaths may act similarly to those with ASPD, but that does not mean that the causes of those behaviours are the same. It appears that having psychopathy classified under ASPD does not add to our understanding of psychopathy and leads instead to unnecessary confusion. The two groups are not the same. They present with different levels of prevalence, one is indicative

\footnotetext{
${ }^{6}$ This equally applies to the DSM-5.
} 
of higher rates of recidivism, psychopaths cannot be as successfully treated as those with ASPD, and those with ASPD will often have other clinical issues that those with psychopathy do not necessarily have.

Patrick, Hicks, Nichols and Krueger (2007) found that by dividing the PCL-R into sub-categories of interpersonal, affective and impulsivity, it was found that there was no significant correlation between affective and impulsivity category scores and ASPD. There was a negative correlation between interpersonal and ASPD $(r=-.08)$. On the other hand, criminality/delinquency and recklessness/aggressive behavior account for large correlations with ASPD $(r=.57, .64)$. That is to say, the personality traits of factor 1 psychopathy are not correlated with ASPD. ${ }^{7}$

This is supportive of the subdivide between factor 1 (personality) and factor 2 (behaviour) psychopathy (Frick et al., 2000; Skeem et al., 2003). In other words, there are two kinds of psychopaths. Those who meet the criteria for ASPD because of their behaviour, and those who don't. Finally, including psychopathy under ASPD entirely misunderstands what is constitutive of psychopathy. There are some who will meet the criteria for factor 1, who will never be diagnosed because they are not antisocial. It is potentially the case that the distinction between psychopaths who do and do not meet the criteria for ASPD is more accurately captured by the distinction between psychopathy and sociopathy where sociopathy is mainly distinguished by behavioural issues. This distinction will be further elaborated in the section that follows.

\footnotetext{
${ }^{7}$ This is a problem for the PCL-R. As will discussed in chapter 8, the DPMJ model offers potential resolution of the conflict between factor 1 and factor 2 psychopathy by considering only cognitive explanations of psychopathy and not the behavioural components.
} 


\subsubsection{Sociopathy vs. Psychopathy}

Both psychopathy and sociopathy were classified under ASPD in the DSM-IV; however, this does not mean that they are the same disorder. It is harder to disambiguate between psychopathy and sociopathy, because both share many of the same behavioural and personality traits. Sociopaths are even known to present with lowered affect than non-sociopaths. Despite this, there are important differences.

Sociopaths are often described as being less focused, more reactive and unable to fit into mainstream than are psychopaths. In contrast, psychopaths are manipulative, secretive, and are understood as being careful planners, which seen in part by their use of instrumental violence (Glenn \& Raine, 2009). ${ }^{8}$ Also, because they are often perceived as being charming and cunning deceivers, they are usually able to fit in well when it suits them.

Walsh and $\mathrm{Wu}(2008)$ provide an account of the differences which focuses on the etiology of the two disorders. As I briefly explained earlier, sociopathy is mainly believed to be a result of environmental factors. Psychopathy is at least partly hereditary; although, environmental factors can contribute. Walsh and Wu explain that while some psychopaths can be considered psychopathic even when they are not criminals, sociopaths are by definition criminals. Supporting Walsh and Wu, Lykken (1995) explains that "Unlike psychopaths, all sociopaths are criminals by definition, and have been colorfully described as: feral creatures, undomesticated predators, stowaways on our communal voyage who have never signed the Social Contract" (Lykken, pp. 22). They believe that while the two disorders may look similar in forensic populations, a psychopath mainly owes his disorder to genetics.

\footnotetext{
${ }^{8}$ This concept of psychopathy stands in contrast to that described by Kennett (2002) in section 3.1. This could demonstrate Kennett's conflation of psychopathy with sociopathy
} 
Walsh and Wu (2008) explain that in comparison to sociopaths, psychopaths have a fairly constant population regardless of time or place at $1-3 \%$ of the male population and $1 \%$ of the female population. ${ }^{9}$ This has been constant throughout history. In comparison, the number of sociopaths within a society is dependent on relative wealth, education, and other environmental factors. In other words, the worse the environmental conditions, the more sociopaths there are likely to be. Further evidence for sociopathy being tied to these factors is the high proportion of sociopaths who come out of poverty. Psychopaths on the other hand are not necessarily correlated to an economic class. ${ }^{10}$ They explain that while both sociopaths and psychopaths may present with a lack of affect, the cause is different in the two cases. Further, while sociopaths present with less affect than normal people, they have more affect than do psychopaths. This was especially apparent in fear responses (Walsh \& Wu, 2008). The reason that a psychopath lacks affect, according to Walsh and Wu (2008), is because it is tied to their genotype. Sociopaths, on the other hand, develop a lack of affect as a survival technique. As most sociopaths have backgrounds of extreme abuse, Walsh and Wu suggest that they develop lack of affect as a means of coping with their environment.

Psychopathy's persistent population speaks to its presenting an evolutionary advantage. Walsh and $\mathrm{Wu}(2008)$ explain that they are a portion of the population that because of their personality and behavioural traits are able to successfully use and maintain cheater strategies. They explain that the psychopaths' lack of social

\footnotetext{
${ }^{9}$ The lower number of female psychopaths is indicative of the DSM-5's insistence on using ASPD for psychopathy diagnosis. This tends to make it more difficult for women to be diagnosed as psychopaths. This will be further discussed in section 3.5.2.

${ }^{10}$ Although it is possible that more criminal psychopaths come out of lower poverty, this could be indicative of some environmental influence.
} 
emotion (including guilt and empathy) with which they are born, allow them to instrumentally use others with ease and that this is something that they are born with regardless of a favourable or unfavourable upbringing. The success of cheater strategies and their use by psychopaths is best captured by the successful psychopath who is able to use these strategies to succeed in their professional field of choice. ${ }^{11}$

\subsubsection{Psychopathy in women}

Psychopathy is underrepresented in women as compared to men (Rutherford, Cacciola, \& Alterman, 2009). This may be partly explained by the continued requirement that psychopathy first be diagnosed as ASPD under the DSM-5. Rutherford, and colleagues (2009) are critical of the fact that psychopathy requires a diagnosis of ASPD, because in order to be classified as antisocial, one must first have had childhood conduct disorder. A diagnosis of conduct disorder requires that children display disruptive behaviours before the age of 15. Rutherford and colleagues (2009) explain that young girls tend not to act out in the ways that are captured by conduct disorder. As these behaviours are less prevalent in girls, less girls present with conduct disorder and, as a result, less women meet the diagnostic criteria for ASPD. Most women who act out criminally, start later than men (Rutherford et al., 2009). According to such tools as the PCL-R, such women could have high psychopathy scores. However, they cannot be classified as psychopaths because of the way the DSM-5 is organized. This at least partly explains why psychopathy appears to be much more prevalent in men. It may also be considered as further reason for why psychopathy and ASPD should be separate diagnoses.

\footnotetext{
${ }^{11}$ Their success will be further discussed in chapter 8 .
} 


\subsubsection{Summary}

I have discussed the history of psychopathy, its diagnosis, and associated problems. Problems with the construct have been considered and while they may remain open, I hope I have shown why the debates are important. Throughout, I have shown that emotion and the issue of psychopaths' lack of affect is extremely important historically, diagnostically, and for etiological explanation. This lack has been discussed since Pinel first introduced the clinical study of psychopathy in the 19th century. As discussed earlier in this chapter, the emotional deficits were the focus of Cleckley's seminal construct and they provide further reason for separating psychopathy from ASPD, as those who are antisocial (but not psychopathic) do not necessarily have emotional deficits. I believe that this overview highlights the importance of emotion's role in the diagnosis of psychopathy and its use in the explanation of the disorder. Even in the early history of psychopathy, the psychopath's lack of emotion is connected to his morally deviant behaviour.

Although historically emotion has received more attention, it is also important to consider the role that reason plays in psychopaths' moral judgment. I hope to build in the coming chapter a convincing case for underlying cognitive issues which make it difficult for psychopaths to be rational. Additionally, I think it is fair to say that while emotions may have been the focus of many of these researchers, as has been discussed, many of the examples they focus on show deficits in reasoning as well as emotion. 


\section{Chapter 4}

\section{Framing the cognitive moral deficits of psychopaths}

\subsection{Emotional deficits}

There is an extensive body of literature that focuses on the emotional deficits of psychopaths. As was discussed earlier, Cleckley (1941/1982) believed that psychopathy represents a form of semantic dementia where one of the key features of the psychopath is his inability to interpret emotional content. This idea has been influential and has encouraged researchers to consider the ways in which emotional understanding in words and other features of language are deficient in psychopaths. Studies have shown that psychopaths have difficulty understanding emotional words. Other studies which have shown the emotional deficits of psychopaths have focused on their inability to reliably identify certain emotions, particularly fear, portrayed by emotional faces, to accurately identify the emotion conveyed in affective prosody, and their lack of reaction to emotional semantic content (Blair, Mitchell, Richell, Kelly 
Leonard, Newman, et al., 2002; Stevens, Charman, \& Blair, 2001; Kiehl, Hare, McDonald, \& Brink, 1999). Most studies lend support to the claim that psychopaths have emotional deficits.

The fact that psychopaths have emotional deficits does not immediately indicate whether psychopaths have general or specific emotional deficits. Here, 'general' is meant to mean an overall lack of affect; whereas, when one considers specific emotions, each, individual emotion's impact on moral judgment becomes important. For example, a lack of affect may be responsible for psychopathic immorality, but I would argue that by considering the impact of individual emotions, we can better understand how these emotions work in moral judgment. However, it is widely believed within the literature that psychopaths do have specific emotional deficits in empathy, guilt, fear, and sadness. Indeed, it is part of the classification of psychopathy devised by Cleckley (1941/1982) and is part of the instrument employed by Hare to diagnose psychopaths in the PCL-R and its variants (Hare, 1991, 2003).

Philosophers, for example, have explored the link between empathy and psychopathy in an attempt to explore psychopath's moral judgments. Empathy's connections to prosocial behaviour, altruism, and morality generally have made the psychopath an interesting figure in philosophy where several philosophical accounts have claimed that the psychopath's lack of empathy can, at least partly, explain his morally deviant behaviour (Maibom, 2008; Nichols, 2002a; Slote, 2007, 2010).

Now that I have provided an explanation of some of the ways in which emotion can be lacking in psychopaths, I will now turn towards giving an explanation for three specific emotions empathy, guilt, fear, and sadness. 


\subsubsection{Empathy}

As has been shown in chapter 2, empathy has been long linked in philosophy to moral judgment where it has been used by philosophers in specific ways (Hume, 1777/1975; Slote, 2007). Psychologists have also defined it several ways (Batson et al., 2009; Blair, 2005; Davis, 1983). The concept of empathy that I find most convincing, and which best applies to psychopathy, focuses on its being a bi-dimensional emotion, comprised of both affective and cognitive empathy (Mullins-Nelson et al., 2006; Oswald, 1996). Cognitive empathy includes the perspective-taking necessary to identify the emotional state of another person and the imagination required to put oneself in that other person's shoes. In other words, it allows a person to imagine how she would feel if she were in circumstances similar to that other person. Affective empathy can be understood as feeling the state that someone else is in. Affective empathy is believed to be very important for altruistic behaviour and personal relationships as it has been shown to increase the likelihood of helpful behaviours (Mullins-Nelson et al., 2006). As in chapter 2, I will again stress that most researchers use empathy where they mean empathy and sympathy. The tools used to measure empathy such as the Interpersonal Reactivity Index (IRI; Davis, 1983) collapse the two emotions together. ${ }^{1}$

Occasionally, cognitive and affective empathy can be further broken down as it is in the IRI which is used as a measurement of empathy. Here empathy is broken into four parts 1) perspective-taking; 2) fantasy; 3) empathic concern; and 4) personal distress), but both 1 and 2 can be portrayed as being part of cognitive empathy; whereas, 3 and 4 contribute to affective empathy which is how Mullins-Nelson and colleagues (2006) interpreted the Interpersonal Reactivity Index (Davis, 1983).

\footnotetext{
${ }^{1}$ For further information on the empathy studies, consult Appendix A, Table 1.
} 
Both McPhedran (2009) and Jolliffe and Farrington (2004) claim that empathy causes a person to be protective as a result of both cognitive and affective aspects. Empathy is, therefore, viewed as an individual protective factor, decreasing the probability of certain types of criminal behavior, while a lack of empathy is assumed to have a facilitating influence on offending (Jolliffe \& Farrington, 2004, pp. 443). A person is discouraged from aggressive activity because they are able to identify another's suffering and are able to sympathize with it. "As such, empathy has been cast as a protective factor' against aggression; empathy provides immediate feedback that discourages aggressive acts by making the perpetrator aware of, and possibly sympathetic toward, another's suffering (Hastings et al., 2000)" (McPhedran, 2009, pp. 2). This example from McPhedran highlights how researchers collapse the distinction between empathy and sympathy. The first part of the distinction clearly applies to empathic perspective-taking, but the second part is sympathy.

Maibom comments that empathy is closely tied to harm norms, which would typically prevent a person from causing others harm.

The collection of norms most central to moral and legal prohibitions may be termed harm norms'. They prohibit harm to others through violence, abuse, exploitation, theft, and so on, and form the core of prohibitions that are mala in se... Only if one is capable of empathizing with others' distress and suffering, can one truly grasp why it is wrong to harm them. As a matter of fact, psychopaths are known to give either abnormal or deficient justifications for the wrongness of actions and they are notoriously callous and lacking in empathy (Maibom, 2008, pp.171).

Drawing on Blair $(1995,1997)$ and Nichols (2002a), Maibom believes that empathy 
deficits seem to prevent a deeper understanding of harm and that to a certain degree psychopaths are unable in this manner, to understand the wrong that they do when they hurt others. This is in agreement with Cima et al. (2010), who have shown that psychopaths know that personal harm is worse than impersonal harm but fail to be motivated to do the right thing.

I agree with Blair, Nichols, and Maibom that psychopaths have empathy deficits. However, I argue that it is inaccurate to claim that psychopaths have general empathy deficits. There is evidence to suggest that what they lack is mainly affective empathy and this is supported by research (Blair, 2005; Jones et al., 2010; Kiehl et al., 2001). Indeed, some research demonstrates that the cognitive empathy in psychopaths is mainly unaffected (Kirsch, Becker \& Allen, 2009), which explains why they are able to read people and use them to their advantage. In a study by Jones and colleagues (2010), it was revealed that males with psychopathic traits are highly proficient in cognitive empathy, scoring at ceiling. There was no significant difference between them and normal populations.

Hitler was noted for his ability to spot emotional vulnerabilities in others (Bullock, 1962). He used this to his advantage. Knowing another's perspective will not on its own motivate good action. Other emotions and reasoning are also necessary to get to moral judgment.

Blair (2005) claims that although both autistics and psychopaths have empathy disorders, they are deficient in different forms of empathy. He claims that autistic individuals tend to have more issues with cognitive empathy or perspective taking. He cites studies which have shown that autistic individuals tend to have difficulty imitating (Williams, Whiten, \& Singh, 2004). This sheds light on the different behavioural 
patterns between the two disorders and why it is that despite having deficiencies in empathy, autistic individuals do not tend to act out as psychopaths do. ${ }^{2}$ For these reasons, any claims by me about psychopaths lacking empathy will be referring mainly to their lack of affective empathy.

A body of psychological literature has emerged to show that psychopaths have empathy deficits. These studies have, for the most part, relied on self-questionnaire reports such as the Interpersonal Reactivity Index (Davis, 1983) and the ImpulsivityVenturesomeness-Empathy (IVE) scale (Eysenck \& Eysenck, 1985, 1991). ${ }^{3}$

Overall, studies focused on empathy in psychopaths suggest that they are deficient in empathy. There is evidence to support that psychopathy scores are negatively correlated with empathy (Flight \& Forth, 2007; Mullins-Nelson et al., 2006; Sterzer, Stadler, Poutska, \& Kleinschmidt, 2007). This finding lends support to my account that emotions and emotional response is important to morality. Empathy is linked to increased moral behaviour and decision-making. Psychopaths' lack of empathy can be used to portray part of the explanation for their deviant moral judgments.

The negative association between psychopathic traits and empathy has also been found in children, although with some interesting differences. Sterzer and colleagues (2007) found a negative correlation between psychopathic traits and both cognitive and affective empathy in a sample of male conduct-disordered youth. Dadds and colleagues (2009) found a similar negative correlation in males using a cross-sectional community sample; however, found that female children who presented with high psychopathic traits did not present with affective empathy deficits, but did present

\footnotetext{
${ }^{2}$ This difference is further explored through the DPMJ model in chapter 7.

${ }^{3}$ As psychopaths are notoriously manipulative, prone to lying, grandiose, and narcissistic, relying on self-report with this population is harder to justify. They are more likely to manipulate their answers to portray themselves in a favourable light.
} 
with cognitive empathy deficits. Indeed, for females there was a medium negative correlation between cognitive empathy and psychopathic traits $(r=-.39)$ and no significant correlation for affective empathy. Interestingly, by adolescence the cognitive empathy impairments seem to disappear in males (Dadds et al., 2009).

Blair has used a different approach from those discussed above for measuring empathy deficits. He relies on startle response and skin conductance responses to show that those with high psychopathy/psychopathic trait scores react less to distress cues from others than those with lower scores (Blair, 1997, 1999). He interprets and advocates this approach as it is consistent with his theory for a Violence Inhibition Mechanism (VIM).

The VIM encourages people to cease aggression when they see distress in others. If you yell at someone and he starts crying, then your VIM will have you lower your voice or change your behaviour in response to this distress response in the other (Blair, 1995). Blair argues that moral emotions, including empathy, are only able to develop if the VIM is intact. A VIM which is impaired or damaged will make it difficult, if not impossible, for a person to develop emotions such as empathy.

Blair's studies, as a result, focus on people's reactions to distress. A lack of appropriate distress reaction would indicate and is the only evidence that a person has a damaged VIM and a likely empathy deficit. In both his 1997 study of adult inmates and 1999 study of children with behavioural problems, Blair showed participants threatening or neutral images and distressed faces. He used skin conductance response and startle response to judge reactions. He found that those with higher psychopathy/psychopathic traits were more likely to show less reaction to distressed faces. However, there were no differences in between groups on threatening and 
neutral images. This, he argues, lends support to the idea that those with higher psychopathy scores likely have damage to their VIM and do not develop empathy in a way that those with intact VIM do.

While the majority of the focus on psychopathy and emotional deficits has focused on empathy, there are other emotions, such as guilt, fear, and sadness which have also been considered as factors in psychopaths' immorality.

\subsubsection{Guilt}

Guilt is an emotion that is most often associated with an acknowledgment that someone has done something wrong. Shame includes clear physiological reactions such as, shrinking into oneself and blushing (Keltner \& Harker 1998). Unfortunately, guilt does not produce any physiological responses. This makes it difficult to determine when someone is feeling guilty. Despite this, however, I believe that it is possible to identify guilt by one's behavioural responses. As the DPMJ integrates specific emotions into its account of moral judgment, it is important to differentiate between different emotions, especially in the case of closely related emotions such as shame and guilt. The most important difference between guilt and shame is the way in which guilt is most often associated with a wrongful act, but shame is associated with the person as a whole being seen as a failure. When someone does a wrongful act, a typical guilt response is to acknowledge that the action was wrong. A shame response would be to link the failure to a failure in self. For example, a person who does poorly on an assignment and typically reacts with guilt, will see it as a one-time event and credit it to his past bad behaviour. He could acknowledge that he did not spend enough time on the assignment. The person who feels shame, however, would 
see it as a failure in himself. The person who feels guilty and associates it with an action can amend that behaviour and correct the wrong more easily than the person who feels shame and sees himself as a failure. In other words, feeling guilty over a particular bad act allows a person to locate a cause for his guilt (the bad act) and to correct through apology and amendment and as a result he can move beyond the guilt. However, as shame is recognizing a failure of self, it is often harder to move past. It is difficult, if not impossible, to change particular traits or other failures in self and as a result people who feel shame are often left feeling useless and unable to improve. For example, the person who does poorly on an assignment because he is truly unintelligent may be able to do little to remedy this deficiency. Shame is much more difficult to be rid of and unlike guilt, which empowers us to make changes and move on, shame can be very debilitating and can cause people to become depressed. Most studies show that those who feel guilty are more likely to confess and amend than those who feel shame; whereas those who feel shame or more likely to hide what they have done (Baumeister, 1994; Keltner \& Harker, 1998). Instead of taking reparative steps, shame causes a person to try and hide herself and in so doing inhibits assertive conduct which could help his situation. According to researchers, the main and clearest difference between guilt and shame is the behavioural response to the felt emotion. People who feel guilty are more likely to do something to improve their situation. People who feel shame are more likely to shrink into themselves or hide and are often unable to move on (Baumeister et al., 1994; Keltner \& Harker,1998).

In trying to further understand the role that guilt plays in moral development, it is important to explain how guilt affects moral judgment. In other words, if moral judgment requires guilt, then a person without guilt will be more likely to develop 
morally deviant decision-making. Guilt is closely linked to moral development and is credited with contributing to the development of conscience in young children, encouraging children to make amends for wrongs, and early differentiation between right and wrong action (Eisenberg, 2000; Kelter \& Harker, 1998; Kochanska, 1997; Kochanska, Gross, Lin, \& Nichols, 2002). As psychopaths lack the development of guilt, it will have important implications for their ability to develop moral judgments as compared to non-psychopathic individuals.

Affective empathy may have received more attention for its contributions to altruistic behaviour compared to other emotions; however, many, such as Nancy Eisenberg and Martin Hoffman, see guilt emotions as intrinsically linked and believe that the same affective component that is featured in empathy is also seen in guilt (Eisenberg, 1986; Hoffman, 1982; Tangney, Marschall et al., 1994; Tangney, 1991; Zahn-Waxler \& Robinson, 1985). It has been claimed by those, such as Daniel C. Batson, that empathy is effective at promoting cooperation, helping behaviour and its close ties to altruism (Batson et al., 2009). ${ }^{4}$ Similarly, guilt is also believed to contribute to prosocial behaviour, especially in close relationships. It has been shown to contribute to amending behaviours, apologies, and an overall desire not to hurt others so as to avoid feelings of guilt (Baumeister et al., 1994).

Although there has been much less work done in the area of measuring guilt in psychopaths than in empathy or affect more generally, guilt does remain a part of both Cleckley's and Hare's understanding of psychopathy (Cleckley, 1941/1982; Hare, 1991). Further the work that has been done in this area has shown that guilt

\footnotetext{
${ }^{4}$ Maibom (2012) argues that most of Batson's work with prosociality and morality focuses on compassion, rather than affective empathy specifically. However, as it is common to use these terms interchangeably in the literature, it is not problematic for my project that I do not further distinguish between the two constructs.
} 
is negatively correlated to high psychopathy (Mullins-Nelson et al., 2006). In a study by Blair and colleagues (Blair et al., 1995) it was shown that adult psychopaths have difficulty ascribing feelings of guilt to others.

Mullins-Nelson et al. (2006) used the Test of Self-Conscious Affect (TOSCA-3; Dearing \& Tangney, 2002), a self-report questionnaire which has individuals report on guilt and other emotional responses (including shame and pride) by having them convey their reactions to different scenarios. Their study supported guilt being deficient in psychopaths as there was a negative correlation between guilt and high psychopathy scores on the Psychopathic Personality Inventory (PPI; Lilienfeld, 2004) as demonstrated by a significant negative correlation between the guilt measures on the TOSCA-3 and the PPI $(r=-.279)$.

Jones and colleagues (2010) used the Emotion Attribution to Self task which shows participants different vignettes depicting specific emotions (fear, disgust, embarrassment, and guilt) and asks how they made them feel. For example: They are told that they made someone cry and are asked whether it makes them feel guilty. This study again lends support to the idea that psychopaths are deficient in guilt. Those with psychopathic tendencies tended to indicate they did not feel much guilt when making others cry or other scenarios which should inspire guilt, as indicated by their lower guilt scores as compared to non-psychopaths. While this trend was not significant, the authors explained that this was likely due to a desire of participants to appear socially desirable and to fit with societal norms. 


\subsubsection{Fear}

Most of Abigail Marsh's research $(2008,2012,2014)$ focuses on the lack of fear in psychopaths as the driving force behind their immorality. This has received very little attention in the philosophical arena. The role of fear as a moral emotion is very much under-developed, but if fear plays an important role in the moral development in non-psychopaths, then its role as a moral emotion is worthy of consideration. ${ }^{5}$

There is a longstanding tradition of considering the lack of fear in psychopaths. Cleckley (1941/1982) considered it to be one of their emotional impairments. Hare (1965) was one of the first to try and measure the lack of fear in psychopaths. When applying a strong electrical shock to participants, Hare found that psychopaths registered less fear response than non-psychopaths as measured by their having less skin conductance reactivity compared to non-psychopathic criminals. Further, Hare (1966) used shock treatments to assess whether psychopaths differed in their preference of immediate versus delayed shock punishment. They were assessing whether psychopaths learn to fear shock in a similar way to non-psychopaths. Psychopaths showed that they would rather delay the discomfort of shocks, which is a marked difference from non-psychopaths. They chose immediate shocks only $55.5 \%$ of the time as compared to non-psychopaths who chose immediate shocks $82.3 \%$ of the time. It was found that non-psychopaths developed a preference for earlier shocks as they were conditioned to fear the shocks. Psychopaths seemed however, to be immune to fear conditioning and maintained a similar aversion to the immediate punishment.

Psychopaths don't learn to fear the shocks in the way that non-psychopaths do. This lack of fear conditioning (Hare, 1965; 1966; 1968) for psychopaths was believed

\footnotetext{
${ }^{5}$ This is why the DPMJ model incorporates fear into its description of moral judgment.
} 
to contribute to a lack of fear of punishment for illegal activity. Fear of punishment does not deter psychopaths from doing bad things.

Patrick, Cuthbert, and Lang (1994) studied the way in which psychopaths viewed fear-related sentence stimuli. They found that psychopaths as compared to nonpsychopaths do not register the same physiological responses to viewing the sentences. This further substantiated their earlier findings that psychopaths show less startle reflex when viewing emotions depicting fearful picture stimuli (Patrick, Bradley, \& Lang, 1993). This was further corroborated by later research by Blair in which psychopaths demonstrated a lack of startle response when viewing violent imagery (Blair, 2002).

Dindo and Fowles (2010) provided further clarification on how the fear deficits work in psychopathy. They found that similar to the earlier studies, psychopaths show less skin conductance reaction compared to non-psychopaths when viewing fearful images. They found that this deficit tracks factor 1 psychopathy, but not factor 2. In other words, factor 1 which includes the affective traits of psychopaths, is what the fear deficits track. Factor 1 psychopaths' inability to form fear responses is not associated with their behavioural traits, but is instead associated with their cognitively deficient emotions. This offers further support to findings that claim that the means of differentiating between factor 1 and factor 2 psychopathy is that factor 1 psychopaths are low-anxious.

Psychopaths have also been shown to have a difficult time identifying fear in the faces of others (Dolan \& Fullam, 2009; Marsh et al., 2008) and in others' speech (Blair, 2005). A meta-analysis of psychopaths' fear deficits in facial recognition was run analyzing 1,387 participants across 22 studies (Wilson, Juodis, \& Porter, 2008). 
It was found that there were overall deficits for psychopaths in fear $(r=.10)$ and sadness $(r=.12)$ across both verbal and nonverbal response styles. While these effects were small, they were significant. In addition to their ability to read fearful facial expressions, psychopaths demonstrate an inability to recognize demonstrations of fear in body postures (Munoz, 2009).

A lack of fear and having low anxiety can be seen as a partial explanation for the role that fear plays in the immorality of psychopaths. Marsh and Cardinale (2012) demonstrate a further role that fear plays in psychopaths' inability to do the right thing, where psychopaths do bad because they are more comfortable than non-psychopaths with causing fear to others. They compared psychopaths to nonpsychopaths on judgments of acceptability of causing fear to others. They found that there was a significant difference between the two populations, where psychopaths $(M=2.51, S D=1.67)$ find it more acceptable to cause fear in others than did people with low psychopathy scores $(M=5.61, S D=2.58)$. When you consider the role that this would play in prosocial behaviour, it demonstrates a clear way in which psychopaths are impaired in understanding what they shouldn't do when it comes to causing others fear. If they do not understand what causes fear in others, then it is more difficult for them to avoid doing those things.

\subsubsection{Sadness}

As demonstrated by Wilson and colleagues' (2008) meta-analysis discussed above, there is evidence to support a claim that in addition to fear deficits, psychopaths are also deficient in how they process sadness. This study showed that similar to fear, psychopaths show less reactivity to sadness as compared to non-psychopaths 
across a variety of tasks including image viewing tasks and acoustic presentation of information.

In addition to being less affected by presentations of sadness, Wilson, Demetrioff \& Porter (2008) found that, in a task where people are asked to remember characters they are presented with, subjects with high psychopathy scores are more likely to remember sad, unsuccessful female characters $(M=90.48 \%, S D=39.41 \%)$ than they are happy, unsuccessful women $(M=38.10 \%, S D=49.76 \%)$ or sad, successful female characters $(M=42.86 \%, S D=50.76 \%)$. Wilson and colleagues believe that the way in which psychopaths are better at encoding sad, unsuccessful women could be used to explain how psychopaths choose their victims. Babiak and Hare (2006) claim that psychopaths allocate resources to identifying and remembering vulnerable individuals. Sadness could likely play a way in identifying vulnerable individuals and as their systems cognitively prioritize this encoding, it ensures that a potential victim is later remembered.

From the perspective of the DPMJ model, this is important information: sadness plays an important role in forming moral judgments, one that is distinctive from other emotions. Not only can emotions be important in judgment, but as shown by the use of sadness by psychopaths, people can be more sensitive to emotional information and use it for reasoning purposes, such as in the case of psychopaths for victim selection.

\subsubsection{Discussion of affective empathy, guilt, fear, and sadness}

Evidence suggests that affective empathy/empathic concern, guilt, and fear are central emotional deficits for psychopaths. This would explain why it is that they fail to place importance on the harm principle of Haidt's moral foundations. If you cannot 
empathize with others, then you will be less motivated to stop harm caused to others. Further, if you cannot feel guilty about it, then you will not make amends and will be more likely to engage in harmful behaviour in the future, as you do not have the negative reinforcement of guilt feelings to inhibit you (Baumeister et al., 1994). A lack of appropriate recognition of fear makes it difficult to appreciate the harm that your causing another. If you fail to feel the fear that you are causing the other person, then it is as if you have a blindness to what you are causing them. Additionally, a lack of fear makes it difficult for psychopaths to fear punishment for their actions. These emotions are important to socialization and to moral development more generally. It makes sense that if psychopaths are deficient in them, they will be less motivated to care about others.

\subsection{Psychopathic Moral Reasoning}

Moral reasoning is thinking about what one ought to do in life. This 'ought' can be derived from a number of considerations. For example, one could decide that the right thing to do is that which produces the most overall utility. Another could argue that what should be done is what leads one to become the most virtuous person. Or another could claim that the source of our moral obligations comes from universal law.

Psychopaths' poor reasoning skills, moral and otherwise, are apparent in both their behaviour and their attitudes. As Hare notes in his psychopathy checklist (1980, 2003), psychopaths commonly use and manipulate others, engage in parasitic lifestyles, are grandiose and narcissistic, and are pathological liars. These lifestyle features appear contrary to what reason would suggest is the best course of action, as 
often they result in psychopaths living a very solitary existence with no close friends or family, and often with no long-term prospects. A concrete example of a way in which they do not seem to care about moral reasoning is their callous disregard for others through lying. Other attitudes that show poor reasoning include their highly inflated self-evaluations and an inability to accept responsibility when they have clearly done something wrong.

\subsubsection{Psychopaths' cognitive deficits in reasoning}

Recent and current research in morality and psychopathy indicate that psychopaths are not only deficient/impaired in emotions, but also present with other cognitive deficits such as impulse control issues, especially in the face of reward. This leads to poor reasoning, because they are unable to overlook rewards and as a result they often confabulate to get what they want.

Drawing on Hare $(1993,2001)$, lack of self-control is part of the psychological construct for psychopathy. Additionally, their inability to refrain from action in the face of a possible reward makes it difficult for them to weigh other factors when a reward is present. This has been examined with both psychological and neurological research. For example, in a study by Kalinian and Wisniewski (2005) using the Wisconsin Card Sorting Task, it was demonstrated that when a psychopath comes across high rewards he becomes fixated and is unable to shift attention elsewhere. In fMRI and PET studies, M. Sib Ansari and colleagues (2010), found that the dopaminergic reward system in the brain of psychopaths become highly activated when presented with reward and that psychopathic brains are hypersensitive to rewards, such as monetary and pharmacological rewards. This led the team to conclude that psychopaths 
are more likely to give in to reward than are non-psychopaths and that this is likely part of the explanation of their deviant behaviour.

A study by Elsa Ermer and Kent Kiehl (2010) demonstrated that psychopaths have mostly intact general reasoning abilities but that their ability to think about social and precautionary rules is compromised. Ermer and Kiehl explain that psychopaths have specific reasoning impairments tied both to their understanding of and ability to reason about precaution and risks and also in their understanding of social exchange rules. The following is one of their stimuli concerning social exchange,

"If you borrow my car, you will have to fill the gas tank"

and another dealing with precaution

"If you work with tuberculosis patients, you must wear a surgical mask"

(Ermer \& Kiehl, 2010). Participants were then given scenarios in which a person either complies or fails to comply with the rule. They were required to judge whether or not the person described complies with the rule in the situation. Psychopaths showed a significant lack of ability to comprehend and properly apply precautionary rules, $(M=42.0 \%$ correct, $S D=40.22)$, compared to non-psychopaths $(M=73.3 \%$ correct, $S D=31.53)$. They had comparably bad performance in the social exchange category, where psychopaths showed little to no understanding of the social contract rules.

Wray Herbert (2010) explains that these findings help to better explain Ted Bundy's appreciation or lack thereof of moral rules. He uses the following quote from Bundy to help solidify his point. "I didn't know what made things tick. I didn't know what made people want to be friends. I didn't know what made people 
attractive to one another. I didn't know what underlay social interaction" (Herbert, 2010). Here Bundy is explaining his lack of social understanding and how the world is supposed to work. Herbert explains that it is this lack of understanding of the social contract combined with poor inhibition that can offer insight into Bundy's, and other psychopaths, immorality.

\subsubsection{Summarizing deficits and linking the summary to the model}

As shown throughout this chapter, the evidence available on psychopathy shows that psychopaths have cognitive impairments that result in both emotional and reasoning deficits which affect their morality.

Psychopaths' lack of empathy, guilt, fearfulness, and other emotions central to morality, has the potential to lead to deviant moral judgments in several ways. Lack of affective empathy/sympathy reduces the likelihood of prosociality, where people with higher empathy are more likely to respond to others in need. People lower in empathy are less likely to respond to others' distress (Blair, 2005). This lack also contributes to the inability to refrain from causing harm to others. In nonpsychopathic individuals, when they take the perspective of the other and recognize that what they are doing is causing distress, they will share this affective state and this will incline them to stop what they were doing. As psychopaths lack affective empathy, this deterrent does not exist for them.

Guilt is important to relationship maintenance (Baumeister, 1994). When people make mistakes or hurt another person, feelings of guilt lead them to make amends for their bad behaviour. The anticipation of guilty feelings can deter people from 
these courses of action entirely. As psychopaths lack guilt, they lack both the emotional incentive to make things right when they do wrong and they do not have the anticipation of guilty feelings to stop them from the course of action in the first place.

Sadness plays an interesting role in the psychopath's cognitive system. They are less affected by sadness in others, which means that they will be less affected by causing it. However, they are also able to use sadness cues to identify victims.

Fearfulness plays an important role in moral development. Children's early moral development is partially tied to their understanding of moral repercussions and the fear of punishment (Kohlberg, 1970; Marsh, 2008). As demonstrated in this chapter, psychopaths lack normal fear responses. This means that they have less deterrence for avoiding punishment. Their lack of fear extends to a greater willingness to cause fear in others (Marsh, 2012).

Psychopaths are also shown to have several cognitive impairments which affect their moral judgment. They have difficulty understanding social and precautionary rules (Ermer \& Kiehl, 2010). I would argue that these rules are important in a lot of moral decision-making. Many of our important moral choices have to do with making good choices when it comes to the safety of others. If you are more willing to make risky choices and are impaired in understanding precautionary rules, this could lead to an increase in deviant moral choices.

Their hyper-focus on rewards has top-down effects which impair the ability to reason generally. ${ }^{6}$ In chapter 7 , I will further discuss how top-down processing which includes previous moral beliefs, emotional states, and stress affect moral decision-

\footnotetext{
${ }^{6}$ Top-down processing are the beliefs, expectations, and other cognitive processes that are formed based on past experiences that bias perception (Bernstein, 2013). I would argue that this definition is too narrow. It is not just perception, but beliefs and other mental states which can be biased as well by top-down processes.
} 
making. Being focused on reward, could impair your reasoning ability (Ansari et al., 2005; Kalinian \& Wisniewski, 2005). Additionally, even if psychopaths are able to reason things through to a moral judgment, then they still have to overcome their self-control issues (Hare, 2003). Psychopaths poor self-control means that even if they are able to reason to a moral judgment, they can still show weakness of will or lack of self-control which will impair the ability to act on this judgment.

Neither the emotion-backers nor the reasoning-backers have put forward theoretical accounts which can fully account for the full-range of cognitive deficits presented in psychopaths. The issues raised throughout this chapter show a need for a dualprocess model of moral judgment in psychopaths. As will be shown in chapter 7, the DPMJ model can account for these deficits. Using a dual-process model that includes cognitive processes such as self-control, provides a description of where in the moral decision-making process psychopaths deviate. In addition, it will be clear that it offers the most theoretically complete picture of the underlying cognitive processes involved in psychopathic moral judgment and moral judgment more broadly. 


\section{Chapter 5}

\section{Explaining psychopaths' moral judgment}

In the previous chapter, I provided an overview of psychopaths and their cognitive deficits - both those linked to emotion and reasoning — in an attempt to understand the breadth of cognitive processes contributing to their deviant moral judgment. In the sections that follow, I offer the ways in which philosophers and psychologists have attempted to explain moral judgment in psychopaths. ${ }^{1}$

\subsection{Kantianism applied to psychopaths}

Reasoning-driven explanation has been applied to the problem of psychopaths by several philosophers including Kennett (2002). Kennett uses Kantianism to show that the psychopath would fail to be a moral agent under the requirements of rationality

\footnotetext{
${ }^{1}$ For further information on the moral judgment studies discussed in this chapter, refer to Appendix A, Table 2.
} 
and practical reason set by this account. The deontological ${ }^{2}$ tradition is a reasoningdriven approach to morality which judges the rightness of actions based on adherence to universal moral rules. According to this moral system, a person's actions should be judged according to their intentions rather than the consequences. For example, a waiter inadvertently serves a person who is allergic to nuts a peanut dish. The person needs to be hospitalized as a result. The waiter was not told of the allergy and had no intention to harm the person; and so, his action should not be considered morally deviant.

According to Kant, moral rightness was derived from universal maxims. Maxims, such as a duty not to lie, are obligatory regardless of whether we find pleasure or displeasure in their performance. Through the use of practical reason, a rational person sees the rightness of the duty and is motivated to act in accordance with it (Kant, 1785/2005). While Kant believed his account to be mainly normative, or a set of claims as to what one ought to do, proposing a mainly normative account is not necessarily the case for all moral reasoning-backers, such as Korsgaard (2010) and Kohlberg (1970).

Kennett claims that psychopaths could not qualify as Kantian moral agents as they lack respect for rules, often make exceptions for themselves, and lack the ability to make life plans and follow through towards a goal. The last point is the most important as it suggests that the psychopath is irrational. Rational action requires that one be able to follow through on the goals that one sets. The psychopath's inability to do so highlights his difficulty being rational, or perhaps more strongly, his irrationality. Not only does he not understand the importance of other people's

\footnotetext{
${ }^{2}$ Please refer to definition in section 2.2 .2 , pp.32.
} 
goals, but also lacks an appreciation of working towards his own. He will often act counter to the goals he sets, self-sabotaging and acting impulsively.

It is not the psychopath's lack of empathy, which (on its own, at any rate) explains his moral indifference. It is more specifically his lack of concern, or more likely lack of capacity to understand what he is doing, to consider the reasons available to him and to act in accordance with them (Kennett, 2002, pp. 354).

This lack of rationality would be detrimental to moral agency in a Kantian account. As our ability to be moral agents, according to Kant, depends on our being rational, a consistently irrational person would not meet the requirements for this kind of moral agency. This impairment in psychopaths' practical reason lends credence to the moral reasoning-backers claim that a psychopath's deficit is not an emotional disturbance or lack but one which is founded in reasoning.

To further demonstrate this, consider Cleckley's (1941/1982) description of Alcibiades. Cleckley described Alcibiades as intelligent and possessing many good qualities; however, he often acts against his own self-interest. He does things which do not make sense as they hurt himself and are at odds with what he would hope to accomplish. He shows little respect for his own goals or those of others. In other words, Alcibiades often acts irrationally. "When we look back upon what has been recorded of Alcibiades we are led to suspect that he had the gift of every talent except that of using them consistently to achieve any sensible aim or in behalf of any discernible cause" (Cleckley, 1941/1982, pp. 335). From a Kantian perspective, it seems unlikely that Alcibiades meets the requirements for moral agency. 


\subsection{Utilitarianism as applied to psychopaths}

Utilitarianism is the philosophical position that the right action is determined by that which produces the most utility, where utility is often understood as happiness. Greene and colleagues (2001) claim that the choice to pull the switch in the trolley cases predominantly involves utilitarian reasoning. When someone is choosing whether or not to pull a switch and save five people and kill one or to not pull the switch and allow the five to die, it is claimed that people do some kind of utilitarian calculation. Indeed, in studies run by Joshua Greene, amongst others, people will often explain their actions in the following way: "It's better to save five people, and to let one person die, because five lives saved is better than one". There is more overall utility to be had in the promotion of the happiness of five people than in that of the one.

In a study by Michael Koenigs and colleagues (2012), it was found that psychopaths are better at making the utilitarian choice in cases where harm is caused to others than are non-psychopaths. This was especially the case with low-anxiety psychopaths. Less fear or anxiety allows these psychopaths to make consistently utilitarian judgment that many non-psychopaths find difficult to make. The results of the study showed a significant endorsement of utilitarian choice from low-anxiety psychopaths $(M=0.74, S D=0.19)$ compared to non-psychopaths $(M=0.61, S D=$ $0.19)$ cases where personal harm ${ }^{3}$ was necessary for achieving the utilitarian choice.

\footnotetext{
${ }^{3}$ Personal harm is defined by Koenigs et al. (2012) as harm directly done to a specific person.
} 


\subsection{Kohlberg moral reasoning interview and the Defining Issues Test}

Researchers using Kohlberg's moral reasoning interview have not found consistent differences in moral reasoning abilities between psychopaths and non-psychopaths. Psychopaths do not demonstrate an inability to perform Kohlberg's moral reasoning tasks. Offenders do not perform as well as non-offenders. However, when compared to similar non-psychopathic, offending populations, psychopaths perform equally well (Lee \& Prentice, 1988; Trevathan \& Walker, 1988) ${ }^{4}$.

One of the main problems with Kohlberg's approach is that an interview does not allow for easy replication. As a result, it is difficult to show whether it is a reliable assessment measure. James Rest (1974) took Kohlberg's moral reasoning levels and developed the Defining Issues Test (DIT). This again presents individuals with a dilemma; however, it also limits their responses to twelve possible answers.

O'Kane et al. (1996) found similar results using DIT to those of Lee and Prentice (1988) and Trevathan and Walker using Kolhberg's interview (1988). They found that psychopathic offenders did not perform as well as non-offenders, but had similar results to other offenders. Indeed, Kane and colleagues were critical of moral reasoning tasks, such as the DIT, as they are so dependent upon the participant's intelligence. Once intelligence has been factored in to the DIT, there do not seem to any significant differences between individuals.

Heinze and colleagues (2010) ran the DIT-2 (Rest, Narvaez, Thoma, \& Bebeau,

\footnotetext{
${ }^{4}$ Lee \& Prentice (1988) found that there were no significant group differences between groups of delinquents (including psychopaths) on this task. Indeed when intelligence and social economic factors are taken into consideration, psychopaths do not appear to be impeded in comparison to those of similar backgrounds (Blair et al., 2005)
} 
$1999)^{5}$ on a sample of Master's of Business students. They found that overall high scores on the Psychopathic Personality Inventory (Lilenfeld \& Andrews, 1996) were not predictive of moral reasoning abilities on the DIT-2. This is consistent with O'Kane et al. (1996) and others who have used Kohlbergian-style moral reasoning tasks.

In summary, the Kohlberg moral reasoning interview task and the similar DIT have not had much success at showing differences in moral judgment between nonoffenders, offenders and other psychopathic offenders. The differences that are found, are attributable to differences in intelligence, education, and background rather than any clear moral deficits.

In chapter 2, I considered the case that reasoning-backers make for the role of reasoning in moral judgment. Kohlberg was the most radical proponent for this view. It is important therefore to note that his account cannot differentiate between psychopathic and non-psychopathic moral judgment. That is to say, there is more to moral judgment than Kohlberg-type reasoning; otherwise, psychopaths wouldn't be so deviant from the norm in the types of judgments they make and how they apply them. Psychopaths appear to have intact utilitarian reasoning; however, this doesn't prevent them from making judgments which are deviant from non-psychopaths. In other words, in order to explain their deviance one has to move beyond solely moral reasoning-based models, at least of the Kohlbergian variety.

\footnotetext{
${ }^{5}$ Definining Issues Test — Version 2.
} 


\subsection{Turiel's Moral-Conventional (M-C) Distinction}

Turiel's M-C distinction has enjoyed more success than Kohlbergian-style moral reasoning tasks at differentiating psychopath's moral abilities from non-psychopaths (Blair, 1995, 2005). Turiel $(1978,1979,1983)$ found that most people are able to distinguish between rules of convention and rules of a moral nature. The main differences between moral and conventional rules can be distinguished by 1) the perceived gravity of the breach of the rule; 2) whether the rule is considered to be universally applicable and; 3) by whether or not breaking the rule would harm a particular victim. Most people see the transgression of moral rules as being worse than and more serious than breaches of conventional rules. Moral rules are applicable regardless of where you are and independent of institutional or individual authority (authority figures cannot change moral rules ${ }^{6}$; whereas, conventional rules are often localised and dependent upon authority. Finally, moral rules often have to do with a person being harmed or an injustice being done against particular people and the same does not apply to conventional wrongs (Kelly, Haley, Eng, \& Fessler, 2007). For example, most people recognize that murder is wrong even if there is no explicit rule. Even if a rule was passed making it permissible, most would still feel that it was wrong to kill others. A rule not to chew gum; however, is only seen as wrong as long as the rule is in place. If someone were to change the rule, then people would no longer see it as wrong. (There are exceptions to this such as killing in self-defence or killing in the army in defence of one's country.)

The moral-conventional distinction task has been administered across most age

\footnotetext{
${ }^{6}$ I disagree with Turiel's claim. There are examples where authority figures do change the moral rules. Examples of this include authority figures taking positions on things such as abortion and homosexuality. Their voices tend to have an impact on the moral views of others.
} 
groups (adults, youths, and children); however, its initial focus was on the moral development of children. It has been found that preschool aged children who are given stories about moral and conventional rules are able to distinguish between the two and believe that it is more wrong to breach a moral rule. For example: they are told a story where a child hits another and then were asked whether what that child did was wrong. Children are able to decide that it is never right to hit another person even if there is no explicit rule. Even if there were a rule saying that it was permissible, they still viewed it as being wrong to do. It is widely believed that most people have the ability to make the moral-conventional distinction, with signs of the ability appearing as early as 39 months (Smetana 1981, 1993; Smetana \& Braegges, 1993; Song et al., 1987).

Despite the fact that children as young as three years of age show no difficulty making this distinction, it was found that adult psychopaths with normal intelligence could not. Blair ran the M-C distinction task on both adult offenders and nonoffenders with high psychopathy scores and children with psychopathic traits. Blair claimed his studies showed that most psychopaths were unable to make the distinction (Blair, 1995). Blair took eight stories (four moral and four conventional stories) from the M-C literature. Although the stories have to do with situations that children are likely to have encountered, Blair chose not to modify them for the adults as he found that teachers in a school environment were seen as universally authoritative.

The four moral stories involved a child hitting another child, a child pulling the hair of another child and the victim crying, a child smashing a piano and a child breaking the swing in the playground. The four conventional stories involved a boy child wearing a skirt, two children talking in class, 
a child walking out of the classroom without permission and a child who stops paying attention to the lesson and turns his back on the teacher (Blair, 1995, pp. 14).

The participants were read the story and were then asked four questions. These questions had to do with 1) whether the action was wrong (or right) to do; 2) how wrong (or right) it was; 3) why they think it was wrong (or right); and 4) if they think it's wrong, would it be permissible if there was a rule in place which said it was alright to do it (Blair, 1995). Answers were coded according to whether the participant appealed to: harm to a victim, a rule, disruption caused, considerations of rudeness, whether the person thinks there is chance of repeating the offence, or another reason.

All participants were able to identify the transgressing of both moral and conventional rules as 'wrong'. Psychopaths, however, were not able to categorize moral wrongs as being more serious than conventional wrongs in the category of authoritative jurisdiction (AJ). ${ }^{7}$ Blair's findings showed that other offenders could make this distinction in all categories of the moral-conventional distinction. An interesting difference between the two groups was that psychopaths tended to use personal welfare violations as explanations of actions' 'wrongness' less than other offenders. Blair (1995) demonstrated that not only do psychopaths have moral reasoning abilities different from non-offenders, specific to their understanding of rule dependence in moral judgments and in welfare considerations, but also that they differ from other offending populations. Blair claimed that psychopaths were more swayed by authority figures changing the rules, than were non-psychopaths; this deviance was especially clear in

\footnotetext{
${ }^{7}$ Authoritative Jurisdiction applies to the questions where an authority changes the rule from what it was before, for example making a rule where it is permissible to hit other students.
} 
cases where the rule resulted in someone getting hurt.

Shaun Nichols described the phenomenon succinctly by referring to an interview with presumed psychopath Ted Bundy.

It was almost as if he $[\mathrm{I}]$ said it was wrong for all these things to happen. "It is wrong for me to jaywalk. It is wrong to rob a bank. It is wrong to break into other people's houses. It is wrong for me to drive without a driver's license. It is wrong not to pay your parking tickets. It is wrong not to vote in elections. It is wrong to intentionally embarrass people" Presumed psychopath Ted Bundy (Michaud \& Aynesworth 1989, pp. 116) (Nichols, 2002a, 287).

Bundy acknowledges that all of these acts were wrong. However, he does not make distinctions between the kinds of wrongs that are being perpetrated. Most people would find burglarizing someone's home to be a much greater wrong than jaywalking; however, it appears that Bundy applies the same catch-all concept of 'wrongness' to all of the infractions in the same way.

Blair's early results with M-C tasks seemed promising in that they appeared to provide a picture of the form of psychopaths' moral deficits; however, Blair later found that his initial claims about the inability of psychopaths to perform the task were overstated. He found that children with psychopathic traits do not perform any worse than other children on this task except in one respect and that is in the fourth condition (discussed above) where the rule is modified by an authority figure (Blair, 1997; Blair, Monson, \& Frederickson, 2001). The impairment of psychopaths in the area of M-C is more restricted than he had previously found in his earlier study. Blair had claimed that psychopaths had a blanket inability to make the moral-conventional 
distinction, could not make a genuine distinction between the two. In reality, their inability was only in the area of the authority rule-change condition.

In contrast to Blair $(1995,1997)$, Dolan and Fullam (2010) found that not only do adults and children with psychopathic traits seem able to perform as well as most non-psychopaths in most aspects of the M-C task, but also that psychopaths' main disability when it comes to moral reasoning may be an issue of lack of motivation rather than an inability to distinguish between right and wrong. ${ }^{8}$ Dolan and Fullam (2010) showed that an ability to make the M-C distinction is not enough to account for the morally deviant acts of which psychopaths are capable. They seem to be as proficient in almost all aspects of the M-C task and indeed Dolan and Fullam found no substantial differences between adolescent psychopaths and non-psychopaths on the task. This led them to conclude that likely more is needed to account for the moral deviance of psychopaths than just an inability to perform the M-C distinction. This is an interesting contrast to Ted Bundy's case, where Bundy seems unable to make the moral-conventional distinction. However, even if it is the case that Bundy fails to make a proper distinction, this does not diffuse Dolan and Fullam's point, which is that psychopaths as a whole do seem able to differentiate between right and wrong on the moral-conventional task. Bundy's misunderstanding could however, speak to a misunderstanding of social and precautionary rules. This is an area that requires further study.

\footnotetext{
${ }^{8}$ For example, in the modified rule condition there were no significant differences found between psychopathic and non-psychopathic groups for neither moral transgressions, nor conventional transgressions.
} 


\subsection{Further applications of moral reasoning and psychopaths}

In addition to Kant, Kohlberg, and Turiel, I want to consider a final account of the moral judgment of psychopaths. In chapter 2, I discuss the moral reasoning-backers. Reasoning-backers about psychopathy have been interested in psychopaths' disregard of moral reasoning and rules as their disregard for the rules challenges reasoningbackers' accounts (Maibom, 2008; Nichols, 2007; Shafer-Landau, 2007; Smith, 1994). According to the reasoning-backer, if someone knows the rules and can reason about the right thing to do, then their judgment motivates them to do it. However, psychopaths appear to be unmotivated by reasoning-based judgments. Smith (1994) explains that psychopathic moral deviance is not an issue for moral reasoning-backing because psychopaths lack 'deep' moral understanding. What is meant by 'deep' moral understanding will be explained shortly.

As shown in chapter 4, psychopaths have distinctive reasoning deficits. In some decision-making, such as in the trolley cases, this may allow them to arrive at morally sound judgment, which shows that their reasoning, while impaired in some areas, is at times sufficient for morality. ${ }^{9}$ However, more often their moral reasoning is overridden by other considerations which results in morally deviant judgments. For example, in a moral situation where utilitarianism is the preferred moral system for making a decision, then perhaps their reasoning would lead to a non-deviant judgment; however, without emotional responses to temper the judgment then these utilitarian judgments may seem too calculated to non-psychopaths and as a result very few non-psychopaths

\footnotetext{
${ }^{9}$ Indeed, the performance of people in the general population on trolley cases is evidence for the sufficiency of reasoning to certain kinds of moral decisions.
} 


\subsection{FURTHER APPLICATIONS OF MORAL REASONING AND}

would be willing to make this choice. ${ }^{10}$ This is evidenced by people's reactions to the footbridge cases, where most people will not push the large man onto the tracks. While the psychopaths are still making a moral judgment, it's clearly different from that which most non-psychopathic people make. The difference between the psychopath's and normal person's judgment on this speaks to there being something different occurring in the cognitive system of non-psychopaths. Namely, something emotional likely prevents most people from pushing people off even hypothetical footbridges.

Often the psychopath is offered as reason to reject the concept that morally right actions are self-motivating. Indeed, as will be later discussed, psychopaths appear to have fairly intact moral reasoning capacities on a range of measures, but despite this they are not motivated to do what normals do. The reasoning-backer explains that the psychopath does not have a genuine understanding of morality. If they truly understood their own reasoning, then they would follow-through on the judgments. Michael Smith (1994) explains that while psychopaths may be able to demonstrate moral reasoning, they lack a genuine or deep understanding of the moral rules. Genuine understanding is the kind of understanding a mature adult with normal development has. The DPMJ dual-process model introduced in Chapter7, demonstrates two ways in which Smith's argument fails to grasp psychopathic moral judgment. First, is that psychopaths genuinely understand most moral rules, including utilitarian reasoning. Second, even when they understand a moral rule, they can experience lapses in self-control that will result in a morally deviant action regardless of the judgment

\footnotetext{
${ }^{10}$ It is not necessarily that psychopaths' moral judgment in the case of footbridge cases is 'bad', this would be a normative claim that is a subject for another time. However, their judgment is indeed morally deviant and not representative of how the majority of people make decisions in these cases.
} 
that was formed. By claiming that psychopaths fail to understand morality, Smith runs the risk of misunderstanding the cognitive processes involved in moral judgment.

Reasoning-backers tend to see psychopaths as lacking genuine moral understanding which stems from a fundamental lack of reasoning capacities (Smith, 1994). Maibom (2012) has argued that psychopaths are noted for having poor future planning, lack of appropriate concern for self in future, and for displaying other reasoning deficits, which would suggest that a reasoning-backer interpretation may be appropriate. Her concerns are similar to those held by Kennett (2002) who argues that psychopaths would never be capable of having Kantian moral agency, due to inability to reason from moral rules and a tendency to make exceptions for themselves. Smith (1994) has argued that psychopaths' morally deviant tendencies can be explained by their not having genuine moral understanding. Smith views psychopathic choices as amoral. Essentially, psychopaths claim to know right from wrong, but there is a lack of understanding of what these concepts mean.

Despite the reasoning-backers' claims of a lack of genuine moral understanding, psychopaths have successfully demonstrated moral understanding on traditional moral reasoning tasks, such as those used by Kohlberg as well as the moral-conventional distinction (Blair, 2007; Nichols, 2007). Those, such as Smith, will argue that successful performance on these tasks is not enough to show 'deep' understanding, because their inability to follow through on their judgment shows a lack of motivation. However, I argue that Smith's position is unsatisfactory. The claim that psychopaths cannot understand because they are not motivated by reasoning, is an uninteresting, and perhaps unimportant, claim. It is shown every day that non-psychopathic people reason about 'what they should do' and yet remain unmotivated by this line of 


\subsection{FURTHER APPLICATIONS OF MORAL REASONING AND}

reasoning. This does not mean that they don't understand but only that they are unmotivated by their judgments. If Smith insists that 'deep' moral understanding requires that we be motivated by all of our moral reasons, then moral understanding truly only applies to a small number of people. If, however, he also wants to claim that psychopaths cannot use reasoning and fail in this respect, then this is not empirically supported.

The empirical data in chapter 4 and in this chapter, show that psychopaths can use moral reasoning in explanations of wrongness quite well. In fact, their performance on Kohlbergian moral reasoning tasks, which are dependent upon people being able to give reasons for wrongness is comparable to non-psychopaths (Lee \& Prentice, 1988; Trevathan \& Walker, 1988). The cognitive deficits that they have do not make them amoral, or in other words unable to invoke 'true moral understanding'. Smith (1994) is making similar claims to Kennett. She too was trying to claim that psychopaths, at least under a Kantian interpretation, are amoral. In response, I would direct you to my earlier comments on weakness of will in section 2.2 where I introduce the idea that weakness of will plays a role in moral judgment. Above and beyond whether psychopaths are able to reason well, they just often fail to be moral because of a weakness of will. The role of weakness of will in moral decision-making is more fully explored in chapter 7. Rather, the fact is that psychopaths do not care about moral reasoning because they are more focused on other things, such as rewards. Their cognitive deficits do not make them amoral, just bad at acting on their moral reasons. What is wrong in psychopaths is not amorality, but rather 'akrasia'.

Akrasia, as named by the Ancient Greeks, has long been understood as a problem for acting morally. In the Nicomachean Ethics, Book VII, Aristotle (350BCE/2000) 
explained that there were two types of akrasia - impetuosity and weakness of will. In both cases, people are able to reason to the right choice, but due to competing desires will not choose the right thing to do. Aristotle claimed that there are two main emotions that tend to override our rational choice - pleasure and anger. Namely, we are deflected from what we judge to be the moral choice by that which we perceive as pleasurable or by a flash of anger. This classically describes many of the behaviours of psychopaths. In section 4.2.1, I explained that psychopaths often act out in anger and, as the empirical evidence shows, they have a very hard time not focusing on rewards (Kalinian \& Wisniewski, 2005). What psychopaths have is a classic case of weakness of will. Aristotle explains that this is moral badness, not amorality. Smokers are a good example of weakness of will. Many smokers acknowledge that there are good reasons for them to quit, but when it comes to it they do not, because of the pleasure, addiction, or other reasons. However, we do not say that smokers cannot reason, but instead that they fail to act on those reasons. Indeed, the fact that people such as psychopaths are not motivated by reasoning alone is problematic for Smith's reasoning-based account.

\subsection{Caring in psychopaths}

Blair (2007) claims that caring-based morality is affected in psychopaths and that can be correlated with reduced activity in the amygdala and ventral medial prefrontal cortex. He argues that there is reason to believe that the emotional problems, which are linked to the amygdala among other areas of the brain and are present in psychopaths, can be linked to not caring as much about the harm that they cause others, resulting in an inability to care about caring and to reason about caring. To expand 
on this, Blair is making the case that due to amygdala dysfunction psychopaths have an inability to care about caring. Blair believes that psychopaths' deficient caring can explain differences that he found in the M-C distinction. As explained in section 5.4, Blair claimed that the only difference that psychopaths tend to make on the moral-conventional distinction task is in a very small part of the task known as the rule-change condition. When psychopaths are presented with a rule change that allows for one person to cause harm to another, they will now consider it morally permissible to cause that person harm. This is the only difference between the psychopaths and non-psychopaths on this task. Blair believes that the psychopaths' lack of consideration in this area is caused by errant caring-based reasoning (Blair, 2007).

The amygdala dysfunction and its effects on caring has interesting applications for the DPMJ model. First, this lack of caring-based morality can have top-down effects on the moral decision-making process, where from the beginning psychopaths will be less likely to have moral beliefs about and have preferences towards caring. Second, it implies that neurological dysfunction in the amygdala affects moral decision-making in both the development of key emotions (such as fear), as well as the development of caring-based moral considerations.

Blair's argument that psychopaths are deficient in caring is consistent with other studies previously discussed (Aharoni et al., 2011; Glenn et al., 2009) which claim that psychopaths are deficient in caring about harming others. Furthermore, it helps to explain the behavioural evidence which suggests that psychopaths engage in more instrumental violence than others (Blair, 2007; Glenn \& Raine, 2009; Woodworth \& Porter, 2002). Because they care less, causing harm to others does not deter them from doing so. 


\subsection{Personal/impersonal harm (trolley/footbridge cases)}

Similarly, Cima, Tonnaer, and Hauser (2010) have found that psychopaths are able to distinguish between the right and wrong acts, but fail to be motivated to do the right thing. They conducted a study where psychopathic delinquents, non-psychopathic delinquents, and a non-delinquent control group were asked to identify whether causing personal harm (typically associated with moral wrongs on the M-C distinction) was worse than causing impersonal harm. This distinction of personal and impersonal harm dilemmas was presented by Greene and colleagues (2001). It used Foot's (1978) trolley and footbridge cases. This experiment used the trolley/footbridge cases to show that people are more averse to doing things that involve personal harm. Green and colleagues showed that people are much more willing to save the people in the trolley cases where they do not have to personally harm another; whereas, in the footbridge cases they are reluctant to use personal harm to one even if it means saving five.

Both delinquents who had high psychopathy scores and non-psychopaths claimed that the personal harm is wrong. This seems to indicate that psychopaths are able to understand that moral wrongs are to, at least some degree, worse than conventional wrongs. This study shows that they understand that it is wrong to use harm, and that personal harm is worse, but in the real world they are more likely to use violent and instrumental crim $\epsilon^{11}$ to achieve their ends. I would suggest that this lends itself to providing explanation for the higher prevalence of instrumental crime in psychopathic

\footnotetext{
${ }^{11}$ Instrumental crime is purposeful activity aimed at achieving a particular goal through the use of illegal means.
} 
populations (Glenn \& Raine, 2009). As I provided evidence for in sections 5.3 and 5.4, the difference between the two groups seems to be more a failure to be motivated to do the right thing when faced with the knowledge that something is wrong, than a misunderstanding of what is and is not wrong. This overlaps with Nichols sentiments that Bundy seemed not only unable to distinguish between degrees of wrongness of moral and conventional wrongs, but that more than that he failed to be motivated to do the right thing even when he acknowledged that something was wrong.

The traditional paradigms appear to be unable to fully account for the moral deficits of psychopaths. For this reason, I turn to a new approach which has only recently been applied to psychopathy.

\subsection{Haidt's moral foundations}

Haidt's moral foundations have recently been used as a means by which to measure moral reasoning in psychopaths (Glenn et al., 2009). Glenn and colleagues used the Moral Foundations Questionnaire (MFQ; Graham, Nosek, Haidt, Iyer, et al., 2009) to assess the weight that people attach to each of the foundations when faced with a moral decision. They further determined the value that people place on the individual foundations using the Moral Foundations Sacredness Scale (Graham, Haidt, \& Nosek, 2009), which measures people's willingness to give up moral foundations for financial incentive. They used the Levenson Self-Report Psychopathy Scale (LSRP) (Levenson, Kiehl, \& Fitzpatrick, 1995) to measure psychopathic traits in a community sample. They found that the main failure of those with high psychopathy scores was to appreciate the importance of the principles of harm and fairness. Psychopathy was shown to have significant negative with both harm $(r=-.205)$ and fairness $(r=$ 
-.158). ${ }^{12}$ There were no significant differences on the other foundations.

These results have been replicated by Aharoni, Antonenko and Kiehl (2011) within a prison population. They found that similar to Glenn et al.'s (2009) community sample, criminals with high psychopathy scores also show little to no concern for fairness and harm. Despite that psychopaths did not appreciate harm and fairness principles, they showed a similar appreciation to that of non-psychopathic offenders for the other three principles.

This is an interesting addition to the discussion of moral reasoning and psychopathy for two reasons. The first is that it is complementary to and helps to provide an explanation of difficulties associated with the M-C distinction task; such as the fact that the task does not offer a clear distinction between psychopaths and nonpsychopaths. An important distinction between moral and conventional rules is that the transgression of moral rules is associated with harm caused to a particular person. It shows that the moral-conventional distinction does focus to some degree on the right affectation in psychopaths, namely a failure to care about harm. However, as morality in this task is also determined by other considerations such as an appreciation of seriousness and universality, psychopaths are likely able to provide an appropriate answer to which breaches of conduct are moral by appealing to these other considerations. Furthermore, if Glenn et al. (2009) were correct then even if a psychopath was able to make the distinction that breaking a particular rule would be considered wrong ${ }^{13}$, failure to appreciate the harm that one is causing leaves him unmotivated to care about doing the right thing. In my view, a psychopath could

\footnotetext{
${ }^{12}$ These correlation effect sizes may be small, but they are significant and as such are worth consideration and mention.

${ }^{13}$ As is found by psychopaths' performance on the M-C distinction in Dolan and Fullam's (2009) study
} 
understand that his act would be considered morally deviant, but because he does not care about or is unconcerned with causing harm to others, he can do the wrong thing regardless of his views about its moral wrongness.

\subsection{The failure of current accounts to explain psy- chopaths' moral judgments}

All of the accounts considered in this chapter fail to account for some of aspects of moral judgment of psychopaths. They focus too narrowly on either the role of emotion(s) or reasoning. They are also too narrow in their concept of what is meant by moral reasoning. In order to have a fully descriptive account of moral judgment, the account cannot narrowly focus on one type of reasoning, such as Kantianism or utilitarianism. All types of reasoning that have a role in moral judgment need to be accounted for. This includes more traditional reasoning-based accounts such as deontological, utilitarian, and care-ethics. As discussed in chapter 4, moral reasoning also likely involves social and precautionary rules.

The accounts of moral decision-making discussed so far in this chapter, excluding Haidt's, also fail to consider an adequately wide range of the factors that go into making moral decisions. Most are narrowly focused on harm or fairness considerations as they are tied to morality. As shown by Haidt (2012), there are many other sources of moral concern. People such as Kohlberg focused exclusively on rights, justice, and fairness, but Haidt's studies show the importance of including a broad range of moral considerations, including harm, fairness, purity, and others. These moral foundations have top-down effects on the way in which we make moral judgments. For example, 
people who are more justice-prone will tend to be more sensitive to these kinds of moral situations than those who lack this moral concern. Psychopaths are low in concern for harm and fairness (Aharoni et al., 2011; Glenn et al., 2009). With the DPMJ model, top-down processes such as Haidt's moral foundations are incorporated to capture this feature of moral judgment.

A further issue, that has come up in section 5.5 of this chapter, as well as in chapters 2 and 4, is the issue of weakness of will. All of the psychological accounts of moral judgment discussed through this chapter make no mention of self-control or weakness of will in making of moral decisions. In 5.5, this was shown to be especially problematic for reasoning-based accounts, such as Smith's (1994). In chapters 7 and 8, I examine further the role that self-control plays in moral judgment, especially how it helps differentiate between successful and unsuccessful psychopaths. I argue that a lack of self-control is one of the most important differences between the two groups.

Before presenting the DPMJ model, I first examine the other formal reasoningbased and emotion-based models from which it was developed. 


\section{Chapter 6}

\section{Models of moral decision-making}

Psychological box-and-arrow models of moral judgment have mainly taken one form and this is a reasoning-based decision-making approach which focuses on the types of reasons that people have to do the right thing. Rest (1986) created a popular model of moral-decision making that accounts for people's reasons, intentions, and actions but does not make room for the role of emotion in judgment. ${ }^{1}$ Rest was concerned with how people think when they are making judgments, not with how they feel. It has only been more recently that the role of emotion has been receiving attention. Even today, decision-making models dominate the field with those such as Gaudine and Thorne's (2001) and Thorne and Saunders' (2002) models, built upon Rest' original model, being central to the state-of-art.

Haidt (2001) introduced a social-intuitionist model of moral judgment where, in contrast to Rest's model, the judgments that are made are fast and intuitive. For example, an American's disgust reaction to seeing someone desecrate their flag is their

\footnotetext{
${ }^{1}$ Although I will at times use 'decision-making' model in this chapter, it should be understood as being interchangeable with moral judgment modelling. The use of this terminology is only to remain consistent with the researchers presented in this chapter.
} 
moral judgment that this is the wrong thing to do. The role of reasoning in Haidt's account in entirely post-hoc and does not play a role in generating judgments.

The role of emotion in moral judgment has also been investigated in dual-process models. In 6.3., I discussed how Greene et al. (2001) distinguish between two types of moral processes — deontological and utilitarian. They argue that the former are an intuitive, emotional process and that the latter is reasoning-based. For example, in the trolley cases when you decide to pull the switch, this is a reasoning-based decision. Your hesitancy to push the man onto the tracks in the footbridge; however, is an example of deontological judgment. While I argue that empirical evidence from psychopathy supports a dual-process model, the distinction presented by Greene and colleagues is inherently problematic. The types of judgments generated by their deontological examples arguably involve a form of reasoning.

Reynolds (2006) uses neurocognition to argue that information from the environment can result in both intuitive judgments with post-hoc reasoning and slower, deliberative reasoning-based mechanisms to produce moral judgments. Messervey, Nelson and Peach (in publication) build upon Reynolds' model by introducing situational factors, and place a special importance on the role of stress' effects on the decision-making process. Stress has been shown to have important effects on reasoning, making it difficult, if not impossible, to reason under stress. Messervey and colleagues' model is more robust than previous models. However, it overlooks several cognitive processes involved in judgment, such as imagination. For example, Amit and Greene (2012) showed that those with visual cognitive styles tend to make people fewer utilitarian judgments than those with verbal cognitive styles.

This chapter considers the state of psychological moral judgment modelling. It 
examines existent models and argues that they do not offer an account robust enough to accommodate the available empirical evidence on psychopathy. I offer a cognitive model that can account for the breadth of empirical moral judgment evidence and can explain the differences in moral judgment between abnormal populations such as psychopaths and people with autism. I explain the cognitive processes involved in my model and show how it accounts for existent data.

\subsection{Reasoning-based modeling}

I previously asserted that psychology was, because of Kohlberg, largely in favour of reasoning-based accounts of moral decision making. This bias was also present in the psychological modelling of moral decision-making Developing out of Kohlberg's (1976) work on moral development, Rest (1986), creator of the Defining Issues Test, also saw morality as reasoning-based. Rest developed a decision-making model comprised of four components (Jones, 1991). These components in order were:

1) Recognize the moral issue 2) Make a moral judgment (Based on reasoning based principles) 3) Resolve to place moral concerns ahead of other concerns 4) Act on the moral concerns

This model works well when dealing with straight forward moral issues. For example, if you witness someone stealing. You would recognize this as a moral issue. You would judge this person as bad according to whichever moral reasons you are using, for example a utilitarian or deontological framework. You would then resolve to place other concerns such as your fear of repercussion to the side and place your 
moral obligation to do the right thing at the front and then report the theft. In other words, stage 3 is forming your moral intent (see Figure 6.1).

This model was popularly used and although additions have been made over time, such as the addition of the influence of situational factors on moral decision making ${ }^{2}$ (Trevino, 1986). Models of moral judgment have similarly almost exclusively focused on reasoning-based decision making for the past thirty years. Figure 6.1 is a compilation of various adjustments to Rest's model and while Trevino and others added to the model's complexity by acknowledging that situational factors can have an influence on the process at both the onset and also at the stage of intent, many have used the four fundamental steps outlined by Rest (Jones, 1991).

\subsubsection{Criticism of Rest's model}

An important oversight of decision-making based models such as Rest's is it overlooks that much of moral judgment happens quickly. In other words, while Rest's model may help people to generate and act on their moral judgments, many of the judgments we do in fact make happen with no prior deliberation. Many of the moral decisions we make require very little deliberation and occur rapidly. They are not a slow, stepby-step process. A commitment to moral judgment being entirely reasoning-based precludes the possibility of fast moral judgment.

\footnotetext{
${ }^{2}$ Trevino (1986) viewed moral decision-making as being influenced by context. Namely, the situation that one is in has an effect on the types of decisions we make. The importance of context in decision-making has now been well established in psychology and moral psychology. For example, people are less likely to provide to someone in need when in the presence of others. The bystander effect has been shown to arise across a variety of contexts and group sizes (Darley \& Latané; Latané \& Nida, 1981).
} 
FIGURE 1

\section{Synthesis of Ethical Decision-Making Models}

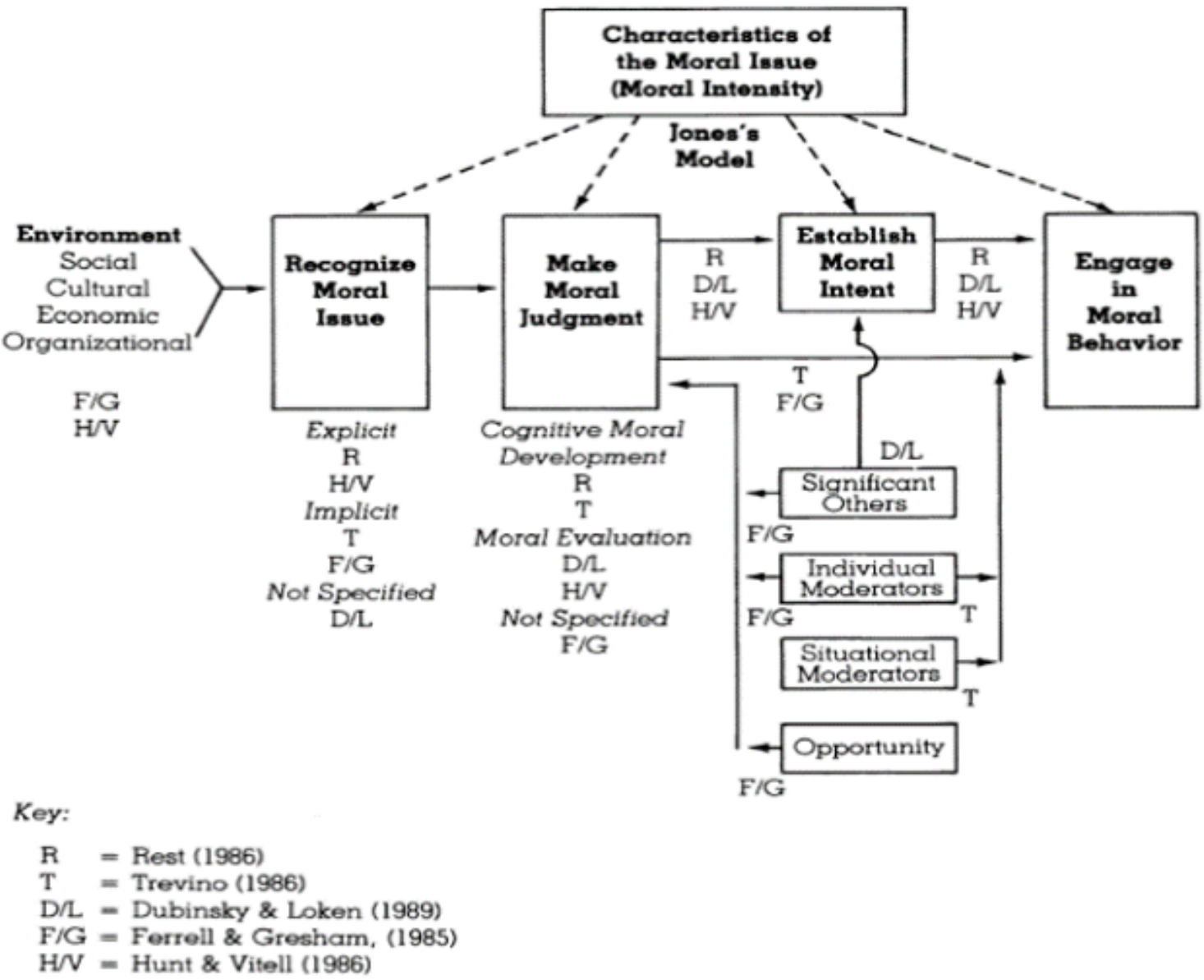

Figure 6.1: Jones' (1991) synthesis of ethical decision-making models which built on Rest's 


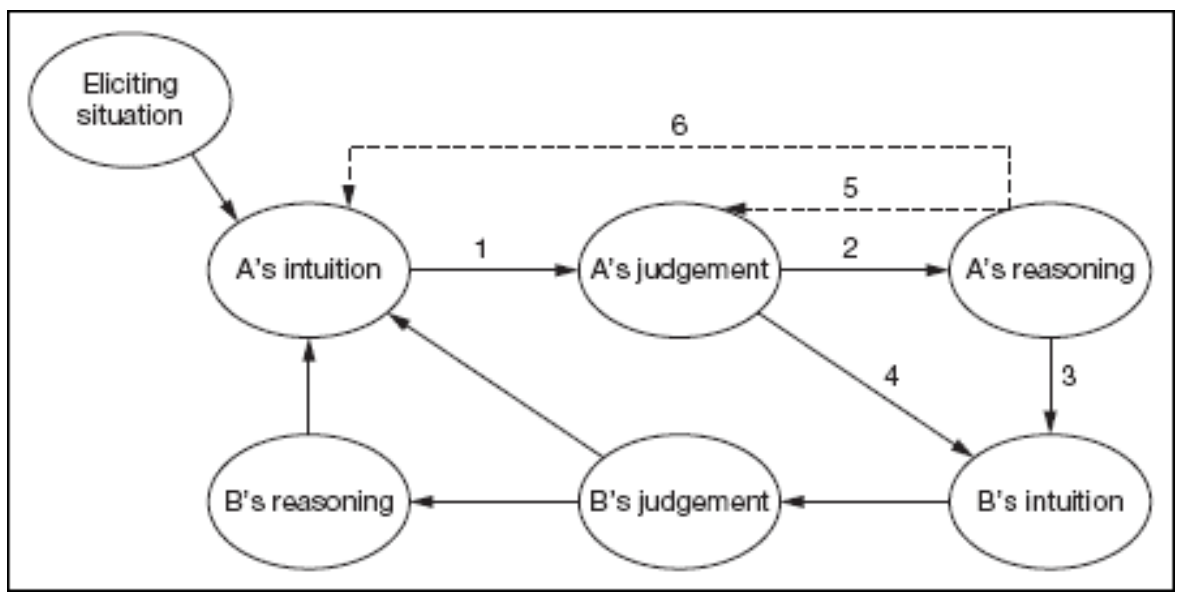

Figure 6.2: Haidt's (2001) Social Intuitionist Model of Moral Judgment

\subsection{Haidt's social intuitionist model}

As discussed in chapter 2, Haidt (2001) changed the discussion in moral psychology away from reasons and towards intuitions. Haidt took issue with the idea that morality is based on reasoning alone. He explained that reasoning is a slow, deliberative process; however, moral judgments occur rapidly and often without conscious deliberation. This distinction between slow reasoning and rapid moral judgments led to Haidt's (2001) development of his theory of social intuitionism. Most of our moral judgments are made based on emotional instincts. Humans have evolved intuitions that allow us to make moral judgments.

The role of moral reasoning is post hoc (see Figure 6.2). Once we have already made a snap judgment, we use moral reasoning to justify the decision we have already made. Reasoning also has a secondary function of influencing the intuitive judgments we make. However, Haidt explains that one's reasoning alone very rarely changes the initial judgment, but that people are more open to the reasoning of others. There are times when persuasive reasoning from others can change our intuitive judgment. 
Figure 2 (see above) is a model of Haidt's theory of moral judgment and it represents how moral judgments are formed between two people in conversation. We have a situation which elicits an intuition (such as the brother-sister incest story Haidt used in the moral dumbfounding study). Often this situation elicits an intuitive reaction, for example that the brother and sister did something wrong. This is followed by post-hoc reasoning to justify the answer that you have. The second person in the conversation hears both the judgment and post-hoc reasoning of the first person, both of these things can elicit an intuition in the other person which will generate a judgment and post-hoc reasoning which can generate a new intuition in the first person.

As previously discussed in Chapter 2, Haidt's best empirical support for the posthoc role of reasoning in moral judgment comes from his moral dumbfounding experiments where he presented subjects with various moral scenarios and found that most would have an emotional judgment of things and hold that judgment even after their reasoning fails to support it.

\subsubsection{Criticism of moral dumbfounding findings}

I am critical of Haidt's claim that the moral dumbfounding findings support a singleprocess model of moral judgment. Examination of his results indicates that depending on the scenario people sometime change their minds or in other words their original intuition can be changed by their post-hoc reasoning. 10-23\% of people changed their judgments when presented with counter-evidence to their original intuitions. For example, when prompted to consider various ways in which the incest case is not actually morally wrong; i.e. no one is getting hurt, there will not be an infant 
conceived, etc., people will sometimes change their minds and arrive at a new moral judgment. I argue that while Haidt is correct that some moral judgments (and perhaps most) are of the fast, intuitive variety, the moral dumbfounding experiment does not relegate reasoning to some kind of inner lawyer where it only defends the intuitive position we already hold (Haidt 2001; Haidt et al., 2000). While the reasoning that is being presented may come from an external source, it is the individual themselves who applies reasoning and deliberates about them to produce a new judgment.

\subsection{Dual-process models}

Dual-process models of moral judgment are a relatively new area of investigation across disciplines. As a result, there are few existent models that take this approach. While it has been gaining traction in psychology, neuroscience, and other more applied disciplines, very little to date has been done from a philosophical standpoint.

Dual-process models of moral decision-making claim that emotion/intuition and reasoning are both integral to human morality. ${ }^{3}$ Joshua Greene and his colleagues in the early 2000's were the first team to apply this framework.

\subsubsection{Trolley and footbridge cases}

Greene and colleagues used Foot's (1978) trolley/footbridge cases to examine how people make moral judgments. Greene et al. (2001) found that the large majority of people are willing to pull the switch in the trolley case. They argue that this is because

\footnotetext{
${ }^{3}$ This approach aligns moral decision-making much closer to current theories of decision making more broadly. Daniel Kahneman's (2013) work on decision-making has shown how both reason and emotion play separate and integral roles in decision-making. They can cause different judgments. They influence each other. They are both necessary for decision-making to work well.
} 
when choosing whether or not to pull the switch people do some kind of utilitarian calculus. In this study, people will often explain their actions in the following way: "It's better to save five people, and to let one person die, because five lives saved is better than one". This reflects a utilitarian type of reasoning where people are willing to make sacrifices for the greater good. Greene et al. were interested in explaining why it is that despite willingness to pull the switch in the trolley case, people will not act to save the five in the footbridge case where it is required that you physically push another person onto the tracks to save the five people's lives.

To explain this finding, Greene et al. (2001) invoke a dual-process model of moral judgment. They claim that people are more averse to doing things that involve personal harm and that footbridge cases involve an entirely different type of process than in the trolley case. They explain that when faced with footbridge cases, people invoke a deontological approach to morality. Greene and colleagues explain that deontological approaches are emotional and that the idea of personally harming another harming another person causes an emotional interference that impedes doing a utilitarian calculation. Greene and colleagues (2001) found that despite Kant's and Kohlberg's assertions that deontological judgments were reasoning-based, this was not the case. They base their claim that this is an emotional response on the fact that as indicated on fMRI scans, areas of the brain, such as the dorsolateral prefrontal cortex are highly activated when making deontological choices such as to hurt someone. 


\section{Criticism of Greene and colleagues}

Greene and colleagues' findings suggest that people treat trolley and footbridge cases differently. However, this does not appear sufficient to justify the claim that the utilitarian process is a reasoning-based process and that the deontological process is emotion-based. Greene and colleagues claimed that participants take longer to arrive at a deontological judgments and that this is because of emotions interfering in the utilitarian reasoning process. However, Haidt's (2012) research among other accounts of emotion's role in judgment (Kahneman, 2013), show that emotional judgments happen very quickly. That is to say that if all that was happening in the footbridge case was an emotional process then it should happen more quickly than the utilitarian process. Further, in a follow-up study, McGuire, Langdon, Coltheart, \& Mackenzie (2008) found that additional analyses of Greene and colleagues' data (2001) found no difference in reaction time data between footbridge and trolley cases. Further, there has been evidence to suggest, as far back as Kohlberg (1970), that in moral situations that are deontological in nature, there is a distinct use of reasoning. When people are presented with Heinze-type dilemmas they will appeal to reasoning to explain their answers. In all fairness, these could be post-hoc explanations to justify an emotionbased judgment; however, I think a more accurate portrayal of what is happening is that these kinds of judgments require dual-process type reasoning. Our emotional responses can be changed by reasoning and many people do appeal to reasoning in these dilemmas.

A more accurate description of the deontological process is that both deliberative and emotional reactions are occurring in tandem and that an emotional judgment trumps. This isn't necessarily a problem for Greene's account as it still supports a 
dual-process account. However, it challenges his definition of deontological. Further, it would be early to rule out that any reasoning happens in deontological judgments.

It could be argued that footbridge and trolley cases involve different reasoning processes. Greene's findings support can be seen as support for the idea that moral reasoning has several approaches including those of a utilitarian calculus or the deontological duty-based approach. The reasoning component of moral judgment involves more than one type of reasoning and that dependent on the type of situation one is dealing with, a different type of reasoning may be used.

\subsubsection{Reynolds (2006)}

Reynolds takes a neurocognitive approach to explaining moral decision-making. He explains that people take in information from the environment and pattern match it against similar situations that they've previously experienced. He claims that the mind has prototypes of a variety of ethical situations that it has previously encountered. For example, Reynolds explains that when a person encounters a situation where an employer offers a promotion in exchange for sexual favours, this falls under a prototype for workplace sexual harassment.

While prototype theory in itself could be applied to any of the models discussed (reasoning-based, emotion-based, and dual-process). Reynolds (2006) uses it as the foundation of a dual-process approach. From this prototype, two processes can be invoked, a reflexive process or a concession, deliberative processes (see Figure 6.3). Reynolds explains that the reflexive process is, similar to Haidt's, intuitive and quick. Also, much in the same way as Haidt $(2001,2012)$ views reasoning as post-hoc, so too does Reynolds. The concession involves the application of moral rules, followed 


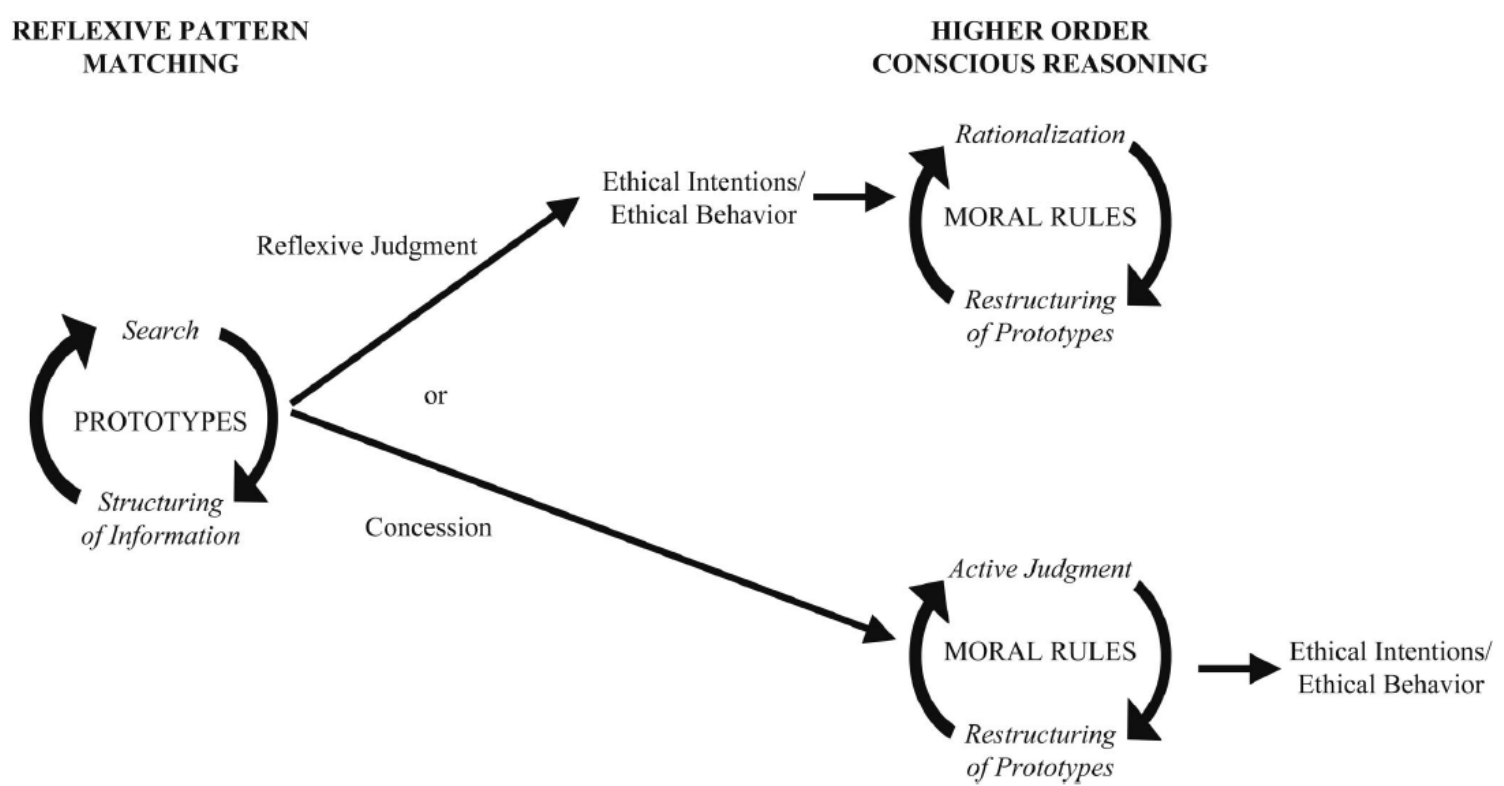

Figure 6.3: Reynolds (2006) dual-process model of ethical judgment

by the formation of an intention and production of a behaviour, much as in Rest's.

Reynolds' use of prototypes offers a cognitive explanation for how people identify situations as moral or ethical. Identification is automatic, unconscious practice that happens very quickly. Similar to Greene, he also integrates the two existent and competing models of ethical decision-making. His model is very similar to Greene's although it doesn't narrowly focus on deontological and utilitarian judgments.

Reynolds' approach also offers a good, if incomplete, explanation of unethical behaviour. He explains that a failure to be ethical can best be understood as a failure to find a prototype reflecting the ethical situation, a misapplication of the appropriate prototype, the application of misguided moral rules (such as moral egoism), or a misapplication of socially sanctioned rules. He presents the example of the Golden Rule and a masochist to show how a masochist's do onto others as you would have them do onto you, could quickly run into problems. A masochist would be okay with, 
or further to this would enjoy, having people cause pain or discomfort. If this is your perspective, then it could lead to problematic applications if you assume that others endorse your concept of permissibility.

\subsubsection{Messervey, Nelson, and Peach (manuscript in progress)}

Messervey and colleagues present a dual-process model equipped for the fact that depending on situation and context people can appeal to two different processes for moral judgment. Their model is similar to Reynolds' (2006) model of ethical decisionmaking and is further informed by other dual-process cognitive models (Evans \& Stanovich, 2013; Lieberman, 2007). All of these models see decision-making relying on two processes.

The first process is similar to Haidt's. It is intuitive, emotional, and fast. The second process is similar to Rest's in that it is reasoning-based, slow, and deliberative. Depending on the situation a person is in, the involved processes may change. The main contribution that is added to the dual-process model discussion by Messervey and colleagues is their focus on stress' influence on ethical judgment. They explain that in situations where you are under time constraints, uncertain, or stressed, reasoning-based processing is difficult if not impossible. In other words, when a person is stressed out, they are likely to rely on intuitive moral judgments. However, at other times where there are no time constraints and people are not under stress they are able to rely on reasoning-based processing. They can reflect on times when they have had to make similar decisions and judge whether a similar course of action would work well in this situation and result in the best moral action. They explain that when dealing with moral dilemmas, reasoning-based processing is engaged. 
Messervey (2013) has used this approach to argue in favour of ethical training being immersive or adopting an approach such as Hagman's (1980) 'train as we intend to fight' approach to ethics training in the military, which is her area of focus. If we know that reasoning-based processing is impaired by stress, then it is important to train in stressful conditions so that what is taught is more likely to be applied in similar situations. For example, by forcing soldiers to make real-time decisions in similar conditions to those which they would experience while in combat situations.

\subsection{Broader criticisms of dual-process models}

The discussed dual-process models have advanced the fields of philosophy, psychology, and neuroscience and have changed the way in which we think about morality. However, these accounts are under-developed in several ways: 1) They fail to offer a well-developed account of top-down mental states; 2) They do not show the ways in which self-interest limits moral decision-making; 3) They do not incorporate selfcontrol into their models; 4) They do not consider the impact of imagination; 5) They have a narrow or under developed concept of "moral deliberation". ${ }^{4}$

As explained in chapter 4, top-down mental states are cognitive processes, such as beliefs, that are based on past experiences, which bias the perception of new incoming information (Bernstein, 2013). They have important effects on cognitive processing generally and more particularly on moral decision-making. We can see one such example in Messervey and colleagues' (manuscript in progress) model which focuses on how stress can reduce the availability of deliberation and reasoning and force emotional decision-making. However, this is too limited a view of top-down effects.

\footnotetext{
${ }^{4}$ For example, Greene and colleagues (2001) narrowly focus on utilitarian rule use.
} 
For a model to accurately explain moral decision-making, it must include top-down emotion-states and existent moral foundations. These mental states have important effects on the rest of the model. For example, feelings of disgust make people more judgmental even before they enter into any kind of deliberative processing (Haidt, 2012).

Existent models also fail to incorporate self-interest into their models. In addition to the way in which self-interest can impede moral action, it can also affect decision-making earlier in the process where people have been shown to make different judgments when their own self-interest is involved. When presented with the following scenario of recuperating legal fees, there was a drastic difference in answer whether you were the one responsible for payment or not (Greene, 2013). 85\% of people think that if you win a legal case that the other person should be responsible for your legal costs, but when cast as the loser in the case only $44 \%$ of people think that they should be responsible for costs.

Another feature that has not been integrated into the existent frameworks is the role of self-control and weakness of will and how they affect intention and more interestingly in a top-down fashion emotional judgment. People can form the best intention but if it conflicts with their self-interest or they're particularly lazy, they are unlikely to do it. For example, many people recognize that voting is important and will say we have an ethical obligation to do so, but when it comes down to doing it, will not vote because it is slightly inconvenient. A lack of self-control has also been shown to be an underlying cause for people's failure to maintain dieting habits (Vohs \& Heatherton, 2000) and to control impulse spending (Vohs \& Faber, 2007). Lack of self-control also plays an interesting role in top-down processing. Depleted self-control 
has been shown to increase anger responses in respondents and conversely those with higher self-control are less likely to respond with anger (Denson, Capper, Oaten, Friese, \& Schofield, 2011). To this point, Finkel and colleagues (2009) administered a survey to participants which offered scenarios in which their significant other upset or provoked them and had participants their likelihood of reacting aggressively. They had participants perform self-control bolstering in both physical and verbal categories. The physical bolstering involved having participants work with their non-dominant hand and the verbal bolstering had participants avoid using slang and curse words. After two weeks, those who were in the bolstering categories were less likely to respond that they would be aggressive with their partner than were the control-group, for whom there was no change. They found that those these participants were less inclined to answer to get angry and punish their partner. ${ }^{5}$ In other words, less selfcontrol increases the probability of an anger reaction / judgment.

These models also do not acknowledge the role of imagination and the way in which it affects moral decision-making. Visual imagery has been shown to have an effect on the ways in which people use reasoning. For example, being asked to visualize a situation before making a judgment about it tends to make people less utilitarian in their rule-application. When tasked with visualizing trolley/footbridgetype scenarios, people become more deontological or less utilitarian in their decisionmaking. They tend to reject the concept that the ends justify the means compared to those who do not visualize the situation (Amit \& Greene, 2012).

\footnotetext{
${ }^{5}$ There was a significant difference decrease in aggresive responses of participants that had been in the physical bolstering condition and verbal bolstering group but not those who had been in the control group.
} 


\section{Chapter 7}

\section{The Dual-process moral judgment (DPMJ) model}

The emotional, reasoning, and other deficits of psychopaths can tell us what is important for morality more broadly. After extensive consideration of the impairments of psychopaths, I have created a dual-process model which includes all of the cognitive features associated with moral judgment in psychopaths and fit these components together to create a cognitive model of moral judgment for the general population. The Dual-Process Moral Judgment (DPMJ) model is a descriptive, empirically-informed model which draws on information from research in psychology, philosophy, and neuroscience to provide the most complete model of moral judgment to date. The DPMJ model also opens a whole new area of further investigation to quantify the model and the relationships among its components.

The DPMJ dual-process model of moral judgment builds on previous models such as those of Messervey and colleagues and Reynolds. It involves both the intuitive and deliberative processes, similar to those of Haidt and Rest. However, it adds 
to these models in important ways that results in a more comprehensive picture of moral judgment. It also incorporates the considerations raised by Greene and colleagues, where deliberative process has been expanded to include several forms of rule application including both utilitarian and deontological reasoning.

Important ways in which my model (see Figure 7.1) deviates from previous models are its introduction of: 1) A more sophisticated account of top-down mental states; 2) The role of imagination in generating experience different from sensory input alone; 3) The separation of cognitive and affective empathy; 4) A feedback process from emotion to reasoning and reasoning to emotion, as well as the possibility of moving from an emotional judgment to rule application without new input. 5) A more complete picture of the role of individual emotions that are important in generating emotion judgments than do other models; 6) An expanded role for reasoning; 7) Space for the role of self-control and its effects on judgment and intention; and for 8) Self-interest and the role it plays in judgment.

\subsection{Top-down mental states}

There are many ways in which top-down processing can affect decision-making. Longheld beliefs and desires, for example, will have an impact on the way in which we perceive incoming information as well as constrain our imaginative processing. Our phenomenological experiences are determined by the interaction of mental states with either sensory input or imagination.

The types of mental states that can influence moral judgment are broad. However, I want to focus on three ways in which mental states affect moral decision-making. 


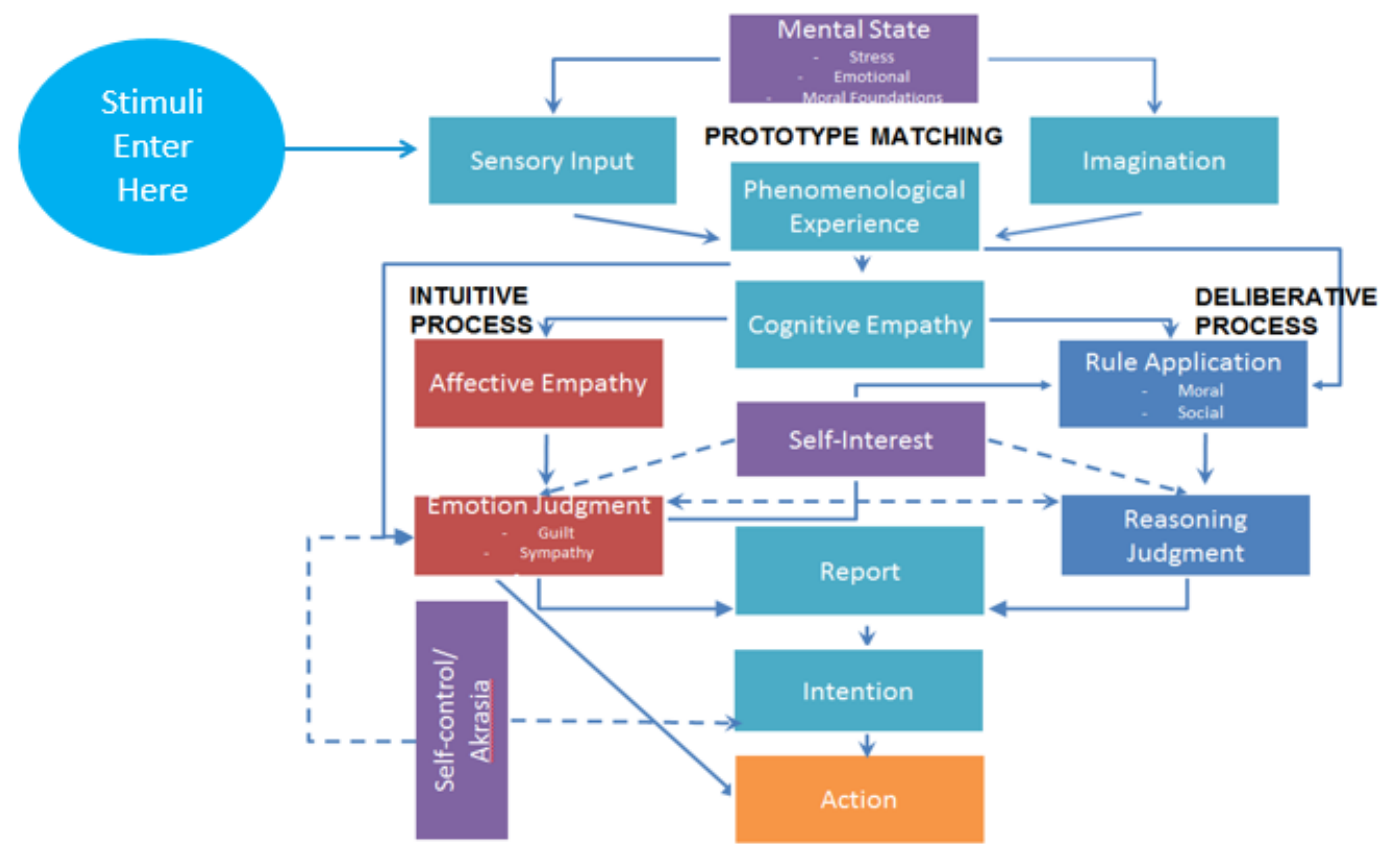

Figure 7.1: The DPMJ dual-process model of moral judgment

\subsubsection{Stress}

The first was introduced by Messervey and colleagues' (manuscript in progress) model and that is the role of stress. Being in a stressed mental state has consequences from the onset of decision-making. The major consequence of stress is that it makes it difficult to reason effectively. In other words, if someone is stressed, then a deliberative process will be unlikely to occur. ${ }^{1}$

A classic example which can be shown as highlighting stress' role is Darley and Batson's (1973) good Samaritan study. This study used participants from Princeton University's Seminary School. Participants were asked to give a lecture on the Good

\footnotetext{
${ }^{1}$ The exact relationship between stress and the decrease of reasoning-based decision-making has not yet been quantified by Messervey and colleagues (manuscript in progress); however, they provide examples to help support the statement, such as that of a soldier in Abu Ghraib who 'goes nuts' and is unable to reason and ends up torturing a detainee.
} 
Samaritan. Some of the participants were told that were running on time for the lecture, others that they were, and lastly that some had time to spare. On the way to the lecture they run into a person in need of help. The people who were running late were significantly less likely to help than those who were not (40\% vs. 63\%). Darley and Batson claimed that the $63 \%$ of people who helped did so partly because they were under less stress than their counterparts. Darley and Batson concluded that being placed in a situation where there are time constraints can reduce the likelihood of people being helpful. Presumably, these people know that helping others is a moral obligation (in fact they are on their way to give a lecture to that effect). Yet, despite this they do not provide help.

Messervey (2013) explains that a deliberative process requires working memory and when under stress working memory is not available to do the conscious processing required for moral rule application. The seminarians in this study knew the rules, but were in a situation that made those rules difficult to apply. However, intuitive processes should have remained intact. It could be that the pressing obligation of their lecture made them likely to place their self-interest above any kind of emotion judgment that they had.

\subsubsection{Emotional}

The next type of mental state is emotions. Research has highlighted the important role that disgust plays in moral judgment (Haidt, 2012; Pizarro et al., 2011). Haidt $(2012,2001)$ argues that disgust reactions, such as that which is felt when faced with the previously-discussed incest case or the idea of your neighbour eating his dead dog are in themselves moral judgments of the wrongness of the acts. Pizarro takes this 
a step further in his research. He and his colleagues argue that even the presence of disgust is enough for someone to frame the situation they are later presented with as being moral. In other words, disgust can trigger a moral mindset.

Disgust offers a clear way in which our emotional state can affect the moral judgment process from its onset. Other emotions may prove similarly prejudicial, but this section confines itself to disgust. However, I acknowledge that other emotions, such as anger, could take its place. Disgust demonstrates how an emotion can lead directly to an affective moral judgment without requiring any further cognitive process, including empathy. Often the feeling of being disgusted is all that is required for a judgment that the thing causing the disgust is wrong. This can be seen, for example, in Haidt's moral dumbfounding example of incest where people have disgust reactions and maintain that the act of incest is wrong even when all of their reasons for saying so fail (Haidt, 2001; Haidt et al., 2000). Avramova and Inbar (2013) explain that these kinds of findings support the idea that emotional distress will lead to an automatic affective judgment. In other words, when a person has a distressing emotional state, they are more likely to make a snap moral judgment than when they experience emotions which are not distressing.

A second way to from emotion moral judgment is through empathy. This will be further elaborated in a later section.

\subsubsection{Moral foundations}

The last mental state discussed within this chapter is that of moral beliefs, more specifically moral beliefs tied to Haidt's moral foundations. Moral foundations develop differently across cultures and even across individuals. As a result, moral views differ 
based on your moral development and people can have widely different moralities. For example, Haidt (2012) offers empirical support for American liberals dominantly favouring harm and fairness moral foundations in comparison to conservatives who develop across all six foundations. These foundations will directly impact moral beliefs and will impact the moral decision-making process. For example, a liberal is less inclined to view something such as using the flag to clean a toilet as morally wrong than someone who has a more highly developed loyalty foundation. This means that right from the beginning the types of moral prototypes a liberal has would differ from that of those with wider moral foundations, such as a conservative.

\subsection{Imagination}

Imagination should not be thought of as having a fixed content. Its content can change based on situational and environmental factors. Drawing on Eysenck, imagination is meant to apply strictly to visual imagination or in other words the mind's visual representation of the world without external input (Eysenck, 2012). This is the component of imagination that has been shown to have an impact on moral decisionmaking by Amit and Greene (2012).

Amit and Greene (2012) ran a study which examined the role of visual imagination in moral judgments. They found that those with more visual cognitive styles compared to those with verbal styles were significantly more likely to make emotional judgments. They tended to prefer the rights of the individual over that of the collective or the greater good. Further, impairing visualization ability by overloading visual capacity made all participants less emotional in their judgments.

Amit and Greene's findings lend support to the introduction of the role of imag- 
ination in the DPMJ model. People with a greater capacity for visual imagery are going to be more likely to favour deontological over utilitarian concerns than those who do not. Including this as part of the model makes the DPMJ more explanatorily complete than models that do not account for imagination's effect on moral judgment.

\subsection{Empathy}

As was discussed in chapter 3, empathy has long been linked to morality, dating as far back as Hume. More recently, some theorists, Slote (2007) for example, have argued that morality is founded on empathy. While I hold that empathy is neither sufficient nor necessary for moral judgment, the ability to empathize with another person can change the ways in which people reason and make emotion judgments. As such, it is important that it be included as part of a moral judgment model.

My model uses the characterization of empathy from chapter 4, where empathy is explained as being two distinct cognitive processes. These are cognitive and affective empathy. ${ }^{2}$

\subsubsection{Cognitive empathy}

Cognitive empathy includes the perspective taking necessary to identify the emotional state of another person and the imagination required to put oneself in the other person's shoes. In other words, it allows a person to imagine how she would feel if she were in circumstances similar to that other person. Batson et al. (1997) has shown that participants who take on others' perspectives were more considerate of

\footnotetext{
${ }^{2}$ While there are possibilities of further subdividing empathy, this would unnecessarily over complicate my model at this point.
} 
stigmatized groups such as homeless people. For example, subjects who were made to feel empathy for a homeless man depicted in a story were more likely to feel favourably towards him than were those who were not. ${ }^{3}$ The subjects became less judgmental about the homeless person's situation and more likely to think he deserved help.

Cognitive empathy involves distinguishing between one's own mental perspective and the other's and maintaining the two as separated. While it is possible to distinguish this monitoring as a third type of empathy process, as Lamm and colleagues do (2007), doing so does not add to the descriptive power of the model and as such, the distinction is not included as something separate from cognitive empathy.

\subsubsection{Affective empathy}

Affective empathy can be understood as vicariously experiencing the emotion that another is in. It is a state of emotion matching the other person's. As discussed in chapters 2 and 4, affective empathy is believed to be very important for non-deviant morality, altruistic behaviour and 'good' personal relationships as it has been shown to increase the likelihood of helpful behaviours (Baumeister et al., 1994; Mullins-Nelson et al., 2006; Slote, 2007).

\subsubsection{Final thoughts on empathy}

Cognitive empathy may increase the likelihood of helpful behaviour but is not sufficient on its own to generate ethical behaviour. However, it does appear to have the ability to change the way in which we reason when we have a better understanding of

\footnotetext{
${ }^{3}$ The mean scores were higher for those who were led to empathize ( $M=6.75$ on a scale 1-9 scale) than did those who were asked to remain objective $(M=5.94)$ (Batson et al., 1997).
} 
what the other person is going through. For example, being able to see the homeless person's perspective can make us see that person in a more favourable light. However, cognitive empathy without affective empathy may result in increases of unethical behaviour. Let's take for example psychopaths who are noted for their manipulative behaviours and are known to exploit the information that they have on others (Hare, 2003). Perspective taking without appropriate emotional response may result in a higher occurrence of unethical behaviour.

\subsection{Emotional Judgment}

The following is a list of the moral emotions that are included in my model as emotion judgments: Disgust, guilt, fear for others, anger, and happiness. This is not a complete list, but instead represents emotions which have been shown empirically to affect moral behaviour. This list supports the idea that models of moral judgment need to incorporate specific emotions.

In 7.1.2, I presented in detail how disgust is a judgment in and of itself. Guilt will also be used as a further example.

In chapter 2, I examined philosophers such as Gibbard (1990) and Greenspan (1995) that asserted that guilt is necessary for 'good' moral judgment and action. Psychological evidence has corroborated these claims in finding that guilt contributes to amending behaviours in the face of wrongdoing, empathic responding to other people in need, and the promotion of stable relationships (Keltner \& Harker, 1998; Tangney, 1995; Baumeister, Still, \& Heatherton 1994, 1995).

From the perspective of the DPMJ model, guilt offers us an interesting possibility for how we go from having an emotional judgment of wrongness to application of 
moral rules. Developmentally, children are taught that feeling guilty means that they have done something wrong. This could lead to application of rules to arrive at the appropriate reparative actions.

Taking into consideration once again the unethical behaviour of psychopaths, it is important to note that a lack of guilt is part of the diagnosis of psychopathy (Hare, 2003). In chapter 4, empirical evidence was presented for psychopaths' lack of feeling of guilt (Jones et al., 2010; Mullins-Nelson et al., 2006). Psychopaths' lack of feeling of guilt is part of the explanation of their judgment. They also lack the anticipation of feeling guilt. This means that they do not have the top-down association that normal people would have to deter them from acting immorally in the first place.

\subsection{Rule application}

I have discussed how applications of rules occur in both Kantian deontology and utilitarian reasoning. However, it is important to note again that psychopaths are adept at utilitarian reasoning (Koenigs, Kruepke, \& Zeier, 2012). This is problematic for accounts of moral decision-making, such as Greene's, which narrowly focuses its concept of deliberative moral reasoning on utilitarian reasoning.

Again, by looking at psychopaths' deficiencies it is clear that psychopaths' moral reasoning capacities are as good as non-psychopathic populations across a variety of moral reasoning tasks including Kohlberg's moral reasoning tasks (Lee \& Prentice, 1988; Trevathan \& Walker, 1988), Rest's Defining Issues Test (Heinze, Allen, McGai, \& Ritzler, 2010; O'Kane, Fawcett, \& Blackburn, 1996), the Moral/Conventional Distinction (Dolan \& Fullam, 2010), and the personal/impersonal harm distinction (Cima, Tonnaer, \& Hauser, 2010). If psychopath's reasoning abilities were intact, 
then a dual-process model would have to be able to explain the ways in which they fail to be motivated by their reasoning-based processing.

This led to the inclusion and expansion of the deliberative processes to include social and precautionary rule application (Ermer \& Kiel, 2010). Ermer and Kiehl's (2010) research highlights the importance of social and precautionary rule understanding and application to moral judgment.

By expanding the scope of rule application to include precautionary and social rules, I am better able to explain how psychopaths' reasoning abilities differ from non-psychopaths and shows how they generate moral judgments that deviate from normal individuals.

I am also better able to differentiate between psychopathic and autistic morality. In chapter 4, I explain that a shared 'deficit' of empathy but different moral behaviour made autistics and psychopaths of interest to researchers. By its inclusion of social and precautionary rules, the DPMJ model can offer a fuller description of how the two differ than was previously available. When making moral decisions, people with autism do not use emotional cues (Brewer et al., 2015). They are solely reliant on deliberative, reasoning-based approaches. They rely on utilitarian and deontological approaches, but there is another possible approach as well. One of the most effective strategies for teaching children with autism is the use of social scripts. These scripts include everything from everyday tasks such as proper hygiene and setting the dinner table to more complex, such as how interact with someone in distress. Kelly and Maibom (2012) argued that autistic morality is founded on these social scripts. It could be argued that they have a fairly good understanding of the types of situations described in the scenarios outlined by Ermer and Kiehl (2012) and this may offer 
insight into how, despite having emotional deficits (Blair, 2005) that impair emotion processing, they are able to make 'good' ethical judgments and act accordingly.

Expanding 'moral' reasoning to include social and precautionary rules is as of yet underdeveloped and requires further empirical exploration and validation (Ermer \& Kiehl, 2010). However, using these rules, I have offered insight into the ways psychopaths fail to reason morally as we do and I have established cognitive differences between them and people with autism. Psychopaths' failure to use and understand these rules put them at a disadvantage when it comes to the generation of moral judgments because they tend to make choices which are deviant to those of the general population, resulting in solitary lifestyles. On the other hand, people with autism can use these rules and it allows them to generate 'good' moral judgments accordingly.

\subsection{Self-control/Akrasia}

The final cognitive component in my model was also made by appealing to psychopathy. As asserted earlier, a person can enter a situation with depleted self-control; however, self-control can also fail at some point in the process. The former has an effect on the type of moral judgment that will be formed and the latter will affect whether we follow-through on the judgment. A place where it seems to fail in psychopaths is at the level of acting on intention.

As was established earlier, psychopaths can avail themselves of utilitarian reasoning, but even with this mechanism in place and even when they judge that something is wrong, they often seem unable to act accordingly (Cima et al., 2010). This is a failure of self-control.

Lack of self-control is part of the psychological construct for psychopathy (Hare, 
2003). Additionally, their inability to refrain from morally deviant action makes it difficult for them to weigh other factors when a reward is present. This has been examined with both psychological and neurological tools. As was shown in chapter 4, psychopaths under-perform on the Wisconsin Card Sorting Task, for further information see section 4.1.2.

People with impulsivity issues may fail to act ethically because of a failure of selfcontrol, even after producing the right moral judgment. In addition to psychopaths, non-psychopaths with low self-control have been shown to be more aggressive and are more likely to be angry than people with higher self-control (Denson et al., 2011). Further, people with low self-control can fail to act morally after making the appropriate judgment. For example, dieters who know they should eat healthily and judge that eating healthily is the right thing to do will also fail to act on their intentions (Vohs \& Heatherton, 1999).

The inclusion of and focus on self-control as an integral part of acting on moral judgment highlights a further weakness in both the emotion-backers and reasoningbackers accounts. As discussed in chapter 2, Smith (1994) tries to explain that psychopaths lack 'deep' moral understanding because they are unmotivated by reasons. It may be the case that it is not a lack of understanding, but instead a weakness of will or self-control that is lacking in their cognitive processes and the resultant behaviour.

\subsection{Self-interest}

Psychopaths are known to act for their own benefit. As many people tend to do, but because of emotional and reasoning deficits psychopaths are willing to different means 
to attain their own self-interest. Even when they show evidence of moral foundations, they are willing to act against them for financial incentives (Glenn et al., 2009). Glenn and Raine (2009) explain that psychopaths use instrumental violence more than other populations as a means for getting what they want. They are calculating and do whatever it takes to get what they want (Babiak \& Hare, 2006). This extends to their reasoning, where they tend to prioritize their own needs and wants over others, as is captured by the narcissistic criteria of the PCL-R (Hare, 2003).

In the Ultimatum Game two people are expected to split an amount of money. One person offers a split and the other gets to choose to accept it or refuse it. If the second person accepts the divide, then the two people share the amounts as specified. If the offer is rejected, then neither gets anything. Primary ${ }^{4}$ psychopaths are better than secondary psychopaths at rejecting low-ball offers (Koenigs, Kruepke, \& Newman, 2010). A possible explanation is that they would rather take nothing than be unfairly taken advantage of. Their performance on the Dictator Game is perhaps more telling of the role that their self-interest plays in their moral judgment.

The Dictator Game is meant to measure prosocial tendencies. People are allowed to make whatever offer they want and the other person has to accept it. Primary psychopaths were found to give significantly lower offers than both secondary psychopaths and non-psychopaths (Koenigs et al., 2010). Koenigs and colleagues (2010) claim that part of what causes more generous offers in the Dictator Game are prosocial emotions such as guilt and sympathy. As this is a central impairment for primary psychopaths, it makes sense that they would be ruthless in a game where the outcome

\footnotetext{
${ }^{4}$ Primary and secondary psychopathy are definitional equivalents to factor 1 and factor 2 psychopathy. See chapter 3.2.1 for further information on the distinction.. The different terminology is only used here to remain consistent with the authors I am discussing here.
} 
is largely determined by one's capacity to show compassion for the other player.

Psychopaths are not alone in their tendency to put their own self-interest over the interests of others. Non-psychopaths have also been shown to have their judgment affected by self-interest. As discussed in section 6.4 (pp.116), people are more willing to have burdens placed on others than they are on themselves, such as the attribution of court costs (Greene, 2013). This inconsistency in judgment is explained by the role that self-interest plays in affecting judgment

\subsection{Running a trolley case through the DPMJ model}

In order to best highlight how the DPMJ model works, I will walk you through an example of a moral decision. Please refer back to figure 7.1, to follow the steps that making a moral decision take. to Iwill use a variant of the trolley dilemma to explain what happens within each cognitive function.

First, you are presented with the following choice: Choose between saving five people and one person, by pulling a switch to divert the train from the five to the one, but the one person is your child. Even before you make the decision, there will be top-down moral beliefs that will affect your decision. For example, if you are higher on the loyalty foundation you will be more likely to show preferences to family members. Additionally, the fact of having to make such a choice at all would be likely to cause a stress reaction which will impair your ability to reason through the scenario.

Next, there will be differences if you are asked to imagine or simulate the scenario. In imagining the dilemma, you will be more likely to have an emotional judgment to the scenario. This emotional judgment will favour your child. 
The phenomenological experience you have can lead to your trying to take on the perspectives of the people.

If this in turn causes you to share their emotional state (fear for life for example), then your affective empathy may lead to an emotional judgment of fearfully choosing to save your child. This could lead to a report that that leads to an intention, that generates the action of not pulling the switch.

If, however, when you take on the perspective of the others, this leads you to consider that there are more people with a multitude of perspectives who will be harmed. Then you may make the utilitarian choice of saving the five. Self-interest could interfere at this point, causing you to prioritize, for example, the happiness of your own child.

However, once you generate a report that the course of action is to save the 5, you may then fail at the level of intention caused by a lack of self-control. The idea of not saving your child could be too much. If you have high self-control, then the resultant action would be that you choose to divert the tracks to your child.

\subsection{Further applications of the DPMJ model of moral judgment}

The DPMJ model is equipped to deal with both trolley and footbridge cases. Here is one possible description that can be generated by the model: Those with higher visual cognitive styles may be more likely to prefer emotional solutions generally. This model allows for either application of utilitarian or deontological rules to the situation resulting in different judgments. It can explain the different responses that 
people have to the trolley and footbridge cases better than Greene and colleagues' (2001) model. This is because it doesn't rule out the role that reasoning plays in deontological judgments.

Given the different reactions that people have to Kohlberg's (1973) moral dilemmas, leaving a broad category for rule application helps to describe the differences between psychopaths and non-psychopaths. Even in adulthood many people continue to use a variety of different moral considerations including care, fairness, and other considerations when making decisions. Broader categories allow for this moral flexibility. Additionally, as mentioned in 7.1.3, including moral foundations as part of top-down mental states, including the foundations will also help in describing how people reason. For example, someone who is high on the fairness consideration may lean more towards not stealing.

Another moral psychological finding for which the DPMJ model makes room is the dime effect. Isen and Levin (1973) ran a study where they found that getting an extra dime out of a payphone increased the likelihood of the person who received the dime helping another by 22 times. $^{5}$ In other words, a positive emotional state produced by good fortune will result in more desirable ethical behaviour. Top-down emotional processing can have immediate effects on the types of moral judgments that one can make, regardless of whether the judgments are reasoning-based or emotion-based.

Finally, as described in chapter 2, in the case of moral dumbfounding, people do change their mind 10-23\% of the time, depending on the situation that they are considering. In other words, when confronted with something like brother-sister incest, they may make an emotional judgment against it, but when forced to reason

\footnotetext{
${ }^{5}$ Subjects were given the extra dime and then presented with a person in need, having dropped their books.
} 
about it will arrive at a different conclusion. My model accommodates these findings well as it allows for going from an emotion-based judgment to rule application which in turn results in a reasoning-based judgment.

\subsection{Conclusions from the DPMJ model}

By investigating the deficits of psychopaths, I developed the DPMJ model which broadly applies to the general population. The DPMJ model offers the most complete available description of moral judgment and assembles all of the pieces that go into making for moral judgments. It builds on past research in ethical decision-making to produce a model which describes and organizes the empirical evidence available from moral psychology and ethics research. Its use of empirical evidence from psychopaths' cognitive deficits results in a more robust concept of emotion judgment, rule application, and the placement of self-control in both psychopaths and non-psychopaths alike than previous ethical models. It allows for a better understanding of autistic moral judgment than do accounts that focus on empathy alone and clearly differentiates autistic moral judgment from psychopathic moral judgment. My mode; provides the means for better description of ethical and unethical judgment and behaviour. Indeed, it augments past research in eight explicit ways: 1) It considers the way in which top-down mental states affect the rest of the decision-making system; 2) It incorporates imagination, allowing for the way in which visual imagery strengthens emotional judgments; 3) It introduces cognitive and affective empathy and clearly distinguishes between the two; 4) It offers a better description of emotion-based and reasoning-based judgment and how the two can affect one another. 5) It makes room for a full-blown account of specific moral emotions and the role that they play in 
moral judgment; 6) It expands moral reasoning to include social/precautionary rules, deontological rule considerations, etc.; 7) It makes room for the way that low selfcontrol affects acting on intentions; 8) It makes room for the role of self-interest and how this can have top-down effects on reasoning and emotion-based judgments. 


\section{Chapter 8}

\section{Accommodating successful}

\section{psychopaths under the DPMJ \\ Model of Moral Decision-Making}

\subsection{The successful psychopath}

In this chapter, I consider the successful psychopath ${ }^{1}$ for two reasons. First, none of the accounts offered by others that I discussed in this thesis can account for successful psychopaths. As the DSM-5 diagnoses psychopathy under ASPD, it neglects those who do not present with criminal behaviour. With ASPD's focus on behavioural issues, it leaves out successful psychopaths. By instead focusing on the cognitive processes involved in psychopathy, the DPMJ model can do what these other accounts fail to do. It can offer clear suggestions about the ways in which successful and

\footnotetext{
${ }^{1}$ I want to re-iterate that 'successful' in this case only refers to their ability to do well within their chosen profession and to avoid criminality. I acknowledge that many so-called successful psychopaths, as will be discussed in this chapter, are morally deviant in both their personal and professional lives.
} 
unsuccessful psychopaths differ from a cognitive perspective. ${ }^{2}$

The second reason for addressing the successful psychopath in relation to the model is that it is an interesting application of the model to an unusual kind of moral judgment. For example, successful psychopaths can make deviant moral judgments without acting illegally and this model can explain why this is the case.

Hare describes the psychopath in the following way: "Psychopaths are social predators who charm, manipulate and ruthlessly plow their way through life...completely lacking in feelings for others, they selfishly take what they want and do as they please, violating social norms and expectations without the slightest sense of guilt or regret" (Hare, 2003, xi). This combination of traits often results in criminal behaviour. However, while it is true that psychopaths make up a large proportion of the prison population, between $1-2 \%$ of the general population meets the diagnostic criteria for psychopathy (Hare, 2003).

Those who meet the diagnostic criteria for psychopathy but maintain successful or at least legal lifestyles are known as successful psychopaths. "Successful psychopaths are, in theory, individuals who fit the criteria of a psychopath, having certain fundamental traits (e.g., callousness), but largely succeed in their exploitation" (MullinsSweatt, Glover, Derefinko, Miller, \& Widiger, 2010). In other words, they use people to get ahead but don't often use criminal means to do so. The main features which distinguish a successful psychopath is their ability to abstain from criminal behaviour

\footnotetext{
${ }^{2}$ There may be some question as to whether or not successful psychopaths can meet the diagnostic criteria for psychopath, for example scoring above 30 on the PCL-R; however, many of the studies I discuss including Glenn and colleagues' (2009) research shows that people in the general population can score high psychopathy scores. I recognize that without the criminal behaviours it makes getting higher scores more difficult, but this, as discussed in Chapter 3, only points to further reason to view psychopathy as a scalar disorder. It is helpful to understand how people score on the test, be it low, medium, or high, and the kinds of characteristics they demonstrate.
} 
and that they succeed in their professional domain (Lykken, 1995).

Psychopaths can be found in a variety of fields. Thus, it has become important to compile a profile of successful psychopaths. Mullins-Sweatt and colleagues (2010) sent out requests to professionals asking for them to return accounts of having worked with psychopaths in their fields. They sent requests to people in three professions: attorneys, psychologists, and professors. From the returned responses, they were able to compile narrative descriptions of the successful psychopath in the three professions. It was found that across the three professions, successful psychopaths were described as dishonest, exploitative, low in remorse, minimizing of self-blame, arrogant, and shallow.

This stable of traits is a clear distinction between the successful and the unsuccessful psychopath, where the unsuccessful are more noted for their criminal irresponsibility, impulsivity and negligence. These traits align with the low scores in conscientiousness that they have on three facets of the NEO PI - R. ${ }^{3}$ Unsuccessful psychopaths tend to have lower scores in the facets of dutifulness, self-discipline and deliberation (Lynam \& Widiger, 2007).

While certain psychopathic traits are disadvantageous, such as low conscientiousness, other traits, such as low affect and remorse, do not impede psychopaths but are instead advantageous (Lykken, 1995; Patrick, 2006). Further, previously discussed, psychopaths, including successful psychopaths, are noted for their low fearlessness or low anticipatory anxiety. ${ }^{4}$ Fearlessness has been linked to achieving success in life (Lilienfeld \& Fowler, 2006).

Further evidence to the usefulness of the fearlessness trait is that it has also been

\footnotetext{
${ }^{3}$ As measured by the NEO Personality Inventory — Revised (Costa \& McRae, 1992)

${ }^{4}$ As measured by the Psychopathic Personality Inventory (PPI) (Lilienfeld \& Fowler, 2006).
} 
linked to heroism (Smith, Lilienfeld, Coffey, \& Dabbs, 2013). In examining nonincarcerated subjects, Smith and colleagues (2013) found that acting altruistically or heroically towards strangers was correlated with primary $(r=.27)$, but not secondary psychopathy. They explain that fearless dominance, which is characterized by low anxiety, is captured by the primary aspects of psychopathy and they believe that one of the contributing factors to heroism is low levels of anxiety and fear which allows people to do what is required in high stress situations.

Hare and Babiak (2007) explain that successful psychopaths have also been found to do very well in business. To this end, they claim that psychopaths hold approximately $4 \%$ of CEO positions. Lack of fear, empathy, and guilt, traits that without high conscientiousness likely contribute to criminality, can also make for good business practice (Ronson, 2011). In an interview with Jeff Bercovici, Jon Ronson, a journalist who spent a year undercover studying psychopaths in business, offered the following description of Al Dunlap, a former CEO of Sunbeam, in an interview for Forbes magazine:

There was his reputation that he was a man who seemed to enjoy firing people, not to mention the stories from his first marriage telling his first wife he wanted to know what human flesh tastes like, not going to his parents' funerals. Then you realize that because of this dysfunctional capitalistic society we live in, those things were positives. He was hailed and given high-powered jobs, and the more ruthlessly his administration behaved, the more his share price shot up (Bercovici, 2011).

Dunlap's coldness and emotional deficits were not seen as problematic in his business. In fact, they allowed Dunlap to be highly efficient and effective at the massive layoffs 
that he affected.

Babiak and Hare (2007) discuss other traits that contribute to the success of the successful psychopath. Their grandiose sense of self, their charisma, and their ability to read people are all very important for doing well in a variety of fields including business, law, and politics. They are also not above using instrumental bullying to get ahead.

To further build the concept of the successful psychopath and who he is, it is important to consider that there is also evidence to suggest that psychopaths represent a higher percentage than average in the army and similar high-risk professions (Kelly, Messervey, \& Nelson, in press). The link between the emotional capacities of psychopaths, including their fearlessness and the choice of military-type professions, is an area that needs further study.

\subsection{The DPMJ model and the successful psychopath}

An examination of the successful psychopath suggests four ways in which the underling cognitive features of their moral decision-making system contribute to their success.

The first process is their cognitive empathy. As Babiak and Hare (2006) note, being able to read people can easily contribute to being able to manipulate them, understand their weaknesses, and use this to one's advantage. While this doesn't necessarily lead to a moral course of action, it can and does lead to success in many professional areas.

The second process is at the level of the emotional. Successful psychopaths lack of fear makes them well-suited to high-risk military positions. A possible explanation is 
that their fearlessness could make them well-suited to this type of profession. Similar to the military, a higher than average number of psychopaths are present in other high-risk professions such as the police force (Dutton, 2012). ${ }^{5}$

A third way in which the successful psychopath fits well with the description of moral judgment in the DPMJ model is that the model incorporates self-control. It explains that those with high self-control, such as the successful psychopath (Lynam \& Widiger, 2007; Mullins-Sweatt et al., 2010), are better at making moral judgments than those with low self-control. In trying to explain why it is that they remain unincarcerated, one needs to refer back to the self-control/akrasia box of the model. This is the last cognitive control that we have over moral action. At the very end, it determines whether we act or refrain from action both in the case of good and bad action. According to Mullins-Sweatt and colleagues (2010), the successful psychopath has better inhibition of action than does the regular psychopath. Even if they were to arrive at a bad choice, they have the ability to refrain from action in the case of dangerous moral judgment because they have more self-control.

Finally, while there has been very little empirical work done investigating the specific moral deficits of successful psychopaths, there is no evidence to suggest that they are different from other psychopaths when it comes to their ability to use utilitarian reasoning to arrive at judgments. They would have the capacity to follow through on these judgments because of their higher self-control. While the use of utilitarian reasoning unchecked by emotional processes can lead to an unemotional moral response which deviates from generally accepted standards, there are times when this is the necessary course of action. For example, for politicians who need to

\footnotetext{
${ }^{5}$ Exact numbers were not provided.
} 
make decisions regarding who and when to send people to war when it means that some will die requires some utilitarian calculations. It is potentially the case that those with only utilitarian reasoning to use for these purposes may be well-suited to making these kinds of decisions, as they are less likely to allow emotions to impede their decision-making process.

To summarize, while the DPMJ model can explain cognitive differences between the successful and unsuccessful psychopath and explain why it is that the former are more successful, it does not conclude that the successful psychopath are necessarily more morally successful. They are better at not doing illegal things because they have higher self-control and different top-down motivations, but many of the ways in which they move ahead professionally are of dubious morality. They are manipulative, cold, hurtful, and will leave a metaphorical trail of bodies behind them to get to where they want to be (Babiak \& Hare, 2007). Their moral lapses may not be as severe as those of the unsuccessful psychopath, but it is a difference in degree. It would not be accurate to conclude that one is moral and the other is not. Both make bad moral decisions in general, just one is more inhibited about it and stays on the right side of the law. 


\section{Chapter 9}

\section{Conclusion}

This thesis aimed to produce a description of moral judgment that improves on existing accounts. It argued that the existing accounts of moral judgments do not provide a complete description of psychopathic moral judgment or that of the general population.

In chapter 2, I drew on research in philosophy and psychology to produce a comprehensive review of the debate between emotion-backers and reasoning-backers of moral judgment. In so doing, it became clear that there are issues for both accounts. Psychologist emotion-backers, such as Haidt, overlook the important role that reasoning can play in changing our initial judgments, leading to entirely new judgments, reasoning-based judgments. And, none of the philosophical accounts offer a full account of moral emotions; instead, they were narrowly focused on at most one or two emotions. On the other side, the reasoning-backers overlooked the large role that emotion plays in initial moral judgment. Finally, my approach tried to show that both sides are descriptively weak when it comes to psychopaths' moral judgment.

In chapter 3, I provided an overview of psychopathy which considered the role 
that emotion and reasoning play in its construct. I identified conceptual issues with the diagnostics used to measure psychopathy. I especially focused on the difficulty of tools such as the PCL-R to differentiate between factor 1 and factor 2 psychopathy because of the construct's focus on behaviour.

In chapter 4, I build on the theory that moral judgment is both reasoning and emotion-based. To do this, I explored which specific emotions are important to morality and which features of morality need to be incorporated. To this end, I considered psychopaths' emotional and reasoning deficits. This investigation revealed that affective empathy, sympathy, guilt, fear, and sadness all contribute to moral decisionmaking. Lack of moral emotions not only decreased the likelihood of doing good for others, but emotions such as sadness were shown to be uniquely used by psychopaths to identify victims which offers insight into the interesting role that sadness plays in moral judgment.

In chapter 5 , I investigated the various approaches that have been used to explore psychopathic moral decision-making. None of these accounts provides a complete description of psychopaths' moral judgment.

Chapter 6 offers a review of the existing models of moral judgment and assessed where there is room for elaboration and improvement.

In chapter 7, I introduced the Dual-Process Moral Judgement (DPMJ) model which was developed to address the weakness of the moral accounts described earlier. I have built a box-and-arrow model of moral judgment which more fully describes the morality and decision-making in both psychopaths and the general population. I have drawn on thirty years of empirical literature to create a model that makes room for the fact that psychopaths are successful in most moral judgment tasks but 
despite this are often still morally deviant. The model offers a full description of the underlying cognitive processes involved in moral judgment, incorporating both emotion and reasoning-based judgments and introducing a self-control/weakness of will component.

This model offers the most complete descriptive model of moral judgment to date. It bridges the divide between emotion-backers and reasoning-backers by showing that both emotion and reasoning are needed. It incorporates all of the cognitive features identified as important in my investigation of psychopathic cognitive deficits. It is a model which not only describes psychopathic moral judgment, but also offers a comprehensive description of moral judgment more broadly in non-psychopaths, where various moral psychological findings can be explored.

Chapter 8, shows how the DPMJ model by focusing on cognitive processes rather than behaviour, provides a method for differentiating between successful and unsuccessful psychopaths which is an area of difficulty for psychopathy diagnostics and all past philosophical accounts.

In addition to the theoretical contributions this research provides, it also has several practical implications across a variety of disciplines, including psychology, law, psychiatry, medicine, teaching, ethical training, and other disciplines. I will describe five practical issues, previously mentioned within my thesis, that highlight the model's broader applications.

First, I have shown that psychopaths perform comparably to non-psychopaths on the majority of moral judgment questionnaires. This is because these tools tend to focus on the use of moral reasoning (in its narrower sense, not including social and precautionary rules). As I have discussed throughout, evidence from psychopathy 
points to the dual-process nature of moral decision-making. Tools used to measure it need to incorporate both emotional and reasoning-based considerations. While some of the tools may have accidentally measured both, tools such as Kohlberg's, Turiel's, and others are not prepared for the task. The development of these tools is necessary to have psychological data which fully represents moral judgment.

Second, the DPMJ model has direct implications and applications for the development of ethics training programs. As was mentioned in section 6.3.3, dual-process models necessitate adding emotional aspects to ethical models focused on reasoning. Real-life experiences often result in emotional reactions. Until training incorporates both emotion and reasoning, people will be unprepared for the making moral judgments in real-time conditions.

Third, I showed how there are issues with relying on the diagnosis of ASPD in identifying potential psychopaths. In order to best diagnose psychopathy, one should rely on cognitive diagnosis focusing on their constitutive deficits. Using a cognitive model, such as the DPMJ model. allows for better diagnosis of psychopathy.

Fourth, I believe that a better understanding of the ways in which psychopaths' moral deviance is linked to their cognitive deficits will contribute to the possibility of better treatment options. Such treatments need to address the various cognitive issues that affect psychopaths, including their emotional and reasoning deficits, as well as self-control issues.

Fifth, the use of social scripts with children with autism has proven successful. The use of social scripts with children who are identified as demonstrating psychopathic traits may benefit these children.

The next logical step for future research using the DMPJ model would be to begin 
empirical validation of the relationships between cognitive processes in the DPMJ model. Quantifying these relationships will allow for the model to have predictive power to be able to predict moral decisions under varying internal conditions. Such studies would be diverse, including investigating the performance of non-psychopaths using dual-process moral judgment tools. It would also be important to do studies which investigate the extent to which specific emotions impact moral judgment. These studies would promote a better understanding of the dual-process nature of moral judgment in non-psychopathic populations.

Comparatively, my model can also be used to better understand psychopaths. To further understand the difference in moral judgment between successful and criminal psychopaths on a cognitive level, a study could be run investigating their differences in self-control and identifying which top-down processes are specifically used by successful psychopaths.

In conclusion, my thesis research provides a novel theoretical contribution which also has broad, real-world applications. It also offers a rich area of future research possibilities. 
Appendices 
Appendix A

Additional information on empathy studies and moral judgment studies 
Table 1: Additional information on empathy studies

Psychopathy and Empathy Measurement Studies

\begin{tabular}{|c|c|c|c|c|}
\hline Author(s) & $\begin{array}{l}\text { Psychopathy } \\
\text { measurement }\end{array}$ & $\begin{array}{l}\text { Empathy } \\
\text { measurement }\end{array}$ & Population & Results \\
\hline $\begin{array}{l}\text { Zagon, \& } \\
\text { Jackson, } 1994\end{array}$ & $\begin{array}{l}\text { Self-report } \\
\text { psychopathy } \\
\text { scale- II } \\
\text { (SRP-II) }^{\mathrm{i}}\end{array}$ & $\begin{array}{l}\text { Interpersonal } \\
\text { Reactivity Index } \\
(\text { IRI) } \\
\text { Four factor empathy } \\
\text { measurement: } \\
\text { perspective taking, } \\
\text { fantasy, empathic } \\
\text { concern, personal } \\
\text { distress, }\end{array}$ & $\begin{array}{l}1^{\text {st }} \text { year psychology students }(n= \\
149)\end{array}$ & $\begin{array}{l}\text { Negative correlation between both SRP-II } \\
\text { factor } 1 \text { and factor } 2 \text { scores and IRI scores. } \\
\text { Females tended to report more personal } \\
\text { distress when faced with the emotions of } \\
\text { others. This is believed to be related to why } \\
\text { females tend to be less socially deviant than } \\
\text { males. }\end{array}$ \\
\hline Blair et al., 1997 & PCL-R ${ }^{\text {iii }}$ & $\begin{array}{l}\text { Using neutral }(\mathrm{n}=8) \\
\text { and threatening } \\
\text { images }(\mathrm{n}=5) \text { and } \\
\text { distressed faces }(\mathrm{n}= \\
5) \text { to assess whether } \\
\text { higher scores on PSD } \\
\text { mean less reaction to } \\
\text { distress in others. } \\
\text { Skin conductance } \\
\text { responses (SCR) were } \\
\text { also measured. }\end{array}$ & $\begin{array}{l}\text { Psychopathic inmates }(n=18) \\
\text { Non-psychopathic inmates }(n= \\
18)\end{array}$ & $\begin{array}{l}\text { Psychopathic inmates showed more SCR } \\
\text { when viewing threatening images than } \\
\text { distressed faces; however, more SCR was } \\
\text { measured for distressed stimuli than for } \\
\text { neutral. } \\
\text { Non-psychopathic inmates did not react } \\
\text { more to threatening images. } \\
\text { Psychopathic inmates showed less reaction } \\
\text { to distressed faces than non-psychopathic } \\
\text { inmates. }\end{array}$ \\
\hline Blair, 1999 & $\begin{array}{l}\text { Psychopathy } \\
\text { Screening } \\
\text { Device } \\
\left(\text { PSD) }{ }^{\text {iv }}\right.\end{array}$ & $\begin{array}{l}\text { (Same measurements } \\
\text { as used in Blair, } \\
1997)\end{array}$ & $\begin{array}{l}\text { Children with behavioural } \\
\text { problems: } \\
\text { High psychopathy scores }(n=16) \\
\text { Low psychopathy scores }(n=16) \\
\text { Community sample of children: } \\
\text { Low psychopathy scores }(n=16)\end{array}$ & $\begin{array}{l}\text { Children with higher PSD scores showed } \\
\text { less SCR than those with lower scores. } \\
\text { Children with higher PSD scores react less } \\
\text { to distress stimuli. }\end{array}$ \\
\hline
\end{tabular}




\begin{tabular}{|c|c|c|c|c|}
\hline & & & & $\begin{array}{l}\text { No differences were found between groups } \\
\text { for threatening images. }\end{array}$ \\
\hline $\begin{array}{l}\text { Book, \& } \\
\text { Quinsey, } 2004\end{array}$ & $\begin{array}{l}\text { PCL-R } \\
\text { Child and } \\
\text { Adolescent } \\
\text { Taxon Scale } \\
\text { (CAT-SR) }^{\mathrm{vi}} \\
\text { was used to } \\
\text { measure } \\
\text { psychopathy } \\
\text { in non- } \\
\text { offending } \\
\text { populations }\end{array}$ & IRI $^{\mathrm{vii}}$ & $\begin{array}{l}\text { Psychopathic inmates }(n=37) \\
\text { Non-psychopathic inmates }(n= \\
40) \\
\text { Community sample }(n=42) \\
\text { Undergraduate students }(n=38)\end{array}$ & $\begin{array}{l}\text { Psychopaths did not score lower on } \\
\text { empathy scale compared to non- } \\
\text { psychopaths. }\end{array}$ \\
\hline $\begin{array}{l}\text { Mullins et al., } \\
2006\end{array}$ & $\begin{array}{l}\text { Psychopathic } \\
\text { Personal } \\
\text { Inventory } \\
\text { Short-Form } \\
\text { (PPI-SF) } \\
\text { This was } \\
\text { further } \\
\text { divided into } \\
\text { two factors } \\
\text { PPI-SF-I and } \\
\text { PPI-SF-II viii }\end{array}$ & $\begin{array}{l}\mathrm{IRI}^{\mathrm{ix}} \\
\text { Cognitive and } \\
\text { affective empathy }\end{array}$ & Undergraduate students $(n=174)$ & $\begin{array}{l}\text { High scores on the PPI-SF-II were } \\
\text { negatively correlated with both cognitive } \\
\text { and affective empathy. } \\
\text { PPI-SF-I showed no significant correlations } \\
\text { between empathy and psychopathy scores. }\end{array}$ \\
\hline $\begin{array}{l}\text { Dolan, \& } \\
\text { Rennie, } 2007\end{array}$ & $\begin{array}{l}\text { Youth } \\
\text { Psychopathic } \\
\text { Trait } \\
\text { Inventory } \\
(\text { YPI) }\end{array}$ & $\begin{array}{l}\text { Impulsivity- } \\
\text { Venturesomeness- } \\
\text { Empathy Inventory } \\
\text { (IVE) } \\
\text { Yes/no questionnaire }\end{array}$ & $\begin{array}{l}\text { Adolescent conduct disordered } \\
\text { (CD) males }(n=115)\end{array}$ & $\begin{array}{l}\text { Significant negative correlation between } \\
\text { the IVE's empathy score and the YPI's } \\
\text { affective subscale. }\end{array}$ \\
\hline $\begin{array}{l}\text { Flight, \& Forth, } \\
2007\end{array}$ & $\begin{array}{l}\text { Psychopathy } \\
\text { Checklist- }\end{array}$ & IRI $^{\text {xiii }}$ & Adolescent male inmates $(n=51)$ & $\begin{array}{l}\text { Total and factor scores were negatively } \\
\text { correlated with IRI. }\end{array}$ \\
\hline
\end{tabular}


Youth
Version
$($ PCL-YV)

Sterzer et al.,

2007

Mahmut et al.,
2008

Statistics

Manual-IV

$(\mathrm{DSM}-\mathrm{IV})^{\mathrm{xiv}}$

and

International

of Disease

$(\mathrm{ICD}-10)^{\mathrm{xv}}$ )

Self-Report

Psychopathy

$\begin{array}{lll}\text { DSL-SSV } & \text { IVE }^{\mathrm{xvi}} & \text { Male adolescents with CD }(n= \\ \text { A } & & 12)\end{array}$

combination

of Diagnostic

Classification

scale (SRP-

III $)^{\text {xviii }}$
Controls $(n=12)$

Support for the theory that psychopaths' lack empathy was found in the language used by participants to describe their crimes. Those with high PCL-YV scores tended to use language which suggested a lack of remorse and affect. Conduct disordered adolescents have significantly lower empathy scores compared to controls.

Reduced gray matter volume in the right dorsal anterior insular cortex (associated with empathy) ${ }^{\mathrm{xvii}}$ in adolescents with CD.

\begin{tabular}{|c|c|c|}
\hline $\begin{array}{l}\text { Emotional Empathy } \\
\text { Question }(E E Q)^{\mathrm{xix}}\end{array}$ & Undergraduate students $(n=101)$ & $\begin{array}{l}\text { Negative correlation between SRP-III and } \\
\text { EEQ }(r=-0.27) \text {. }\end{array}$ \\
\hline $\begin{array}{l}\text { Self-report } \\
\text { questionnaire focused } \\
\text { on affective empathy }\end{array}$ & $\begin{array}{l}\text { High psychopathy scorers ( } n=31 \text {, } \\
23 \text { female, } 8 \text { male) } \\
\text { Low psychopathy scorers }(n=31 \text {, } \\
23 \text { female, } 8 \text { male) }\end{array}$ & $\begin{array}{l}\text { Males had significantly lower emotional } \\
\text { empathy scores than females. }\end{array}$ \\
\hline $\begin{array}{l}\text { Trait Emotional } \\
\text { Intelligence } \\
\text { Questionnaire- Short } \\
\text { Form (TEIQ-SF) } \\
\text { Self-report } \\
\text { questionnaire }\end{array}$ & Undergraduate students $(n=84)$ & $\begin{array}{l}\text { Trait emotional intelligence and neutral } \\
\text { images were negatively correlated with } \\
\text { secondary psychopathy scores }\end{array}$ \\
\hline
\end{tabular}




\begin{tabular}{|c|c|c|c|c|}
\hline & & $\begin{array}{l}\text { Empathy image task } \\
\text { (happiness } \mathrm{n}=15 \text {, } \\
\text { sadness } \mathrm{n}=15 \text {, } \\
\text { neutral } \mathrm{n}=15 \text { ) using } \\
\text { the Self Assessment } \\
\text { Manikin (SAM) } \\
\text { allow to } \\
\text { report their emotional } \\
\text { valence and arousal. }\end{array}$ & & \\
\hline $\begin{array}{l}\text { Dadds et al., } \\
2009\end{array}$ & $\begin{array}{l}\text { A maternal } \\
\text { report which } \\
\text { relies on the } \\
\text { Antisocial } \\
\text { Process } \\
\text { Screening } \\
\text { Device } \\
\text { (APSD) } \\
\text { and the } \\
\text { Strength and } \\
\text { Difficulties } \\
\text { Questionnaire } \\
\text { (SDQ) } \\
\text { Thiii } \\
\text { The APSD- } \\
\text { SDQ }\end{array}$ & $\begin{array}{l}\text { Griffith Empathy } \\
\text { Measure (GEM) } \\
\text { Parental report } \\
9 \text { point Likert scale } \\
\text { (From strongly } \\
\text { disagree -4, to } \\
\text { strongly agree 4) } \\
\text { which measures } \\
\text { cognitive and } \\
\text { affective empathy }\end{array}$ & $\begin{array}{l}\text { Community sample }(n=2760) \\
\text { (Ages 3-13) }\end{array}$ & $\begin{array}{l}\text { High psychopathic trait scores and GEM } \\
\text { scores and negatively related for both } \\
\text { cognitive and affective empathy in males. } \\
\text { They found a negative correlation for } \\
\text { cognitive empathy in females, but not for } \\
\text { affective empathy. } \\
\text { The cognitive empathy deficits diminish in } \\
\text { adolescence. }\end{array}$ \\
\hline $\begin{array}{l}\text { Ali, \& } \\
\text { Chamorro- } \\
\text { Premuzic, } 2010\end{array}$ & LSRP & $\begin{array}{l}\text { Empathy Quotient } \\
(\mathrm{EQ})^{\mathrm{xxv}} \\
\text { Self-report } \\
\text { questionnaire to test } \\
\text { for global empathy }\end{array}$ & $\begin{array}{l}\text { Undergraduate students }(n=112) \\
\text { High psychopathy scores }(n=19)\end{array}$ & $\begin{array}{l}\text { Psychopathy was positively correlated with } \\
\text { global empathy deficits. }\end{array}$ \\
\hline
\end{tabular}


Table 2: Additional information on moral judgment studies

Psychopathy and Moral Judgment Studies

\begin{tabular}{|c|c|c|c|c|}
\hline Author(s) & Psychopathy Measure & $\begin{array}{l}\text { Moral } \\
\text { Reasoning } \\
\text { Measure }\end{array}$ & Population & Findings \\
\hline $\begin{array}{l}\text { Jurkovic \& } \\
\text { Prentice, } \\
1977\end{array}$ & Quay’s Typology ${ }^{x x v i}$ & $\begin{array}{l}\text { Kohlberg's } \\
\text { Moral Dilemmas }\end{array}$ & $\begin{array}{l}\text { Delinquent males (prison } \\
\text { population) } \\
\text { Psychopathic }(n=12) \\
\text { Neurotic }(n=12) \\
\text { Subcultural Delinquents }(n=12) \\
\text { Control Group }(n=36)\end{array}$ & $\begin{array}{l}\text { Psychopathic group were more } \\
\text { immature in comparison to other } \\
\text { groups. }\end{array}$ \\
\hline $\begin{array}{l}\text { Lee \& } \\
\text { Prentice, } \\
1988\end{array}$ & Personal Opinion Study ${ }^{\mathrm{xxvii}}$ & $\begin{array}{l}\text { Kohlberg Moral } \\
\text { Judgment } \\
\text { Interview } \\
\text { Scoring } \\
\text { Manual }^{\text {xxviii }}\end{array}$ & $\begin{array}{l}\text { Delinquent males (prison } \\
\text { population) } \\
\text { Psychopathic }(n=12) \\
\text { Neurotic }(n=12) \\
\text { Subcultural Delinquents }(n=12) \\
18 \text { Controls }(n=18)\end{array}$ & $\begin{array}{l}\text { No significant differences between } \\
\text { groups on moral reasoning tasks. } \\
\text { Inconsistent results with Jurkovic } \\
\text { and Prentice (1977). }\end{array}$ \\
\hline $\begin{array}{l}\text { Trevathan \& } \\
\text { Walker, } \\
1989\end{array}$ & $\begin{array}{l}\text { Psychopathy Checklist Revised } \\
\text { (PCL-R) }\end{array}$ & $\begin{array}{l}\text { Kohlberg Moral } \\
\text { Judgment } \\
\text { Interview }\end{array}$ & 44 Youths & $\begin{array}{l}\text { Psychopathy was not predictive of } \\
\text { poor moral reasoning abilities. }\end{array}$ \\
\hline Blair, 1995 & Psychopathy Checklist (PCL) ${ }^{\mathrm{xxix}}$ & $\begin{array}{l}\text { M-C } \\
8 \text { Stories } \\
\text { involving } \\
\text { children } \\
\text { violating (4 } \\
\text { moral-4 } \\
\text { conventional) } \\
\text { Stories focused } \\
\text { on wrongs } \\
\text { children can do } \\
\text { like slapping } \\
\text { another child, or }\end{array}$ & $\begin{array}{l}20 \text { Violent Adult Criminals } \\
\text { Psychopaths }(n=10) \\
\text { Non-Psychopaths }(n=10)\end{array}$ & $\begin{array}{l}\text { Psychopaths had difficulty with the } \\
\text { modified rules (those having to do } \\
\text { with authority jurisdiction) in } \\
\text { comparison to non-psychopaths. } \\
\text { They also were more likely to see } \\
\text { moral transgressions as permissible if } \\
\text { an authority said they were. } \\
\text { Less likely to use other-person based } \\
\text { reasoning when discussing wrongs. }\end{array}$ \\
\hline
\end{tabular}




\begin{tabular}{|c|c|c|c|c|}
\hline & & $\begin{array}{l}\text { a boy wearing } \\
\text { girls clothes. }\end{array}$ & & \\
\hline \multirow[t]{2}{*}{$\begin{array}{l}\text { Blair et al., } \\
1995\end{array}$} & \multirow[t]{2}{*}{ PCL-R } & \multirow[t]{2}{*}{$\begin{array}{l}\text { M-C } \\
\text { Identical stories } \\
\text { to Blair, } 1995\end{array}$} & $\begin{array}{l}\text { All participants were serving life } \\
\text { sentences for murder or } \\
\text { manslaughter. }\end{array}$ & $\begin{array}{l}\text { Results of measurements regarding } \\
\text { positive acts were similar between } \\
\text { groups. }\end{array}$ \\
\hline & & & $\begin{array}{l}\text { Psychopaths }(n=20) \\
\text { Non-psychopaths }(n=20)\end{array}$ & $\begin{array}{l}\text { Psychopaths were able to make a } \\
\text { significant m-c distinction in regards } \\
\text { to seriousness. } \\
\text { No significant result differences } \\
\text { except in regards to authority } \\
\text { jurisdiction judgments. Psychopaths } \\
\text { are more likely to see things as more } \\
\text { authority dependent. }\end{array}$ \\
\hline \multirow[t]{3}{*}{$\begin{array}{l}\text { O'Kane et } \\
\text { al., } 1996\end{array}$} & $\begin{array}{l}\text { Special Hospitals Assessment of } \\
\text { Personality and Socialization } \\
\text { (SHAPS) }\end{array}$ & \multirow{3}{*}{$\begin{array}{l}\text { Defining Issues } \\
\text { Test (DIT) } \\
\text { (Rest, 1974) } \\
\text { A variation on } \\
\text { Kohlberg moral } \\
\text { reasoning task } \\
6 \text { dilemma } \\
\text { questions }\end{array}$} & $\begin{array}{l}40 \text { patients in Ashworth } \\
\text { Hospital an English Special } \\
\text { Hospital }\end{array}$ & $\begin{array}{l}\text { Moral reasoning was lower in people } \\
\text { who scored higher psychopathy } \\
\text { scores on the PCL-R, but did not } \\
\text { hold when IQ was taken into }\end{array}$ \\
\hline & \multirow[t]{2}{*}{ PCL-R } & & $\begin{array}{l}\text { Psychopaths }(n=20) \\
\text { Non-psychopaths }(n=20)\end{array}$ & consideration. \\
\hline & & & & $\begin{array}{l}\text { Moderate findings were found in } \\
\text { SHAPS psychopaths. Moral } \\
\text { reasoning was lower. }\end{array}$ \\
\hline \multirow[t]{2}{*}{ Blair, 1997} & \multirow[t]{2}{*}{$\begin{array}{l}\text { Psychopathy screening device } \\
\text { (PSD) (Frick \& Hare, 1996) }\end{array}$} & $\begin{array}{l}\text { M-C } \\
\text { Used } 8 \text { stories } \\
\text { (Smetana, 1993) }\end{array}$ & $\begin{array}{l}\text { Children with behavioural } \\
\text { problems. }\end{array}$ & \multirow{2}{*}{$\begin{array}{l}\text { Children who scored higher on PSD } \\
\text { had weaker scores on moral- } \\
\text { conventional distinction measures. } \\
\text { Same children also had more } \\
\text { difficulty attributing moral emotions } \\
\text { to story protagonist. }\end{array}$} \\
\hline & & $\begin{array}{l}\text { Used previously } \\
\text { with adults } \\
\text { (Blair et al., } \\
\text { 1995) }\end{array}$ & $\begin{array}{l}\text { Psychopaths }(n=16) \\
\text { Non-psychopaths }(n=16)\end{array}$ & \\
\hline $\begin{array}{l}\text { Blair et al., } \\
2001\end{array}$ & PSD & $\begin{array}{l}\text { M-C } \\
4 \text { moral -4 } \\
\text { conventional } \\
\text { stories } \\
\text { (Blair, 1995, }\end{array}$ & $\begin{array}{l}\text { High psychopathy scores (score } \\
\text { of } 27 \text { or higher) }(n=18)\end{array}$ & $\begin{array}{l}\text { High psychopathy scorers scored } \\
\text { worse and were more likely to fail on } \\
\text { the stories pertaining to authority } \\
\text { dependent rules (the modified rule } \\
\text { condition). }\end{array}$ \\
\hline
\end{tabular}




\begin{tabular}{|c|c|c|c|c|}
\hline & & $\begin{array}{l}\text { 1997; Blair et al. } \\
1995 \text { ) }\end{array}$ & $\begin{array}{l}\text { Mixed psychopathy scores }(15- \\
27)(n=63) \\
\text { Low psychopathy scores (Below } \\
\text { 15) }(n=21)\end{array}$ & $\begin{array}{l}\text { No significant differences in regards } \\
\text { to other components of M-C }\end{array}$ \\
\hline $\begin{array}{l}\text { Glenn et al., } \\
2009\end{array}$ & $\begin{array}{l}\text { Levenson Self-Report } \\
\text { Psychopathy Scale (LSRP) } \\
\text { (Levenson, Kiehl, \& Fitzpatrick, } \\
\text { 1995) }\end{array}$ & $\begin{array}{l}\text { Moral } \\
\text { Foundations } \\
\text { Questionnaire } \\
\text { (MFQ) (Graham } \\
\text { et al, 2009) }\end{array}$ & $\begin{array}{l}\text { Community sample } \\
\text { High psychopathy scores }(n= \\
\text { 94) }\end{array}$ & $\begin{array}{l}\text { High psychopathy scores strongly } \\
\text { predicted participants not endorsing } \\
\text { the care and fairness foundations } \\
\text { (Factor } 1 \text { was a more likely } \\
\text { predictor, than Factor 2) }\end{array}$ \\
\hline & & $\begin{array}{l}\text { Moral } \\
\text { Foundations } \\
\text { Sacredness Scale } \\
\text { (Graham, Haidt, } \\
\text { \& Nosek, 2009) } \\
\text { Ethics Position } \\
\text { Questionnaire } \\
\text { (Forsyth, 1980) }\end{array}$ & & $\begin{array}{l}\text { Psychopathy was not a significant } \\
\text { predictor of Disgust scores. } \\
\text { High psychopathy scores was a } \\
\text { reliable predictor of participants' } \\
\text { willingness to transgress all of the } \\
\text { moral foundations for monetary } \\
\text { incentive. }\end{array}$ \\
\hline $\begin{array}{l}\text { Glenn, } \\
\text { Raine, \& } \\
\text { Shugg, } 2009\end{array}$ & PCL-R & $\begin{array}{l}10 \text { dilemmas of } \\
\text { the following } \\
\text { kinds: } \\
\text { Moral personal } \\
\text { Moral } \\
\text { impersonal } \\
\text { Non-moral }\end{array}$ & $\begin{array}{l}\text { Participants from a community } \\
\text { sample with varying degrees of } \\
\text { psychopathy }(7.4-32)(n=17)\end{array}$ & $\begin{array}{l}\text { During fMRI participants with high } \\
\text { psychopathy showed less activity in } \\
\text { the amygdala. } \\
\text { Those with higher scores on the } \\
\text { interpersonal factor showed reduced } \\
\text { activity in the medial prefrontal } \\
\text { cortex, angular gyrus and posterior } \\
\text { cingulate which is associated with } \\
\text { complex social interaction. }\end{array}$ \\
\hline $\begin{array}{l}\text { Cima, } \\
\text { Tonnaer, \& } \\
\text { Hauser, } \\
2010\end{array}$ & PCL-R (Hare, 1991) & $\begin{array}{l}\text { Moral dilemmas } \\
\text { (Greene et al. } \\
\text { 2001) } \\
7 \text { impersonal and } \\
14 \text { impersonal } \\
\text { moral stories }\end{array}$ & $\begin{array}{l}\text { Psychopath }(n=14) \\
\text { Non-psychopathic delinquents } \\
(n=23) \\
\text { Healthy control }(\mathrm{n}=35)\end{array}$ & $\begin{array}{l}\text { Psychopaths show a similar ability to } \\
\text { distinguish between personal and } \\
\text { impersonal harm as non- } \\
\text { psychopaths. They view personal } \\
\text { harms as being more wrong than } \\
\text { impersonal harms. }\end{array}$ \\
\hline
\end{tabular}




\begin{tabular}{|c|c|c|c|c|}
\hline & & & & $\begin{array}{l}\text { Psychopaths show no real differences } \\
\text { in abilities to do moral dilemmas. }\end{array}$ \\
\hline $\begin{array}{l}\text { Dolan \& } \\
\text { Fullam, } 2010\end{array}$ & $\begin{array}{l}\text { PCL-Youth Version (Forth, } \\
\text { Kosson, \& Hare, 2003) }\end{array}$ & $\begin{array}{l}\text { M-C } \\
\text { (same stories as } \\
\text { Blair, 1995, } \\
\text { 1997; Blair et } \\
\text { al., 1995, 2001) }\end{array}$ & $\begin{array}{l}\text { Male adolescent offenders } \\
\text { (mean age }=16.2 \text { years }) \\
\text { High Psychopathy }(n=45) \\
\text { Medium Psychopathy }(n=31) \\
\text { Low Psychopathy }(n=39)\end{array}$ & $\begin{array}{l}\text { No differences except in modified } \\
\text { rule condition } \\
\text { Found that psychopaths who scored } \\
\text { higher in regards to superficiality, } \\
\text { grandiosity, and deceitfulness were } \\
\text { more likely to see transgression of } \\
\text { any kind as more permissible. This is } \\
\text { contra Blair's (2005) claims that this } \\
\text { was more closely tied to affect } \\
\text { personality traits. }\end{array}$ \\
\hline $\begin{array}{l}\text { Heinze et al, } \\
2010\end{array}$ & $\begin{array}{l}\text { Psychopathic Personality } \\
\text { Inventory (PPI) }\end{array}$ & $\begin{array}{l}\text { Defining Issues } \\
\text { Test }\end{array}$ & Master of Business Students & \\
\hline $\begin{array}{l}\text { Aharoni, } \\
\text { Antonenko, } \\
\text { \& Kiehl, } \\
2011\end{array}$ & PCL-R (Hare, 2003) & MFQ & $\begin{array}{l}\text { Adult male offenders }(n=222) \\
\text { Psychopaths }(n=37) \\
\text { Scores over } 30\end{array}$ & $\begin{array}{l}\text { Confirmed Glenn et al.'s (2009) } \\
\text { findings that psychopaths within a } \\
\text { criminal population. Psychopaths } \\
\text { showed less support for fairness and } \\
\text { harm principles. }\end{array}$ \\
\hline
\end{tabular}




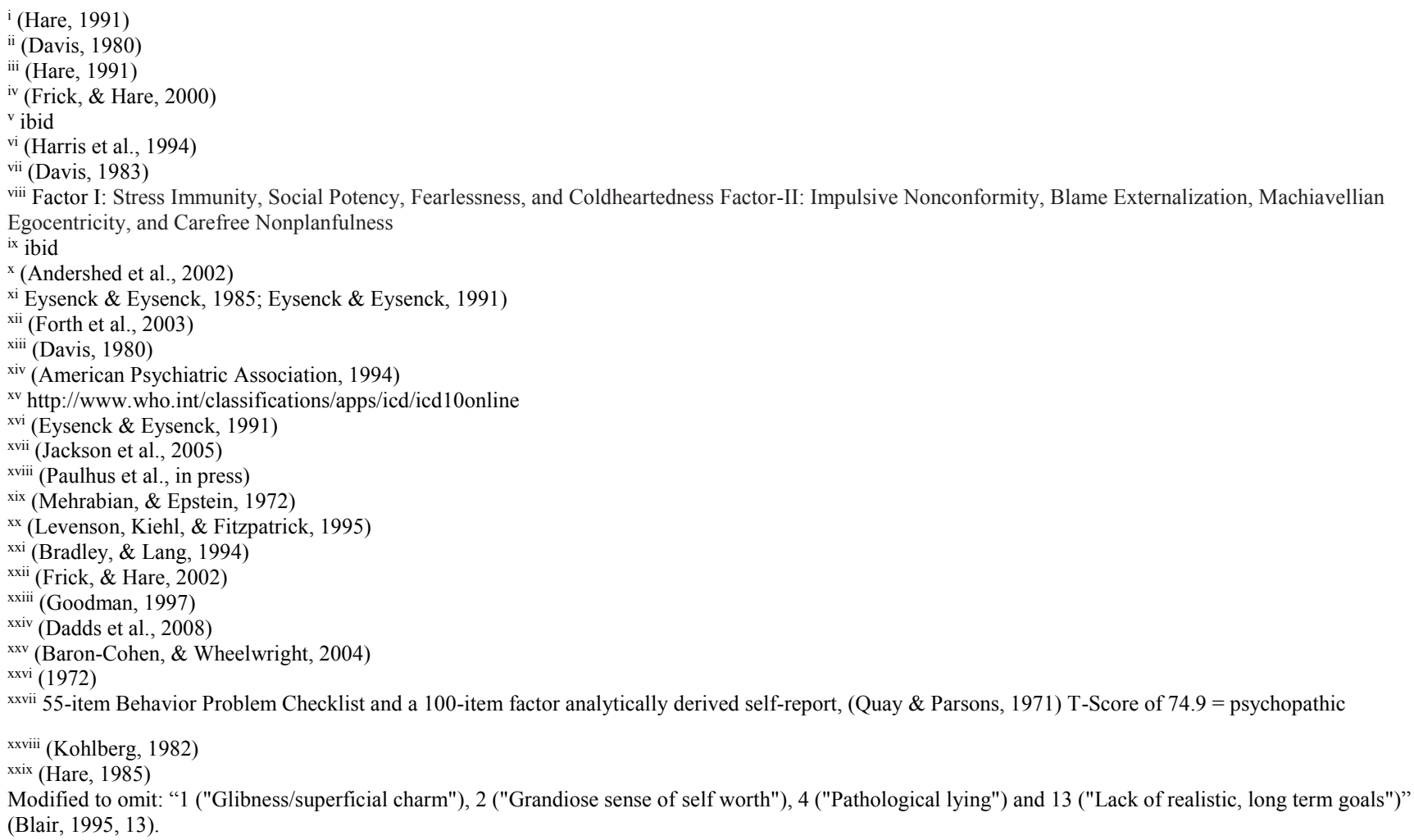

viii Factor I: Stress Immunity, Social Potency, Fearlessness, and Coldheartedness Factor-II: Impulsive Nonconformity, Blame Externalization, Machiavellian Egocentricity, and Carefree Nonplanfulness 


\section{Bibliography}

Agosta, L. (2011). Empathy and sympathy in ethics. Internet Encyclopedia of Philosophy.

Aharoni, E., Antonenko, O., and Kiehl, K. (2011). Disparities in the moral intuitions of criminal offenders. Journal of Personality.

Ali, F., and Chamorro-Premuzic, T. (2010). Investigating theory of mind deficits in nonclinical psychopathy and Machiavellianism. Personality and Individual Differences, 49:169-174.

Ali, F., Amorim, I. S., and Chamorro-Premuzic, T. (2009). Empathy deficits and trait emotional intelligence in psychopathy and Machiavellianism. Personality and Individual Differences, 47:758-762.

Amit, E., and Greene, J. (2012). You see the ends don't justify the means: Visual imagery and moral judgment. Psychological Science, 23:861-868.

Andershed, H., Kerr, M., Stattin, H., and Levander, S. (2002). Psychopathic traits in non-referred youths: A new assessment tool. In Blaauw, E., and Sheridan, L., editors, Psychopaths-Current international perspectives. Elsevier, Den Haag. 
Ansari, M. S. et al. (2010). Mesolimbic dopamine reward system hypersensitivity in individuals with psychopathic traits. Nature Neuroscience, 13:419-423.

Aristotle (350BCE/2000). Nicomachean Ethics. Cambridge University Press, Cambridge.

Association, A. P. (2000). Diagnostic and statistical manual of mental disorders. American Psychiatric Association, Washington, DC, 4th ed., text rev. edition.

Association, A. P. (2013). Diagnostic and Statistical Manual of Mental Disorders. $D S M-I V$. American Psychiatric Association, Washington, DC, 5th edition.

Avramova, Y. R., and Inbar, Y. (2013). Emotion and moral judgment. Cognitive Science, 4:169-178.

Babiak, P., and Hare, R. (2006). Snakes in suits: When psychopaths go to work. US: Harper Business.

Babiak, P., Neumann, C. S., and Hare, R. (2010). Corporate psychopathy: Talking the walk. Behavioral Sciences and the Law, 28:174-193.

Baron-Cohen, S., and Wheelwright, S. (2004). The empathy quotient: An investigation of adults with Asperger syndrome or high functioning autism, and normal sex differences. Journal of Autism and Developmental Disorders, 34.

Batson, C. D. (1991). The altruism question. Hillsdale, N. J.

Batson, C. D., Eklund, J. H., Chermok, V. L., Hoyt, J. L., and Ortiz, B. G. (2007). An additional antecedent of empathic concern: Valuing the welfare of the person in need. Journal of Personality and Social Psychology, 95:65-74. 
Batson, C. D. A., N., and Lishner, D. A. (2009). Empathy and altruism. In Snyder, C. R. and Lopez, S. J., editors, Oxford handbook of positive psychology, pages 417426. Oxford University Press, Oxford.

Batson, C. D. e. a. (1997). Empathy and attitudes: Can feeling for a member of a stigmatized group improve feelings toward the group? Journal of Personality and Social Psychology, 72:105-118.

Baumeister, R., Stillwell, A., and Heatherton, T. (1994). Guilt an interpersonal approach. Psychological Bulletin, 115.:243-267.

Baumeister, R., Stillwell, A., and Heatherton, T. (1995). Personal narratives about guilt: role in action control and interpersonal relationships. Basic and Applied Social Psychology, 17:173-198.

Bercovici, J. (2011). Why (some) psychopaths make great CEOs. Forbes Online.

Blackburn, S. (1998). Ruling Passions: A Theory of Practical Reasoning. Oxford: Oxford University Press.

Blair, R. J., and Mitchell, D. (2009). Psychopathy, attention and emotion. Psychological Medicine, 39:543-555.

Blair, R. J. (1995). A cognitive developmental approach to morality: Investigating the psychopath. Cognition, 57:1-29.

Blair, R. J. (1996). Moral reasoning and the child with psychopathic tendencies. Personality and Individual Differences, 22:731-739. 
Blair, R. J. (1997). Moral reasoning and the child with psychopathic tendencies. Personality and Individual Differences, 22.

Blair, R. J. (1999). Responsiveness to distress cues in the child with psychopathic tendencies. Personality and Individual Differences, 27:135-145.

Blair, R. J. (2003). Neurological basis of psychopathy. British Journal of Psychiatry, $182: 5-7$.

Blair, R. J. (2005). Responding to the emotions of others: Disassociating forms of empathy through the study of typical and psychiatric populations. Consciousness and Cognition, 14:698-718.

Blair, R. J. (2007). The amygdala and ventromedial prefrontal cortex in morality and psychopathy. Trends in Cognitive Science, 11.

Blair, R. J., Colledge, E. ., and Mitchell, D. G. (2001a). Somatic markers and response reversal: is there orbitofrontal cortex dysfunction in boys with psychopathic tendencies. Journal of Abnormal Child Psychology, 29.

Blair, R. J., Jones, L., Clark, F., and Smith, M. (1995a). Is the psychopath "morally insane"? Personality and Individual Differences. 19.

Blair, R. J., Jones, L., Clark, F., and Smith, M. (1997). The psychopathic individual: a lack of responsiveness to distress cues? Psychophysiology. 34, 192-198.

Blair, R. J., Mitchell, D., and Blair, K. (2005). The psychopath: Emotion and the brain. Oxford: Blackwell Publishing. 
Blair, R. J. and Mitchell, D. (2009). Psychopathy, attention and emotion. Psychological Medicine, 39:543-555.

Blair, R. J., Mitchell, D., Leonard, A., Budhani, S., Peschardt, K., and Newman, C. (2004). Passive avoidance learning in individuals with psychopathy: modulation by reward but not punishment. Personality and Individual Differences, 37:1179-1192.

Blair, R. J., Mitchell, D. G., Richell, R. A., Kelly, S., Leonard, A., Newman, C., and Scott, S. K. (2002). Turning a deaf ear to fear: Impaired recognition of vocal affect in psychopathic individuals. Journal of Abnormal Psychology, 111.

Blair, R. J., Monson, J., and Frederickson, N. (2001b). Moral reasoning and conduct problems in children with emotional and behavioural difficulties. Personality and Individual Differences, 31.

Blair, R. J., Sellars, C., Strickland, I., Clark, F., Williams, A., Smith, M., and Jones, L. (1995b). Emotion attributions in the psychopath. Personality and Individual Differences, 19:431-437.

Blum, L. (1994). Moral development and conceptions of morality. In Blum, L., editor, Moral perception and particularity. Cambridge University Press, Cambridge.

Book, A. S. and Quinsey, V. L. (2004). Psychopaths: Cheaters or warrior-hawks? Personality and Individual Differences, 36:33-45.

Bowler, D. M. (1992). "theory of mind" in Asperger's syndrome. Journal of Child Psychology and Psychiatry, 33.

Bradley, M. and Lang, P. (1994). Measuring emotion: The Self-Assessment Manikin 
and the semantic differential. Journal of Behavioral Therapy and Experimental Psychiatry, 1.

Brewer (2015). R., biotti, f., catmur, c., press, c., happé, f., cook, r., \& bird. G. (2015). Can neurotypicals read autistic facial expressions? Atypical production of emotional facial expressions in Autism Spectrum Disorder. Autism Research, 00:110.

Brockner, J., Davy, J., and Carter, C. (1985). Layoffs, self-esteem, and survivor guilt: Motivational, affective and attitudinal consequences. Organizational Behavior and Human Decision Processes, 36:229-244.

Brockner, J., Greenberg, J., Brockner, A., Bortz, J., Davy, J., and Carter, C. (1986). Layoffs, equity theory, and work performance: Further evidence of the impact of survivor guilt. Academy of Management Journal 29.

Burnett, S., Bird, G., Moll, J., Frith, C., and Blakemore, S. J. (2009). Development during adolescence of the neural processing of social emotion. Journal of Cognitive Neuroscience, 21.

Chandler, M. and Moran, T. (1990). Psychopathy and moral development: A comparative study of delinquent and nondelinquent youth. Development and Psychopathology, 2:227-246.

Cima, M., Tonnaer, F., and Hauser, M. D. (2010). Psychopaths know right from wrong but don't care. Social Cognitive and Affective Neuroscience, 5 .

Cleckley, H. (1941). The mask of sanity. St, Louis, MO. 
Colby, A., Kohlberg, L., Gibbs, J., Lieberman, M., Fischer, K., and Saltzstein, H. D. (1983). A longitudinal study of moral judgment. Monographs of the Society for Research in Child Development, 48:1-124.

Costa, P. T., J. and McCrae, R. R. (1992). The NEO PI-R professional manual. Odessa, FL: Psychological Assessment Resources.

Dadds, M. et al. (2009). Learning to "talk the talk": The relationship of psychopathic traits to deficits in empathy across childhood. The Journal of Child Psychology and Psychiatry, 50:599-606.

Dadds, M. R., Hawes, D. J., Frost, A. D., Vassallo, V., Bunn, P., Hunter, K., and Merz, S. (2008). The measurement of empathy in children using parent reports. Journal of Child Psychiatry and Human Development, 39.

Darley, J. and Batson, D. (1973). "from Jerusalem to Jericho": A study of situational and dispositional variables in helping behavior. Journal of Personality and Social Psychology, 27:100-108.

Davis, M. (1980). A multidimensional approach to individual differences in empathy. JSAS Catalog of Selected Documents in Psychology, IO.

Davis, M. (1983). Measuring individual differences in empathy: evidence for a multidimensional approach. Journal of Personality and Social Psychology, 44:113-126.

Delplanque, S., Silvert, S., Hot, P., Rigoulot, and Sequiera, H. (2006). Arousal and valence effects on event-related P3a and P3b during emotional categorization. International Journal of Psychophysiology, 60:315-322. 
Denson, T. F., Capper, M. M., Oaten, M., Friese, M., and Schofield, T. P. (2011). Self-control training decreases aggression in response to provocation in aggressive individuals. Journal of Research in Personality, 42.

Derefinko, K. and Lynam, D. R. (2013). In Widiger, T. A. and Costa, P. T. J., editors, Personality disorders and the five-factor model of personality, pages 103117. American Psychological Association, Washington, DC.

Dolan, M. and Rennie, C. (2007). The relationship between psychopathic traits measured by the youth psychopathic trait inventory and psychopathology in a UK sample of conduct disordered boys. Journal of Adolescence, 30:601-611.

Dolan, M. C. and Fullam, R. S. (2010). Moral/conventional transgression distinction and psychopathy in conduct disordered adolescent offenders. Personality and Individual Differences, 49:995-1000.

Dutton, K. (2012). The wisdom of psychopaths: What saints, spies, and serial killers can teach us about success. New York, NY: Scientific American.

Eisenberg, N. (1986). Altruistic cognition, emotion, and behavior. Lawrence Erlbaum, Hillsdale, NJ.

Eisenberg, N. (2000). Emotion, regulation, and moral development. Annual Review of Psychology, 51:665-697.

Ermer, E. and Kiehl, K. (2010). Psychopaths are impaired in social exchange and precautionary reasoning. Psychological Science, 10:1399-1405.

Evans, J. and Stanovich, K. (2013). Dual-process theories of higher cognition: Advancing the debate. Perspectives on Psychological Science, 8:223-241. 
Eysenck, H. J. and Eysenck, M. W. (1985). Personality and individual differences: A natural science approach. New York: Plenum.

Eysenck, H. J. and Eysenck, S. B. G. (1991). Adult IVE. London: Hodder \& Stoughton.

Eysenck, M. W. (2012). Fundamentals of cognition. Psychology Press, New York, NY:, 2nd edition.

Fernandez, Y. and Marshall, W. (2003). Victim empathy, social self-esteem, and psychopathy in rapists. Sexual Abuse: A Journal of Research and Treatment, 15:1126.

Finkel, E. J., DeWall, C. N., Slotter, E. B., Oaten, M., and Foshee, V. A. (2009). Selfregulatory failure and intimate partner violence perpetration. Journal of personality and social psychology, 97:483.

Flight, J. I. and Forth, A. E. (2007). Instrumentally violent youths: The roles of psychopathic traits, empathy, and attachment. Criminal Justice and Behavior, 34:739-751.

Foot, P. (1978). Virtues and vices and other essays in moral philosophy. CA: University of California Press.

Forsyth, D. R. (1980). A taxonomy of ethical ideologies. Journal of Personality and Social Psychology, 39:175-184.

Forth, A. E., Kosson, D. S., and Hare, R. D. (2003). The Hare Psychopathy Checklist: Youth Version. North Tonawada, NY: Multi-Health Systems. 
Frick, P. J. (2003). The Inventory of Callous/Unemotional traits: An unpublished rating scale. New Orleans: The University of New Orleans.

Frick, P. J. and Hare, R. D. (2000). The Psychopathy Screening Device. Toronto: Multi-Health Systems.

Frick, P. J. and Hare, R. D. (2002). The Antisocial Process Screening Device. Toronto: Multi-Health Systems.

Gadow, K. D. and Sprafkin, J. (1997). Adolescent Symptom Inventory IV. Stony Brook, NY: Checkmate Plus.

Gadow, K. D. and Sprafkin, J. (2002). Child Symptom Inventory IV (4th edn). Stony Brook, NY: Checkmate Plus.

Gaudine, A. and Thorne, L. (2001). Emotion and ethical decision-making, Journal of Business Ethics. 31.

Gibbard, A. (1990). Wise choices. apt feelings: A theory of normative judgment, Cambridge, MA.

Gilligan, C. (1982). In a different voice. Cambridge, Mass: Harvard University Press.

Glenn, A. L., Iyer, R., Graham, J., Koleva, S., and Haidt, J. (2009a). Are all types of morality compromised in psychopathy? Journal of Personality Disorders. 23, 384398 .

Glenn, A. L. and Raine, A. (2009). Psychopathy and instrumental aggression: Evolutionary, neurobiological, and legal perspectives. International Journal of Law and Psychiatry, 32:253-258. 
Glenn, A. L., Raine, A., and Schugg, R. A. (2009b). The neural correlates of moral decision-making in psychopathy. Molecular Psychiatry, 14:5-6.

Goldman, A. (1992). Empathy, mind, and morals. Proceedings and Addresses of the American Philosophical Association, 66:17-41.

Goodman, R. (1997). The Strengths and Difficulties Questionnaire: A research note. Journal of Child Psychology and Psychiatry, 38.

Graham, J., Haidt, J., and Nosek, B. A. (2009a). Liberals and conservatives rely on different sets of moral foundations. Journal of Personality $\&$ Individual Differences, 27.

Graham, J., Nosek, B. A., Haidt, J., Iyer, R., Koleva, S., and Ditto, P. H. (2009b). Broadening and mapping the moral domain: The development and validation of the moral foundations questionnaire. Manuscript submitted for publication.

Greene, J. (2013). Moral tribes: Emotion, reason, and the gap between us and them. New York: Penguin Press.

Greene, J., Sommerville, R., Nystrom, L., Darley, J., and Cohen, J. (2001). Emotional engagement in moral judgment. Science, 293:2105-2108.

Greene, J. D., Morelli, S. A., Lowenberg, K., Nystrom, L. E., and Cohen, J. D. (2008). Cognitive load selectively interferes with utilitarian moral judgment. Cognition, 107:1144-1154.

Greenspan, P. (1992). Subjective guilt and responsibility. Mind, 101:287-303. 
Greenspan, P. (1995). Practical guilt: Moral dilemmas, emotions, and social norms. New York: Oxford University Press.

Haidt, Bjorkland, and Murphy (2000). Moral dumbfounding: When intuition finds no reason. Technical report, Lund psychological reports.

Haidt and Joseph (2004). Intuitive ethics: How innately prepared intuitions generate culturally variable virtues. Daedalus.

Haidt, J. (2001). The emotional dog and its rational tail: A social intuitionist approach to moral judgment. Psychological Review, 108:814-834.

Haidt, J. (2003). The moral emotions. In Davidson, R. J., Sherer, K. R., and Goldsmith, H. H., editors, Handbook of affective sciences, pages 852-870. Oxford University Press, Oxford.

Haidt, J. (2010). Moral foundations.org.

Haidt, J. (2012). The righteous mind: Why good people are divided by politics and religion. New York: Pantheon Book.

Haidt, J. and Graham, J. (2007). When morality opposes justice: Conservatives have moral intuitions that liberals may not recognize. Social Justice Research, 20:98-116.

Haidt, J. and Joseph, C. (2007). The moral mind: How 5 sets of innate moral intuitions guide the development of many culture-specific virtues, and perhaps even modules. In Laurence, S. and Stich, S., editors, P. Carruthers, volume 3, pages 367-391. Oxford University Press, Oxford. 
Haidt, J., Koller, S., and Dias, M. (1993). Affect, culture and morality, or is it wrong to eat your dog? Journal of Personality and Social Psychology. 65, 613.

Hall, J. R. and Benning, S. D. (2006). The "Successful" psychopath: Adaptive and subclinical manifestations of psychopathy in the general population. In Patrick, C. J., editor, Handbook of psychopathy, page 459478. Guilford, New York.

Hare, R. D. (1965). Temporal gradient of fear arousal in psychopaths. Journal of Abnormal Psychology, 70:442-445.

Hare, R. D. (1966). Psychopathy and choice of immediate versus delayed punishment. Journal of Abnormal Psychology, 71:25-29.

Hare, R. D. (1968). Detection for electric shock in psychopaths. Journal of Abnormal Psychology, 73:268-272.

Hare, R. D. (1980). A research scale for the assessment of psychopathy in criminal populations. Personality and Individual Differences, 1:111-120.

Hare, R. D. (1985). Scoring manual for the psychopathy checklist. Unpublished manuscript.

Hare, R. D. (1991). The Hare Psychopathy Checklist-Revised. Toronto: Multi-Health Systems.

Hare, R. D. (1993). Without conscience: the disturbing world of the psychopaths among us. New York, NY: Pocketbooks.

Hare, R. D. (1996). Psychopathy and antisocial personality disorder: A case of diagnostic confusion. Psychiatric Times, 13:39-40. 
Hare, R. D. (2003). Manual for the hare psychopathy checklist-revised (2nd ed.). Toronto: Multi-Health Systems.

Hare, R. D. and Neumann, C. S. (2007). Structural models of psychopathy. Current Psychiatry Reports, 7:57-64.

Harpur, T. J., Hakstian, A. R., and Hare, R. D. (1988). Factor structure of the psychopathy checklist. Journal of Consulting and Clinical Psychology, 56.

Hart, S. D. and Hare, R. D. (1996). Psychopathy and risk assessment. Current Opinion in Psychiatry, 9:380-383.

Hassebrauck, M. (1986). Ratings of distress as a function of degree and kind of inequity. Journal of Social Psychology, 206:269-270.

Heinze, P., Allen, R., Magai, C., and Ritzler, B. (2010). Let's get down to business: A validation study of the Psychopathic Personality Inventory among a sample of MBA students. Journal of Personality Disorders, 24:487-498.

Herbert, W. (2010). The logic of a psychopath. Association for Psychological Science.

Hervé, H. (2007). Psychopathy across the ages: A history of the Hare psychopath. In H. Herv and J. C. Yuille, The Psychopath: Theory, Research, and Practice (pps. Theory, Herv and J. C. Yuille, The Psychopath.

Hidalgo Landa, A., Szabo, I., Le Brun, L., Owen, I., and Fletcher, G. (2011). Evidence based scoping reviews. The Electronic Journal Information Systems Evaluation, $14: 46-52$. 
Higgins, J. and Green, S., editors (2011). Cochrane Handbook for Systematic Reviews of Interventions. The Cochrane Collaboration, version 5.1.0 edition.

Hoffman, M. L. (1982). Development of prosocial motivation: Empathy and guilt. In Eisenberg, N., editor, The development of prosocial behavior, pages 218-231. Academic Press, New York.

Hume, D. (1975). Enquiries Concerning Human Understanding and Concerning the Principles of Morals. Oxford: Clarendon Press.

Isen, A. and Levin, P. (1972). Effects of feeling good on helping: Cookies and kindness. Journal of Personality and Social Psychology, 21:384-388.

Iyer, R., Koleva, S. P., Graham, P., Ditto, H., and Haidt, J. (2012). Understanding libertarian morality: The psychological dispositions of self-identified libertarians. PLOS ONE.

James, W. (1884). What is an emotion? Mind, 9:188-205.

Jolliffe, D. and Farrington, P. (2004). Empathy and Offending: A systematic review and meta-analysis. Aggressive and Violent Behavior, 9:441-476.

Jones, A. P., Happé, F. G. E., Gilbert, F., Burnett, S., and Viding, E. (2010). Feeling, caring, knowing: Different types of empathy deficit in boys with psychopathic tendencies and autism spectrum disorder. The Journal of Child Psychology and Psychiatry, 51:1118-1197.

Jones, T. (1991). Ethical decision making by individuals in organizations: An issuecontingent model. The Academy of Management Review, 16:366-395. 
Kahneman, D. (2013). Thinking, fast and slow. Canada: Anchor Canada.

Kalinian, H. and Wisniewski, A. W. (2006). Abnormal findings revealed in female criminal psychopaths using the sorting test. Journal of forensic neuropsychology, $4(4): 33-48$.

Kant, I. (1785/2005). The Groundwork of the Metaphysics of Morals. Toronto: Broadview Press.

Kelly, D. (2011). Psychopaths just don't care enough: Care ethics as a paradigm for studying moral deficits. Joint Conference of the European and American Society for Philosophy and Psychology, Montreal, Canada.

Kelly, D. and Davies, J. (2015). A dual-process model of moral judgment: What psychopaths can tell us about moral judgment, Canadian Society for Brain, Behaviour and Cognitive Science 2015, Ottawa, Ontario. Canada.

Kelly, D., Haley, K., Eng, S., and Fessler, D. (2007). Harm, affect and the moral/conventional distinction. Mind and Language, 22:117-131.

Kelly, D. and Maibom, H. (2012). "But that's your role": Social models and autistic reasoning. International Conference on Thinking, London, England.

Kelly, D. K., Messervey, D. L., and Nelson, E. (In press). Exploration of the personality types and situational factors in a qualitative analysis of israeli soldiers during the first intifada. Director general military personnel research and analysis scientific report, Defence Research and Development Canada, Ottawa, ON.

Keltner, D. and Harker, L. (1998). The forms and functions of the nonverbal signal 
of shame. In Gilbert, P., editor, Shame: Interpersonal behavior, psychopathology and culture, pages 78-98. Oxford University Press, New York.

Kennett, J. (2002). Autism, empathy and moral agency. The Philosophical Quarterly, $52: 340-57$.

Kiehl, K. A., Hare, R. D., McDonald, J. J., and Brink, J. (1999). Semantic and affective processing in psychopaths: An event-related potential (ERP) study. Psychophysiology, 36:765-774.

Kiehl, K. A., Smith, A. M., Hare, R. D., Mendrek, A., Forster, B. B., Brink, J., and Liddle, P. (2001). Limbic abnormalities in affective processing by criminal psychopaths as revealed by functional magnetic resonance imaging. Biological Psychiatry, 50:677-684.

Kim, K., Kang, J., and Yun, S. (2012). Moral intuitions and political orientation: Similarities and differences between Korea and the United States. Psychological Reports, 111:173-185.

Kirsch, L. G., Becker, J. V., and Allen, J. J. (2010). Psychopathy and Empathy: The Relationship Revealed. Paper presented at the annual meeting of the American Psychology - Law Society, TBA, San Antonio, TX.

Kochanska, G. (1997). Multiple pathways to conscience for children with different temperaments: From toddlerhood to age 5. Developmental Psychology, 33:228-240.

Kochanska, G., Gross, J. N., Lin, M., and Nichols, K. E. (2002). Guilt in young children: development, determinants, and relations with a broader system of standards. Child Development, 73(2):461-482. 
Koenigs, M., Kruepke, M., and Newman, J. P. (2010). Economic decision-making in psychopathy: A comparison with ventromedial prefrontal lesion patients. Neuropsychologia, 48:2198-2204.

Koenigs, M., Kruepke, M., Zeier, J., and Newman, J. (2012). Utilitarian moral judgment in psychopaths. Social Cognitive and Affective Neuroscience, 7(14):708714 .

Kohlberg, L. (1970). Stages of moral development as a basis for moral education. In Beck, C. and Sullivan, E., editors, Moral education. University of Toronto Press, Toronto.

Kohlberg, L. (1973). The claim to moral adequacy of a highest stage of moral judgment. Journal of Philosophy, 70(18).

Kohlberg, L. (1976). Moral stages and moralization: : The cognitive development developmental approach. In Beck, C. and Sullivan, E., editors, Moral Education. University of Toronto Press, Toronto.

Kohlberg, L. and Hersh, R. H. (1977). Moral development: A review of the theory. Theory Into Practice, 16:53-59.

Korsgaard, C. M. (2009). The activity of reason. Proceedings and Addresses of the American Philosophical Association, 83:23-43.

Korsgaard, C. M. (2010). Reflections on the evolution of morality. The Amherst Lecture in Philosophy, 5:1-29. 
Lamm, C., Batson, C. D., and Decety, J. (2007). The neural stubstrate of human empathy: Effects of perspective-taking and cognitive appraisal. Journal of Cognitive Neuroscience, 19:42-58.

Lee, M. and Prentice, N. M. (1988). Interrelations of empathy, cognition and moral reasoning with dimensions of juvenile delinquency. Journal of Abnormal Child Psychology, 16:127-139.

Levenson, M., Kiehl, K., and Fitzpatrick, C. (1995). Assessing psychopathic attributes in a non-institutionalized population. Journal of Personality and Social Psychology, 1.

Lieberman, M. D. (2007). The X- and C-Systems: The neural basis of automatic and controlled social cognition. In Harmon-Jones, E. and Winkleman, P., editors, Social neuroscience, page 290315. Guilford Press, New York, NY.

Lilenfeld, S. O. and Widows, M. R. (2005). Psychopathic Personality InventoryRevised (PPI-R): Professional manual. Lutz, FL: Psychological Assessment Resources.

Lilienfeld, S. and Andrews, B. (1996). Development and preliminary validation of a self-report measure of psychopathic personality traits in noncriminal populations. Journal of Personality Assessment, 66:488-524.

Lilienfeld, S. O. and Fowler, K. A. (2006). The self-report assessment of psychopathy: Problems, pitfalls, and promises. In Patrick, C. J., editor, Handbook of psychopathy, page 107132. Guilford, New York. 
Lilienfeld, S. O. M. (2004). Psychometric Properties of Self-Report Psychopathy Measures. Paper presented at the meeting of the American Psychology-Law Society, Scottsdale, AZ.

Losel, F. (1997). Treatment and management of psychopathstreatment and management of psychopaths. In Cooke, D. J., Forth, A. E., and Hare, R. D. D. H., editors, Psychopathy: Theory, Research and Implications for Society, pages 303354. Kluwer Academic Publishers, Netherlands.

Lykken, D. T. (1957). A study of anxiety in the sociopathic personality. Journal of Abnormal and Social Psychology, 55:6-10.

Lykken, D. T. (1995). The antisocial personalities. Mahwah, NJ: Erlbaum.

Lynam, D. and Widiger, T. (2007). Using a general model of personality to understand sex differences in the personality disorders. Journal of Personality Disorders, 21:583-602.

Mahmut, M. K., Homewood, J., and Stevenson, R. J. (2008). The characteristics of non-criminals with high psychopathy traits: Are they similar to criminal psychopaths? Journal of Research in Personality, 42:679-692.

Maibom, H. (2005). Moral unreason: The case of psychopathy. Mind \& Language, 20:37-57.

Maibom, H. (2008). The mad, the bad and the psychopath. Neuroethics, 1:167-184.

Marsh, A. A. and Blair, R. J. (2008). Deficits in facial affect recognition among antisocial populations: A meta-analysis. Neuroscience $\mathcal{E}$ Biobehavioral Reviews, $32: 454-465$. 
Marsh, A. A. and Cardinale, E. M. (2012). Psychopathy and fear: Specific impairments in judging behaviors that frighten others. Emotion.

Marsh, A. A., Finger, E. E., Schechter, J. C., Jurkowitz, I. T., Reid, M. E., and Blair, R. J. (2011). Adolescents with psychopathic traits report reductions in physiological responses to fear. Journal of Child Psychology $\& 3$ Psychiatry, 52:834-841.

Marshall, W. L., Hudson, S. M., Jones, R., and Fernandez, Y. M. (1995). Empathy in sex offenders. Clinical Psychology Review, 15:99-113.

McGuire, J., Langdon, R., Coltheart, M., and Mackenzie, C. (2009). A reanalysis of the personal/impersonal distinction in moral psychology research. Journal of Experimental Social Psychology, 45:581-584.

McPhedran, S. (2009). A review of the evidence for associations between empathy, violence and animal cruelty. Aggression and Violent Behavior, 14:1-4.

Mehrabian, A. (2010). Balanced emotional empathy scale (BEES).

Mehrabian, A. and Epstein, N. (1972). A measure of emotional empathy. Journal of Personality, 40:525-543.

Messervey, D. L. (2013). What drives moral attitudes and behaviour? [Director General Military Personnel Research and Analysis Technical Report 2013-003]. Ottawa, ON: Defence Research and Development Canada.

Messervey, D. L., Dean, W. H., Nelson, E., and Peach, J. (2016). The Defence Ethical Decision-Making Model. Manuscript in preparation. 
Monchi, O., Petrides, M., Petre, V., Worsley, K., and Dagher, A. (2001). Wisconsin card sorting revisited: Distinct neural circuits participating in different stages of the task identified by event-related functional magnetic resonance imaging. The Journal of Neuroscience, 21(19):7733-7741.

Mullen, P. E. (1992). Psychopathy: A developmental disorder of ethical action. Criminal Behaviour and Mental Health, 2:234-244.

Mullins-Nelson, J., Salekin, R., and Leistico, A.-M. (2006). Psychopathy, empathy, and perspective-taking in a community sample: Implications for the successful psychopathy concept. International Journal of Forensic Mental Health, 5:133-149.

Mullins-Sweatt, S. N., Glover, N. G., Derefinko, K. J., Miller, J. D., and Widiger, T. A. (2010). The search for the successful psychopath. Journal of Research in Personality, 44:554-558.

Munoz, L. C. (2009). Callous-unemotional traits are related to combined deficits in recognizing afraid faces and body poses. Journal of the American Academy of Child 86 Adolescent Psychiatry, 48:554-562.

Newman, J. P., MacCoon, D. G., Vaughn, L. J., and Sadeh, N. (2005). Validating a distinction between primary and secondary psychopathy with measures of Grays BIS and BAS constructs. Journal of Abnormal Psychology, 114.

Newman, K. S. (1988). Falling from grace: The experience of downward mobility in the American middle class. New York: Free Press.

Nichols, S. (2002a). How psychopaths threaten moral rationalism, or is $t$ Irrational to be amoral? The Monist. 85. 
Nichols, S. (2002b). Norms with feeling: towards a psychological account of moral judgment. Cognition, 84:221-236.

Nichols, S. (2004). Sentimental Rules: On the Natural Foundations of Moral Judgment. Oxford University Press, Oxford.

Noddings, N. (1984). Caring: A feminine approach to ethics and moral education. California: University of California Press.

O'Kane, A., Fawcett, D., and Blackburn, R. (1996). Psychopathy and moral reasoning: Comparison of two classifications. Personality and Individual Differences, $20: 505-514$.

Palomba, D., Angrilli, A., and Mini, A. (1997). Visual evoked potentials, heart rate responses and memory to emotional pictorial stimuli. International Journal of Psychophysiology $27,5567$.

Patrick, C. J. (2006). Back to the future: Cleckley as a guide to the next generation of psychopathy research. In Patrick, C. J., editor, Handbook of psychopathy, page 605617. Guilford, New York.

Patrick, C. J., Bradley, M. M., and Lang, P. J. (1993). Emotion in the criminal psychopath: Startle reflex modulation. Journal of Abnormal Psychology, 102:8292.

Patrick, C. J., Cuthbert, B. N., and Lang, P. J. (1994). Emotion in the criminal psychopath: Fear image processing. Journal of Abnormal Psychology, 103:523534. 
Patrick, C. J., Hicks, B. M., Nichol, P. E., and Krueger, R. F. (2007). A bifactor approach to modeling the structure of the Psychopathy Checklist-Revised. Journal of Personality Disorders, 21(118).

Paulhus, D. L., Hemphill, J. F., and Hare, R. D. (In press). Manual for the Self-Report Psychopathy scale. Multi-health systems, Toronto.

Pitcher, G. (1965). Emotion. Mind, 74:326-346.

Pizarro, D. (2000). Nothing more than feelings?: The role of emotions in moral judgment. Journal for the Theory of Social Behaviour, 30:355-375.

Pizarro, D. A., Inbar, Y., and Helion, C. (2011). On disgust and moral judgment. Emotion Review, 3:267-268.

Plato (338BCE/1994). Gorgias. Oxford University Press, Oxford. Trans. Robin Waterfield.

Prinz, J. (2007a). The Emotional Construction of Morals. New York: Oxford University Press.

Prinz, J. (2007b). Is morality innate? In Sinott-Armstrong, W., editor, Moral Psychology, Volume 1: The Evolution of Morality: Adaptations and Innateness, pages 367-406. MIT Press, USA.

Radilova, J., Figar, S., and Radil, T. (1983). Sexual arousal and visual perception. Activitas Nervosa Superior, 25.

Rawls, J. (2001). Justice as fairness: A restatement. USA: Belknap Press. 
Rest, J. (1974). Manual for the Defining Issues Test: An objective test of moral judgement. Minnesota: University of Minnesota.

Rest, J. (1986). Moral development: Advances in research and theory. New York: Praeger.

Rest, J., Power, C., and Brabeck, M. (1988). Lawrence kohlberg (1927-1987). American Psychologist, 43(5).

Rest, J. R., Narvaez, D., Thoma, S. J., and Bebeau, M. J. (1999). Dit2: Devising and testing a revised instrument of moral judgment. Journal of educational psychology, $91(4): 644$

Reynolds, S. J. (2006). A neurocognitive model of the ethical decision-making process: Implications for study and practice. Journal of Applied Psychology, 91:737-748.

Ronson, J. (2011). The psychopath test: The journey through the madness industry. New York, NY: Riverhead Books.

Rutherford, M., Cacciola, J. S., and Alterman, A. I. (1999). Antisocial personality disorder and psychopathy in cocaine dependent women. American Journal of Psychiatry, 156:149-156.

Seneca (4 B.C. - 65 A.D./1963). On Anger. On Moral Essays. Harvard University Press, Massachusetts.

Slote, M. (2007). Ethics of Care and Empathy. London: Routledge.

Slote, M. (2010). Moral Sentimentalism. Oxford: Oxford University Press. 
Smetana, J. G. (1981). Preschool children's conceptions of moral and social rules. Child Development, 52:1333-1336.

Smetana, J. G. (1993). Understanding of social rules. In Bennett, M., editor, The child as psychologist, pages 111-141. Harvester Wheatsheaf, London.

Smetana, J. G. and Braeges, J. L. (1990). The development of toddlers moral and conventional judgements. Merrill-Palmer Quarterly, 36:329-346.

Smith, A. (2007). The Theory of Moral Sentiments. New York: Cosimo Classics.

Smith, M. R. (1994). The moral problem. Malden, MA: Blackwell Publishing, Inc.

Smith, S. F., Lilienfeld, S. O., Coffey, K., and Dabbs, J. M. (2013). Are psychopaths and heroes twigs off the same branch? Evidence from college, community, and presidential samples. Journal of Research in Personality, 47:634-646.

Soderdstrom, H. (2003). Psychopathy as a disorder of empathy. European Child and Adolescent Psychiatry, 12:249-252.

Song, M., Smetana, J. G., and Kim, S. Y. (1987). Korean children's conceptions of moral and conventional transgressions, Developmental Psychology. 23.

Sterzer, P., Stadler, C., Poutska, F., and Kleinschmidt, A. (2007). A structural neural deficit in adolescents with conduct disorder and its association with lack of empathy. NeuroImage, 37:335-342.

Stevens, D., Charman, T., and Blair, R. J. R. (2001). Recognition of emotion in facial expressions and vocal tones in children with psychopathic tendencies. Journal of Genetic Psychology, 162. 
Tangney, J. and Dearing, R. (2002). Shame and Guilt. New York: Guilford Press.

Tangney, J. P. (1991). Moral affect: The good, the bad and the ugly. Journal of Personality and Social Psychology, 61:598-607.

Tangney, J. P. (1995). Recent advances in the empirical study of shame and guilt. American Behavioral Scientist, 38:1132-1145.

Tangney, J. P., Marschall, D. E., et al. (1994). Children's and adults autobiographical accounts of shame, guilt, and pride experiences: An analysis of situational determinants and interpersonal concerns. Unpublished Manuscript.

Tessman, L. (2005). Unburdened Virtues. London: Oxford University Press.

Thorne, L. and Saunders, S. (2002). The socio-cultural embeddedness of individuals' ethical reasoning in organizations (cross-cultural ethics). Journal of Business Ethics, 35:1-14.

Thornton, D. and Blud, L. (2007). The influence of psychopathic traits on response to treatment. In H. Herv and J. C. Yuille, The Psychopath: Theory, Research, and Practice (pps. Theory, Herv and J. C. Yuille, The Psychopath.

Trevathan, S. and Walker, L. J. (1989). Hypothetical versus real-life moral reasoning among psychopathic and delinquent youth. Development and Psychopathology, 1:91-103.

Trevino, L. (1986). Ethical decision making in organizations: A person-situation interactionist model. The Academy of Management Review, 11:601-617. 
Turiel, E. (1978). Social regulations and domains of social concepts. In Damon, W., editor, New directions for child development. Social cognition, volume 1, pages 45-74. Jossey-Bass, San Francisco.

Turiel, E. (1979). Distinct conceptual and developmental domains: social-convention and morality. Nebraska Symposium on Motivation, Lincoln.

Turiel, E. (1983). The development of social knowledge: Morality and convention. Cambridge: Cambridge University Press.

Vohs, K. D. and Faber, R. J. (2007). Spent resources: Self-regulatory resource availability affects impulse buying. Journal of Consumer Research, 33:537-547.

Vohs, K. D. and Heatherton, T. F. (2000). Self-regulatory failure: A resourcedepletion approach. Psychological Science, 11:249-254.

Walsh, H. and Wu, H. (2008). Differentiating antisocial personality disorder, psychopathy and sociopathy: Evolutionary, genetic, neurological, and sociological considerations. Criminal Justice Studies, 21:135-152.

Williams, J. H., Whiten, A., and Singh, T. (2004). A systematic review of action imitation in autistic spectrum disorder. Journal of Autism and Developmental Disorders, 34.

Wilson, K., Demetrioff, S., and Porter, S. (2008). A pawn by any other name? social information processing as a function of psychopathic traits. Journal of Research in Personality, 42:1651-1656.

Wilson, K., Juodis, M., and Porter, S. (2011). Fear and loathing in psychopaths: A 
meta-analytic investigation of the facial affect recognition deficit. Criminal Justice and Behavior, 38:659-668.

Woodworth, M. and Porter, S. (2002). In cold blood: Characteristics of criminal homicides as a function of psychopathy. Journal of Abnormal Psychology, 111:435445.

Yau, J. and Smetana, J. G. (2003). Adolescent-parent conflict in Hong Kong and Shenzhen: A comparison of youth in two cultural contexts. International Journal of Behavioral Development, 27:201-211.

Zagon, I. and Jackson, H. (1994). Construct validity of a psychopathy measure. Personality and Individual Differences, 17:125-135.

Zimak, E. (2014). Psychological and neuropsychological characteristics of nonincarcerated adult males with higher levels of psychopathic personality traits. Journal of Psychopathology and Behavioral Assessment, 36:542-554. 